\title{
LOCALISED ENERGY SYSTEMS IN THE Nigerian POWER NETWORK
}

THESIS SubMITTED FOR THE DEGREE OF

DOCTOR OF PHILOSOPHY

FASINA EMMANUEL TAIWO

Institute of Energy

School of Engineering

Cardiff University

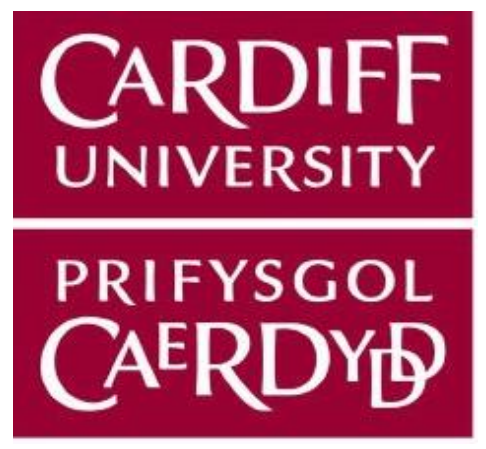

Cardiff, 2019 


\section{ACKNOWLEDGEMENTS}

I would like to acknowledge the support I received from Ekiti State University, Ado Ekiti and the Tertiary Education Trust Fund (TETFund), Abuja, Nigeria.

I would like to acknowledge the support and useful discussions with Cardiff University colleagues and staff.

I would like to express my gratitude to my $\mathrm{PhD}$ supervisor Dr Liana M. Cipcigan, for her help and support through this work. I would also like to thank my PhD supervisor Prof Nick Jenkins for his advice and feedback, which enhanced the quality of this work.

I would like to express my gratitude to all the staff from the Faculty of Engineering, Ekiti State University, Ado-Ekiti, Nigeria. In particular, I would like to thank Prof J.O Aribisala, Prof S.B Adeyemo, Prof E.A. Okunade, Prof S.O Oluwaleye, Dr O.O. Fagbohun, Dr I. B. Oluwafemi and Dr P. K. Olulope for their professional and personal help. I would also like to express my gratitude to Prof S.O. Bandele (EKSU VC), Barrister A.O. Arogundade (EKSU Registrar), Mr Mayowa Ogunlola (HOD Registrar Office) and Mr Adesina Adedapo (Tetfund Desk Officer for EKSU).

I would like to thank my colleagues and friends, Adebayo Patrick Lim, Dr Oluwole Adeuyi, Rilwan Oliyide, Nur Mohd Khairudin, and Hector Bastida Hernandez for their support and help throughout the whole $\mathrm{PhD}$ and for always having a "yes" for an answer when I did require their help.

I would like to thank my elder brothers Mr Oluwole Fasina, Mr Akinlolu Ajayi Fasina, Mr Ayotunde Fasina and my loving sisters Mrs Julianah Idowu Ilesanmi and Mrs Eniola Adeseko for their continuous help and prayers.

I would like to thank my wife Mrs Bosede Adenike Fasina for her invaluable support, love, help and trust during the whole $\mathrm{PhD}$. For being there in the good moments, and more importantly, during the not so good ones. Also, my children Feyisayo, Lois, Obed and Ephraim for their support and encouragement.

Finally, I would like to express my most sincere gratitude to my parents: my mother Late Mrs Felicia Oyefemi Fasina for her continuous support and encouragement, and my father Late Mr Ezekiel Ajayi Fasina for his continuous support and love. 


\section{DECLARATION}

This work has not been submitted in substance for any other degree or award at this or any other university or place of learning, nor is being submitted concurrently in candidature for any degree or other awards.

Signed

ETfasina.

Date...28/05/19.

\section{STATEMENT 1}

This thesis is being submitted in partial fulfilment of the requirements for the degree of $\mathrm{PhD}$

Signed

ETfasina.

Date......28/05/19.......

\section{STATEMENT 2}

This thesis is the result of my own independent work/investigation, except where otherwise stated, and the thesis has not been edited by a third party beyond what is permitted by Cardiff University's policy on the Use of Third Party Editors by Research degree Students. Other sources are acknowledged by explicit references. The views expressed are my own.

Signed

ETfasina.

Date.....28/05/19....

\section{STATEMENT 3}

I hereby give consent for my thesis, if accepted, to be available for photocopying and for inter-library loan, and for the title and summary to be made available to outside organisations.

Signed

ETfasina

Date...28/05/19 


\section{ABSTRACT}

In most of the African countries, particularly Nigeria, the fossil fuel based centralised generation is outdated, lacks proper maintenance and it is unreliable. Access to the transmission grid is limited, and it is costly to upgrade the existing power grid. The localised energy system is an alternative option to address these important challenges.

The thesis analysed the impact of localised energy systems (LES) in the UK power system with respect to benefits, opportunities, and limitations with the aim to transfer the knowledge obtained in the study to the Nigerian power network. The dynamic model of the UK generic distribution network, with different types of LES (residential, commercial and mixtures of these customers), was developed to study the impacts of LES on the steady state voltage, network losses and transformer loading. The results show that the integration of LES improved the steady state voltage by $2.75 \%$, distribution losses are reduced by $15 \%$ and the transformer loading is reduced by $22 \%$.

Similar studies were carried out on a section of the Nigerian network, the Ekiti State $33 \mathrm{kV}$ network, over 24 hours for both rainy and dry seasons, with and without LES. The results show an improvement in network voltage by $2.5 \%$ and a reduction in the network losses by $19.26 \%$. For different levels of solar generation penetration, it is found that for $30 \% \mathrm{PV}$ penetration, the use of storage is required during peak demand in the rainy season (when the solar irradiation is low) to mitigate the generation shortage.

Replacing conventional generation by solar power will reduce the overall inertia of the power system. The impact on frequency control of high PV penetration was studied using the Nigerian two-area hydrothermal systems model developed in MATLAB Simulink. The results show a frequency regulation problem at $30 \% \mathrm{PV}$ penetration. The stored kinetic energy in the existing conventional generators could not absorb electricity output from PV system causing the frequency deviation beyond the safe operation of the system. A flywheel storage system was proposed in this research as a solution to counterbalance the intermittency of the PV generation and to damp out the frequency deviations.

The localised energy systems, if implemented in Ekiti State, will provide annual savings of US $\$ 454,096$ from losses reduction and yield about 46,360MWh electricity annually, which is about $30 \%$ of Ekiti State annual electricity consumption. Localised energy systems used renewable energy technologies and therefore would contribute towards carbon emission reduction target. 


\section{LIST OF PUBLICATIONS}

The following papers were published based on work done for this thesis, or work done within the framework of the doctorate degree:

\section{JOURNAL PAPERS}

1. E. T. Fasina, L.M. Cipcigan, N. Jenkins and M. T. Muhssin, "Frequency Regulation in the Nigerian Power System with High PV penetration" [in preparation].

\section{CONFERENCE PAPERS}

1. E.T. Fasina, A.S. Hassan, L.M. Cipcigan, "Impact of Localised Energy Resources on Electric Power Distribution Systems", 50 ${ }^{\text {th }}$ International Universities Power Engineering Conference (UPEC), Stoke-on-Trent, UK, 2015

2. E.T. Fasina, R.O. Oliyide, L.M. Cipcigan, "Localised Energy Systems in Nigerian Power Networks", $15^{\text {th }}$ International Conference on Industrial Informatics, INDIN 2017, Emden, Germany, 2017.

3. R.O. Oliyide, C. Marmaras, E.T. Fasina, L. M. Cipcigan, "Low Carbon technologies Integration in Smart Low Voltage Network", $15^{\text {th }}$ International Conference on Industrial Informatics, INDIN 2017, Emden, Germany,2017. 


\section{CONTENTS}

ACKNOWLEDGEMENTS ........................................... III

DECLARATION ......................................................IV

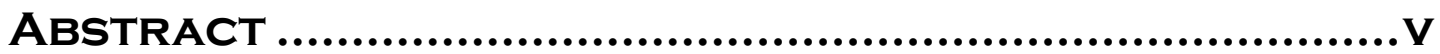

LIST OF PUBLICATIONS.................................................. VI

LIST OF FIGURES .....................................................

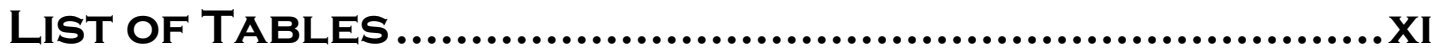

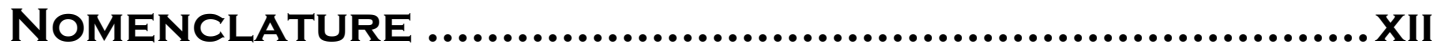

CHAPTER 1 ............................................................ 1

1. INTRODUCTION ................................................. 1

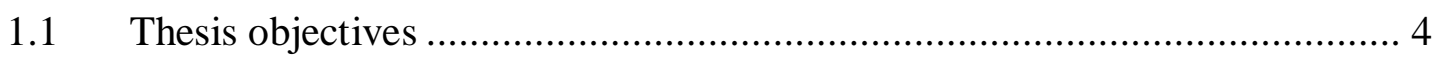

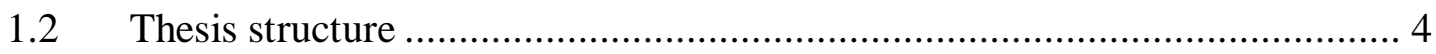

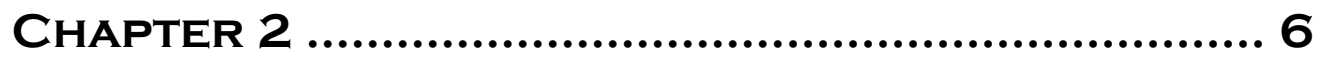

2. LITERATURE REVIEW ..................................... 6

2.1 Smart grids, microgrids and localised energy systems................................. 6

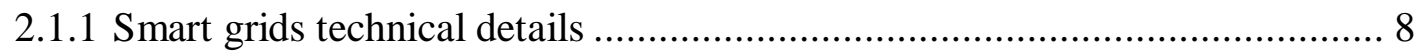

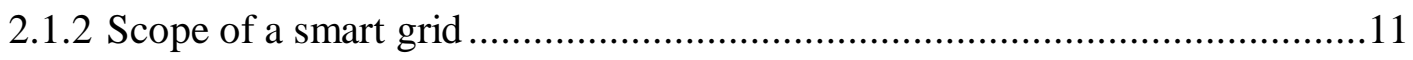

2.1.3 Comparison of microgrids and localised energy system ..............................12

2.2 Renewable energy technology state of art ....................................................13

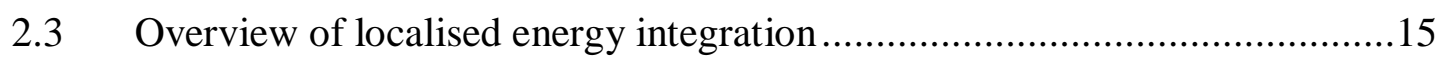

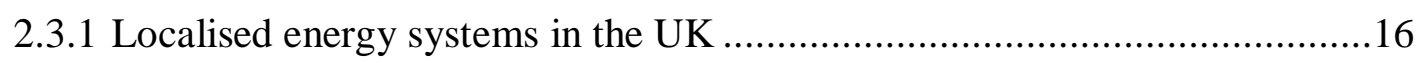

2.3.2 State of the power sector in other developing countries................................19

2.4 Review of the Nigerian energy systems and its power needs ........................22

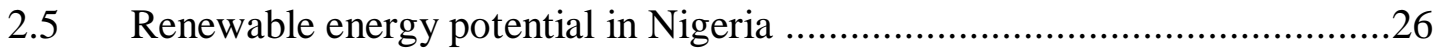

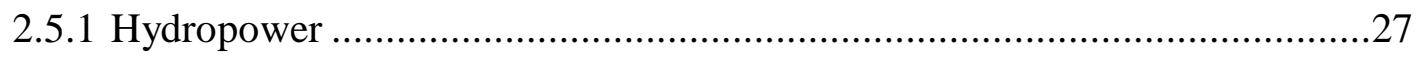

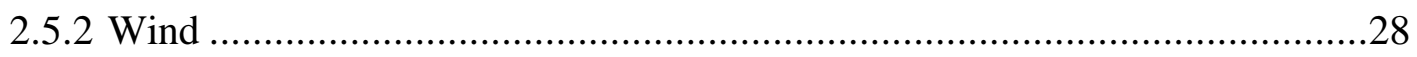

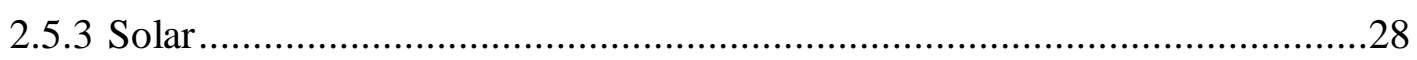

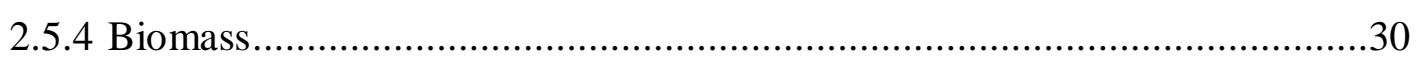

2.5.5 Policy on renewables energy generation ……………................................

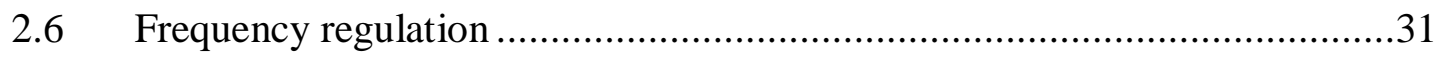

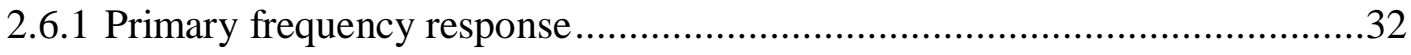

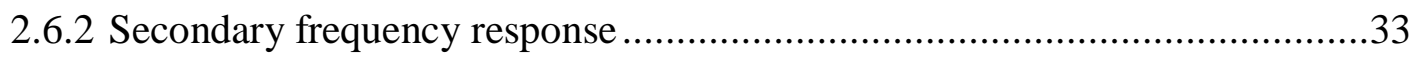

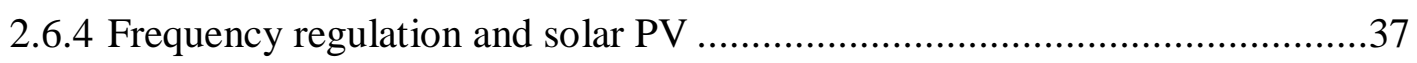

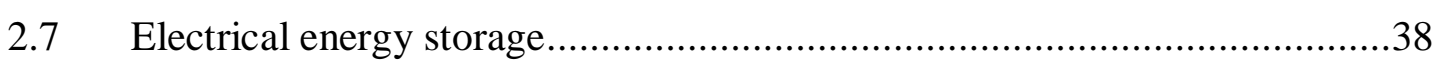




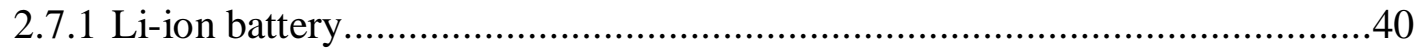

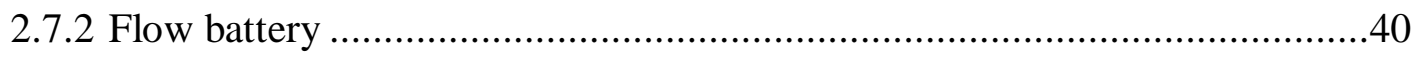

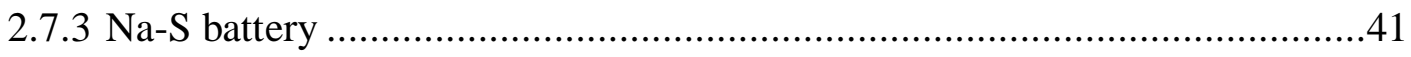

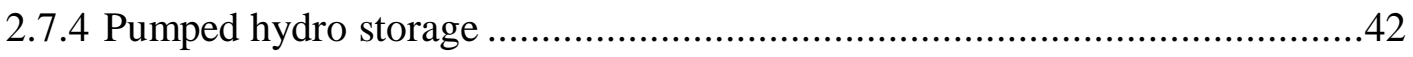

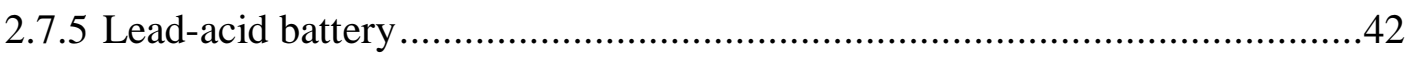

2.7.6 Compressed air energy storage ..............................................................43

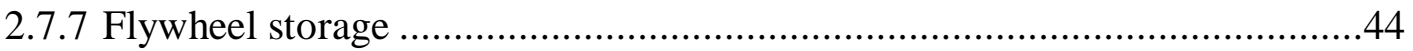

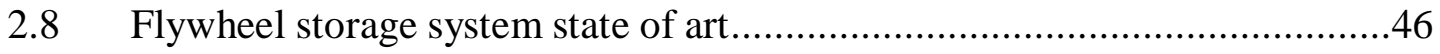

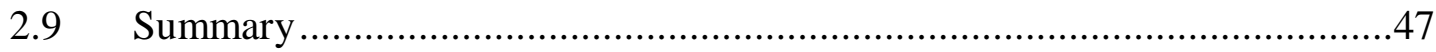

CHAPTER 3 ........................................................... 48

3. A STUDY OF LOCALISED ENERGY SYSTEM IMPACTS IN

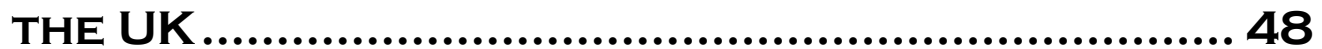

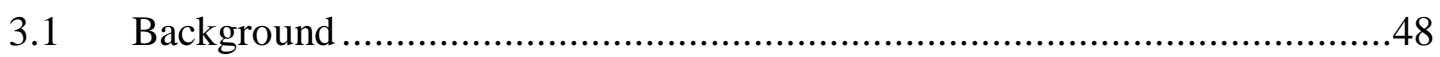

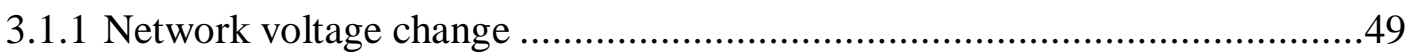

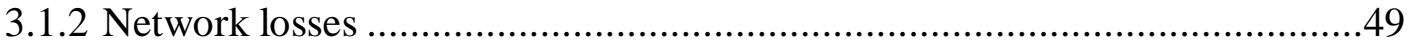

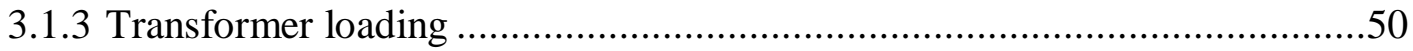

3.1.4 Maximum allowable DG capacity in the LES ........................................50

3.1.5 Charging of electric vehicles in the LES ...............................................51

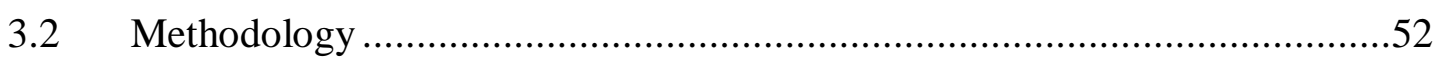

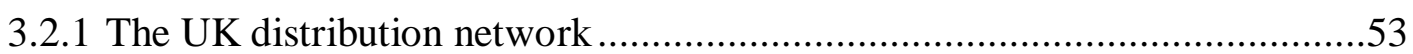

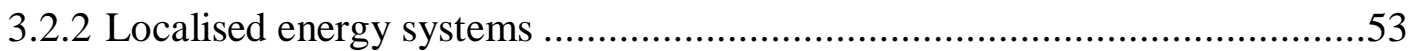

3.3 Case studies of localised energy systems …..........................................59

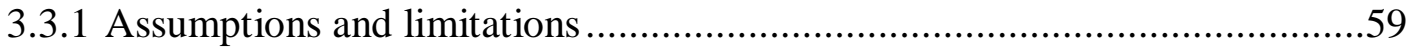

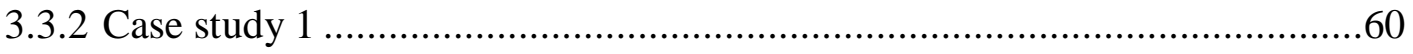

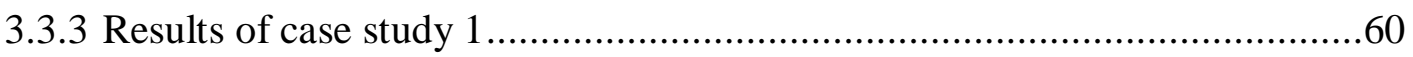

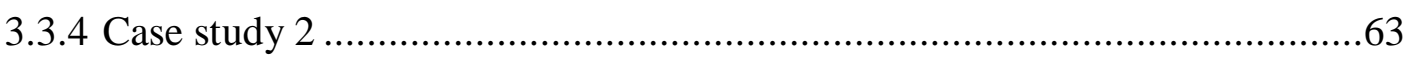

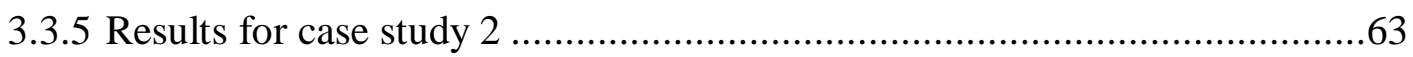

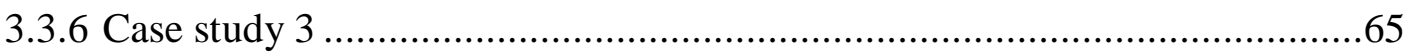

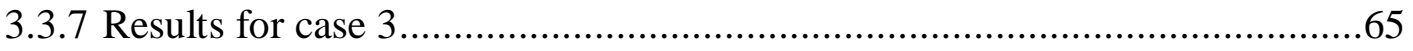

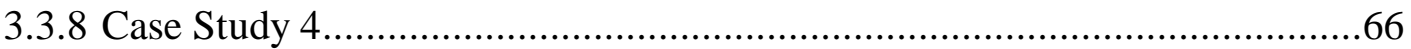

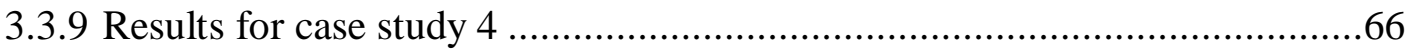

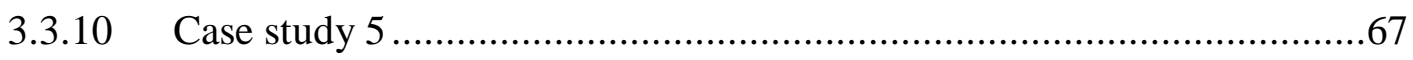

3.3.11 Results for case study 5 .....................................................6

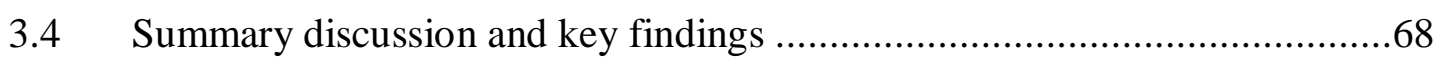

CHAPTER 4 .......................................................... 71

4. A STUDY OF LOCALISED ENERGY SYSTEM IMPACTS IN EKITI STATE......................................................... 71 


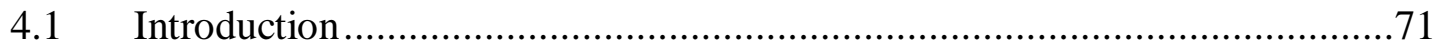

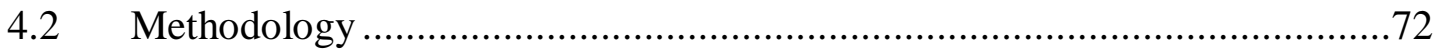

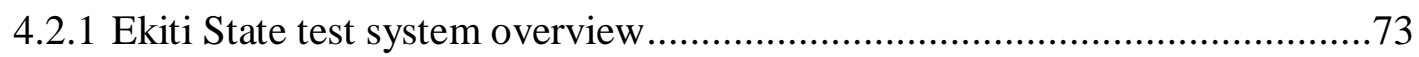

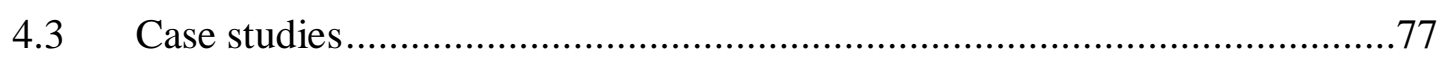

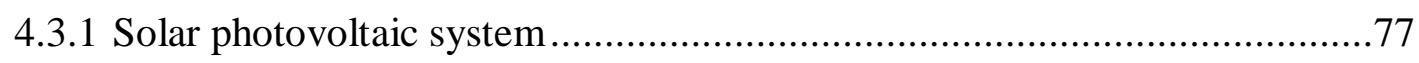

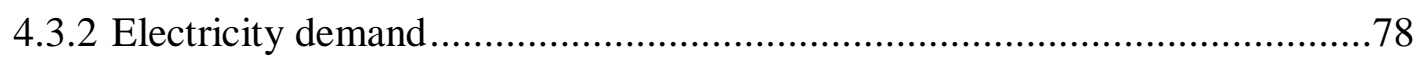

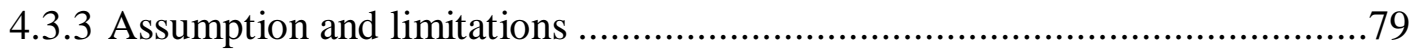

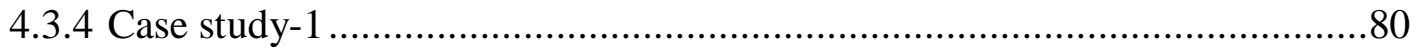

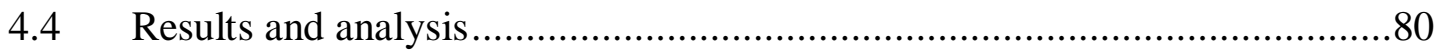

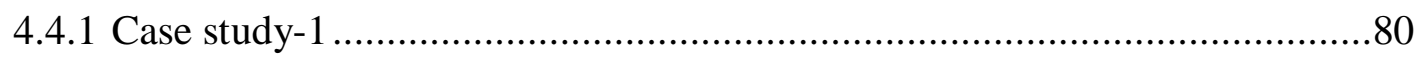

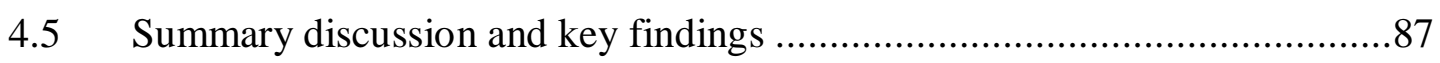

CHAPTER 5 ......................................................... 89

5. A STUDY OF INCREASED PENETRATION OF LOCALISED ENERGY SYSTEM IMPACTS IN NIGERIA AND ENERGY STORAGE OPPORTUNITIES ................................ 89

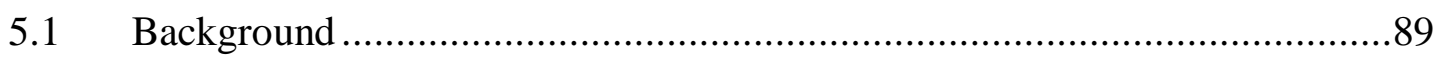

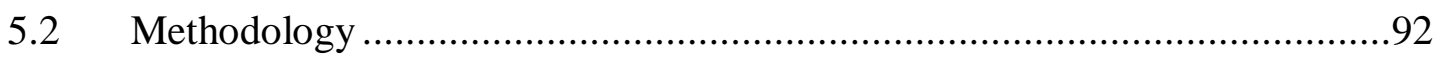

5.2.1 Transfer functions of PV and energy storage systems .............................93

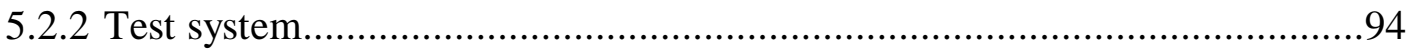

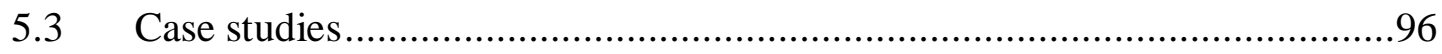

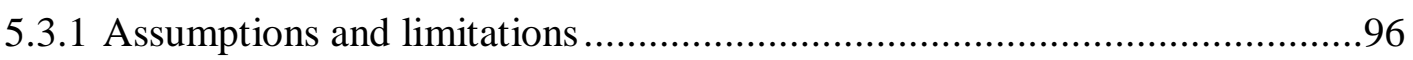

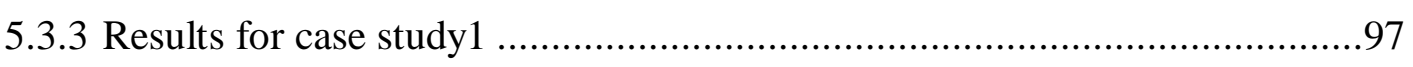

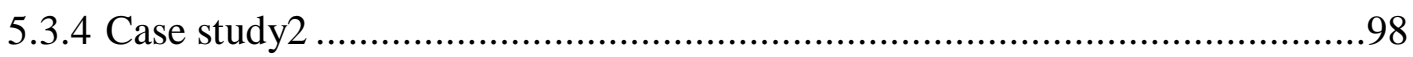

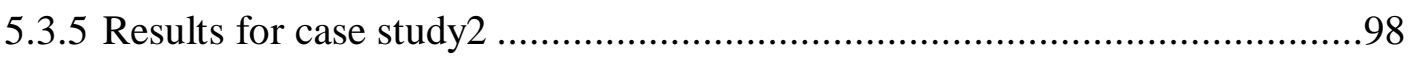

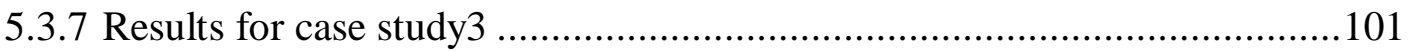

5.4 Summary discussion and key findings .................................................. 102

CHAPTER 6 ................................................... 104

6. DISCUSSION AND CONCLUSION ........................... 104

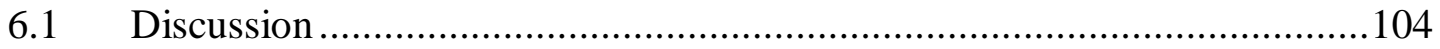

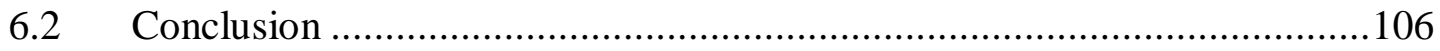

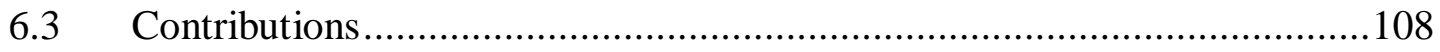

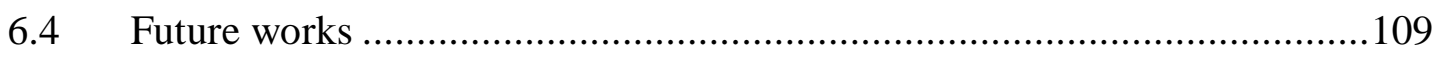

REFERENCES ..................................................... 110

APPENDIX .......................................................... 124

Power flow equation ................................................................ 124 


\section{LIST OF FIGURES}

Fig 2.1 Scope of a smart grid concerns .......................................................11

Fig 2.2 Renewable energy share of global electricity production [42]...............14

Fig 2.3 Renewable energy contribution to electricity in the UK ........................19

Fig 2.4 Installed capacity and losses across the Nigeria power system [14]........24

Fig 2.5 The daily average of global solar radiation in Nigeria [81] ....................29

Fig 2.6 Biomass resources and the estimated quantities in Nigeria [84]...............30

Fig 2.7 Frequency control following a frequency disturbance [89]....................33

Fig 2.8 Equivalent network for two-area power system [97] .............................35

Fig 2.9 Two-area power system with only primary LFC loop [97] ....................36

Fig 2.10 Global energy storage capacity by technology type [104]. ....................39

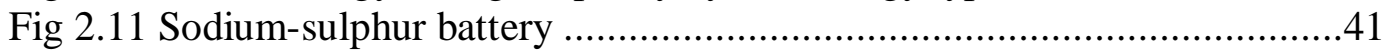

Fig 2.12 A schematic of a flywheel storage system......................................44

Fig 3.1 UK generic low voltage distribution network [127]. ..........................53

Fig 3.2 UK generic low voltage network with localised energy system..............54

Fig 3.3 A residential hourly load profile [141] .................................................54

Fig 3.4 UK generic distribution network with LES2 …..................................56

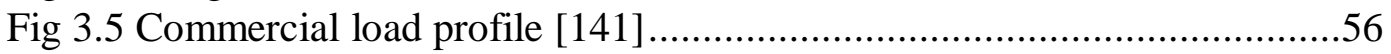

Fig 3.6 UK generic distribution network with LES3 ......................................57

Fig 3.7 Voltage at bus 12 (without DG) ......................................................60

Fig 3.8 Voltage at bus 22 without DG (LES2) ............................................61

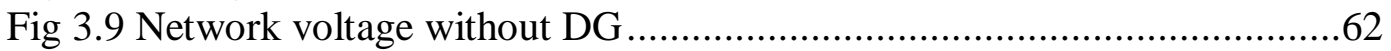

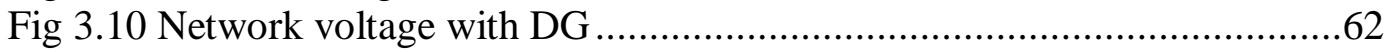

Fig 3.11 Network losses over 24 hours .....................................................64

Fig 3.12 Transformer loading with and without DG......................................66

Fig 3.13 Maximum DG capacity installed in each LES ..................................67

Fig 4.1 Map of Ekiti-State showing local government areas [27] ......................73

Fig 4.2 Ekiti-State $33 \mathrm{kV}$ power distribution network ..................................... 74

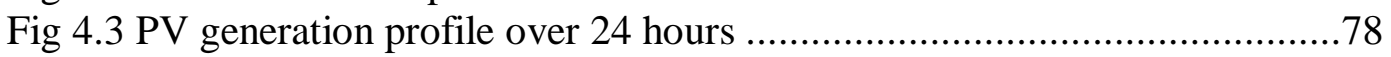

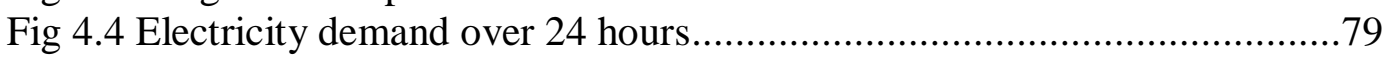

Fig 4.5 Voltage profile with and without PV generation at node 9 (year 2017)....81

Fig 4.6 voltage profile with and without PV at node 9 (year 2020)....................81

Fig 4.7 Voltage profile with and without PV at node 9 (year 2025) ...................82

Fig 4.8 Voltage profile with and without PV at node 9 (year 2030) ....................83

Fig 4.9 Voltage profile at node 9 with cloud shading ....................................8

Fig 4.10 Network losses over 24 hours at node 9 ........................................85

Fig 4.11 Voltage profile with and without PV generation at node 9 (year 2030)..86

Fig 5.1 The Nigeria national grid [174] ....................................................92

Fig 5.2 Nigerian two-area power system with localised energy system [91] ........94

Fig 5.3 Frequency deviation step response of thermal and hydro areas...............97

Fig 5.4 Frequency deviation step response in thermal area..............................99

Fig 5.5 Frequency deviation step response in Hydro area with PV penetration.. 100

Fig 5.6 Response of power system with and without FESS in the thermal area 102

Fig 7.1 A typical bus of the power system [97] 124 


\section{LIST OF TABLES}

Table 2.1 Principal smart grid technologies .......................................................10

Table 2.2 Comparison between microgrids and localised energy systems ............13

Table 2.3 Cost of unserved energy in Nigeria, benchmarked to South Africa .......23

Table 2.4 generation capacity, utilisation factor and network losses .....................25

Table 2.5 renewable energy potential and utilisation in Nigeria [64]..................27

Table 3.1 Network model cable data.............................................................55

Table 3.2 Network cable data ....................................................................58

Table 3.3 Network losses with and without distributed generation........................64

Table 3.4 Summary of the results ..............................................................68

Table 4.1 Injector- Substation........................................................................

Table 4.2 Distribution network parameter...........................................................76

Table 4.3 The main characteristics of the case studies.........................................79

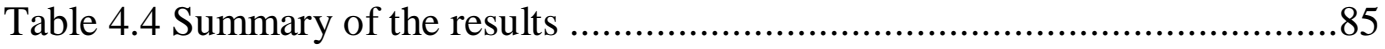

Table 5.1 Base parameter of the system [81] .....................................................95

Table 5.2 Breakdown of peak and off-peak generation .......................................96

Table 5.3 Case studies description ................................................................96

Table 5.4 Change in equivalent inertia with PV penetration................................98

Table 5.5 Summary of the frequency deviation in the thermal area ...................100

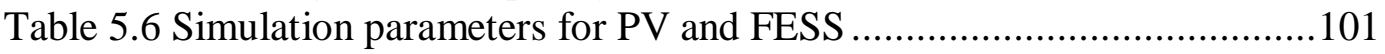

Table 5.7 New operating frequency with and without FESS ..........................102 
NOMENCLATURE

$\begin{array}{ll}\text { AC } & \text { Alternate Current } \\ \text { AGC } & \text { Automatic Generation Control } \\ \text { ACE } & \text { Automatic Control Error } \\ \text { BESS } & \text { Battery Energy Storage System } \\ \text { BMI } & \text { Business Monitor International } \\ \text { CO2 } & \text { Carbon Dioxide } \\ \text { CHP } & \text { Combine Heat and Power } \\ \text { CAES } & \text { Compressed Air Energy Storage } \\ \text { CIS } & \text { Customers Information Service } \\ \text { DC } & \text { Direct Current } \\ \text { DECC } & \text { Department of Energy and Climate Change } \\ \text { DER } & \text { Distributed Energy Resource } \\ \text { DfT } & \text { Department for Transport } \\ \text { DG } & \text { Distributed Generation } \\ \text { DMS } & \text { Distribution Management System } \\ \text { DNO } & \text { Distribution Network Operator } \\ \text { DOD } & \text { Depth of Discharge } \\ \text { DSM } & \text { Demand Side Management } \\ \text { DSO } & \text { Distribution System Operator } \\ \text { EMS } & \text { Energy Management System } \\ \text { EPSR } & \text { Electric Power Sector Reform } \\ \text { ESS } & \text { Energy Storage System } \\ \text { EC } & \text { European Commission } \\ \text { ECN } & \text { Energy Commission of Nigeria } \\ \text { ECO } & \text { Energy Company Obligation } \\ \text { EU } & \text { European Union } \\ \text { EV } & \text { Electric Vehicle } \\ \text { FACTS } & \text { Flexible Alternating Current Transmission System } \\ \text { FDR } & \text { Frequency Distribution Recorder } \\ \text { FiT } & \text { Feed-in-Tariff } \\ \text { GB } & \text { Great Britain } \\ \text { GENCO } & \text { Generating Company } \\ \text { GDP } & \text { Gross Domestic Product } \\ \text { GHG } & \text { greenhouse gases } \\ \text { GIS } & \text { Geographic Information System } \\ \text { GLA } & \text { Greater London Authority } \\ \text { G2V } & \text { Grid to Vehicle } \\ \text { HV } & \text { High Voltage } \\ \text { ICE } & \text { Internal Combustion Engine } \\ \text { IEEE } & \text { Institute of Electrical and Electronic Engineers } \\ \text { IEA } & \text { International Energy Agency } \\ \text { IPPs } & \text { Independent Power Producers } \\ \text { LES } & \text { Localised Energy System } \\ \text { LEM } & \text { Local Energy Market } \\ \text { LFC } & \text { Load Frequency Control } \\ \text { LV } & \text { Low Voltage } \\ & \end{array}$




$\begin{array}{ll}\text { MDMS } & \text { Meter Data Management System } \\ \text { MHI } & \text { Manitoba Hydro International } \\ \text { MO } & \text { Market Operation } \\ \text { MV } & \text { Medium Voltage } \\ \text { MYTO } & \text { Multi-Year Tariff Order } \\ \text { NDA } & \text { Niger Dams Authority } \\ \text { NEEDS } & \text { National Economic Empowerment and Development Strategies } \\ \text { NEPA } & \text { National Electric Power Authority } \\ \text { NERC } & \text { Nigerian Electricity Regulatory Commission } \\ \text { NESI } & \text { Nigerian Electricity Supply Industry } \\ \text { ofgem } & \text { office of gas and electricity markets } \\ \text { OMS } & \text { Outage Management System } \\ \text { OP } & \text { Operational Period } \\ \text { PG\&E } & \text { Pacific Gas and Electric Company } \\ \text { PHEV } & \text { Plug-in Hybrid Electric Vehicle } \\ \text { PHCN } & \text { Power Holding Company of Nigeria } \\ \text { REFiTs } & \text { Renewable Energy Feed-in-Tariffs } \\ \text { RES } & \text { Renewable Energy System } \\ \text { REMP } & \text { Renewable Energy Masterplan } \\ \text { RO } & \text { Renewable Obligation } \\ \text { SCADA } & \text { Supervisory Control and Data Acquisition } \\ \text { SHP } & \text { Small Hydro Power } \\ \text { SO } & \text { System Operator } \\ \text { TCN } & \text { Transmission Company of Nigeria } \\ \text { TSO } & \text { Transmission System Operator } \\ \text { UK } & \text { United Kingdom } \\ \text { UKGDN } & \text { United Kingdom Generic Distribution Network } \\ \text { UKERC } & \text { United Kingdom Energy Research Centre } \\ \text { VAR } & \text { Volt-Ampere Reactive } \\ \text { VPP } & \text { Virtual Power Plant } \\ \text { V2G } & \text { Vehicle to Grid } \\ \text { WAAPCA } & \text { Wide-Area Monitoring System } \\ \text { WAMS } & \text { Wide-Area Monitoring System } \\ \text { WASA } & \text { Wide-Area Situational Area } \\ \text { WMS } & \text { Workforce Management System } \\ & \end{array}$




\section{CHAPTER 1}

\section{INTRODUCTION}

Access to reliable, cost-effective and environmentally sustainable energy is essential to help alleviate poverty and to enable human and economic development. According to [1], 1.2 billion people, around $16 \%$ of the world population, have no or very limited access to electricity with the majority of this population located in East Asia and subSaharan Africa. In fact, over half of this population are located in sub-Sahara Africa, where only $32 \%$ of homes are connected to the national grid. The International Energy Agency (IEA) estimates that electricity demand in sub-Saharan Africa would increase at an average rate of $4 \%$ a year until 2040 [2]. Therefore, there is an urgent need to address this situation to avert prolong negative consequence on Africa social and economic development.

Although the task of addressing greenhouse gas emission and energy poverty seems difficult, price reductions in a number of renewable energy generation are providing new opportunities for achieving energy access [3]. Localised energy system (LES) remains the most viable solution to these pressing policy challenges: reducing carbon emissions, matching energy supply and demand, engaging and empowering communities, tackling fuel poverty, and reviving local economies. The localised energy system is believed to be cheaper, faster to deploy than the power utilities that have served African countries so poorly in the past. In addition, localised energy sources are thought to mitigate carbon dioxide and greenhouse gas emissions from large, centralized power stations, which currently impose major health costs on surrounding communities.

Countries around the world are expanding their energy mix by diversifying the sources of energy to include LES [4]. It is presumed that, with the introduction of LES, the dual priorities of energy supply securities and emission reduction will be realized. Moreover, the energy security that renewable resources allow is another driver of the growing interest in alternative ways of energy supply [5]. 
The localised energy system is widely regarded as one of the promising solutions to address the problem of lack of access to reliable electricity [6]. The concept of LES [7] represents a change to the approaches to energy production, supply and networks which have been prevalent in the UK, though there are countries such as Denmark where LES has been pursued for some decades [8]. Localised energy system also known as decentralised generation is energy generated at or near the point of use. According to Britain's energy regulator, Office of Gas and Electricity Markets (Ofgem), LES is defined as energy produced by generating plant of under 50MW connected to a local distribution network system, rather than to a high voltage transmission system [7]. Localised energy systems could be the most cost-effective way to deliver access to more than a third of the 1.2 billion people across the world who still lack any electricity supply [1]. Unlike centralised generation, they are connected close to the point of use which is responsible for losses reduction in the network with decentralised generation.

Currently, LES and microgrid are gaining momentum in the developed and developing nations as alternative sources of electric power. In [9], [10], microgrid with high renewable energy penetration was proposed to address the challenges of inadequate power generation in sub-Sahara Africa due to massive solar resource across the continent. It was proposed that the installation of a microgrid is more cost-effective than extending the grid power transmission line to the rural villages [8].

Microgrids are small-scale power grids that can integrate a variety of both conventional and renewable sources to generate power, making them more efficient and cost-effective [11]. They are mainly used to supply electricity to remote villages and isolated towns. However, the challenges of microgrids are stability issue, uncertainty, protection and resynchronisation to the utility grid. Localised energy systems are much larger in capacity than microgrid, usually with sufficient capacity to supply a town, city or region. They are a local electricity supply that has the potential to expand the penetration of renewable energy sources and create a new opportunity for smart grid investment [12]. Localised energy system also enables full utilization of smart meters features such as demand management, enables new business models and addresses economic issues such as fuel poverty [13]. For the purpose of this thesis, localised energy system (LES) is defined as a medium-sized electricity generation system of capacity not larger than 50MW connected to a local distribution network. In 
LES, the proximity of electricity generating plant to consumers allows loss reduction in the system. Localised energy system also includes stand-alone systems entirely separate from the public networks.

Like many other African countries, the performance of the Nigerian power sector has remained poor and unreliable due to a series of challenges. These challenges include inadequate generation capacity, under voltages, overloaded transformers and high transmission and distribution losses. According to [14], Nigeria power has cumulative transmission and distribution losses of $19 \%$ of generated power and is one of the highest in the world [14]. The Nigeria power system has an installed electricity generation capacity of 12,522 MW [15], with an available generation capacity of $4,500 \mathrm{MW}$, to meet the needs of Nigeria's population of around 190 million people [14]. The increasing demand for electricity in Nigeria is greater than the available generation, thus resulting in transmission systems being heavily loaded beyond their allowable tolerable limit. The demand for electricity in Nigeria was estimated to be 12,800 MW [15]. As a matter of fact, the imbalance between the power demand and supply in Nigeria has led to a reliance on diesel generators. The outcome of this reliance is environmental pollution and inflation in the prices of goods and services since the overhead costs are passed to the consumers [16]. The historically low level of investment in Nigeria's power sector has been a significant barrier to private investment in the country [17]. The power system is faced with challenges to meet its ever-increasing power demand in the face of overall low power generation.

The rising concern about the security of supply has stimulated the country's efforts in considering power generation from renewable energy sources. Electricity generation in Nigeria is mainly from hydro and gas-fired thermal power plants, with hydro plants providing 2,380MW (approximately 26 per cent of the total generation capacity) and thermal plants $10,142 \mathrm{MW}$ (approximately 74 per cent of the total generation capacity). In Nigeria, the government has committed to increasing its power generation to $30,000 \mathrm{MW}$ by 2030 with $30 \%$ of its energy from renewables in 2030 [18]. It is expected that, with the introduction of renewable energy generations, the dual priorities of energy supply securities and emission reduction will be realized. Whilst the persistence of these challenges in a privatised framework does not call into question the validity of the recent reform in the sector, they point to the need for Nigeria to do more in addressing these challenges. There is no doubt that the present 
power challenges facing Nigeria power sector will persist unless the government diversifies the energy sources in domestic, commercial, and industrial sectors and adopts new available technologies such as LES to reduce energy wastages and to save $\operatorname{cost}[19]$.

\subsection{THESIS OBJECTIVES}

The aim of this research is to examine the opportunity and benefits of localised energy systems (LES) in a constrained power system by undertaking three distinct technical studies. The first is a study of LES impact on a low voltage distribution system in the UK to gather knowledge and understanding of the impacts; the second is a study of LES in Ekiti-State $33 \mathrm{kV}$ distribution network in Nigeria using the methodology applied in the first case study and the third investigates the impacts of increasing deployment of LES in the Nigerian power grid with respect to frequency regulation and the opportunity for storage to offer arbitrage. This work is innovative as it examines a distribution system in a developing country and the impacts of the localised energy system on the overall power system. This is important considering that many developing countries are pushing in their energy policy planning for localised energy systems to mitigate against expensive grids build costs and large utility combustion plant.

\subsection{THESIS STRUCTURE}

This thesis contains six chapters and an appendix. Chapter 1 introduces the challenges facing modern power systems to meet electricity demand due to an economic and technical constraint. Chapters 2 is a state-of-the-art literature review of the technical, environmental and policy background of modern power systems considering energy demands, renewable energy integration, new smart transport, storage and heating/air-conditioning technologies (e.g. electric vehicles) with a focus on the United Kingdom to inform grid planning and development in Nigeria in Chapter 3. Chapters 3, 4 and 5 presents three case studies of LES in the UK and Nigerian power system. In Chapter 3, a generic distribution system model of three different LES (i.e. residential, commercial and mixtures of these customers) in the UK to assess the levels of DG and EV penetration is presented to prepare for the work in Chapter 4 and allow 
comparison. In Chapter 4, a model of Ekiti-State $33 \mathrm{kV}$ distribution network to investigate the impact of PV integration over 24 hours, for both rainy and dry seasons, with respect to steady state voltage and network losses is presented. The use of a storage system during peak demand in the rainy season (when the solar irradiation is low) to mitigate the generation shortage is discussed. The effects of cloud shading on the performance of PV generation during the rainy season are also considered. 


\section{ChAPTER 2}

\section{LITERATURE REVIEW}

The main purpose of this chapter is to provide the essential background of microgrid, localised energy systems and recent developments in smart grid technologies. This chapter also reviews the renewable energy technologies, an overview of localised energy systems in the United Kingdom and the review of the Nigerian energy systems and its power needs. Summary discussion and key findings are also provided.

\subsection{SMART GRIDS, MICROGRIDS AND LOCALISED ENERGY SYSTEMS}

The current electric power industry is facing major challenges in moving from centralised generation into decentralised generation, as a result of advancements in power system technology. These advances in technology will affect the ways the energy is produced, delivered and consumed [20]. There will be a complex mix of technologies generating, transmitting, distributing and storing energy. They will operate at a number of different scales, from clusters of buildings to community systems and industrial and national networks. These new technologies are being developed in anticipation of a more widespread smarter grid [21]. Accommodating these new technologies would be easier with smart grids.

A smart grid is an intelligent, digitized network delivering electricity in an optimal way from source to consumption [22]. This is achieved by integrating information, telecommunication and power technology with the existing electricity system. It has self-healing capabilities to correct problems and maintain resilience and reliability [22].

The introduction of the smart grid will replace the traditional vertically integrated electric power industry, which had in the past resulted in higher energy costs. For instance, both microgrids and localised energy systems can have a tremendous impact 
on distribution system development and may offer a number of important advantages for the end users and for the utilities. Microgrids have the potential to reduce energy costs, improve service continuity and bidding system services and flexibility for distribution system operators. They may reduce or postpone investments, increase hosting capacity and improve quality of services.

A microgrid is a localised grouping of electricity generation, energy storage, and loads that is capable of operating in grid-connected and stand-alone modes [23]. Generation and loads in a microgrid are usually interconnected at low voltage and can be controlled as if it were one entity [23]. A microgrid can integrate various sources of distributed generation (DG) especially renewable energy sources and can supply emergency power, changing between connected and island modes. The concept of microgrids provides opportunities for economic development in electric power and clean energy industries [24]. Besides economic development opportunities, microgrids are environmentally friendly and believed to be a positive way of building net-zero energy communities, which have the ability to operate separately from the bulk grid and sustain themselves in the event of a grid outage [24]. Some of the key technical challenges for microgrid development are system controls, monitoring, and protection.

A reliable and high-speed supervisory and monitoring system is required to accommodate a wide range of generation and load variations [24]. Other challenges include steady-state and dynamic performance, microgrid sizing and planning, interconnection requirements and utility system and equipment upgrades. Localised energy systems are medium-sized electricity generation system of capacity not larger than 50MW connected to the local distribution network. Localised energy systems mean different things to different people in different contexts. Who or what qualifies as 'local' is interpreted differently, leading to a wide variety of forms of local systems in practice. There is no established 'best practice' business model or organisational structure for LES; therefore, flexible forms of institutional and financial support are essential [25]. Localised energy systems are typically experimental and innovative, and involve new technologies and new ways of working. Skilled and knowledgeable individuals are required to lead and manage LES at the start, but there is significant potential for knowledge and skills transfer and development between individuals and between communities. 
Localised energy systems must actively respond to particular local needs and contexts. They must be built in and around the existing local infrastructure and the place determines both the constraints and the opportunities of the system [26]. Smart technology can be used to adapt and improve this infrastructure to better align with local needs [25]. Localised energy systems provide an opportunity to incorporate people as a key component of the system. It has the potential to benefit a wide range of different types of communities, including deprived, fragmented communities as well as more traditional, cohesive, remote rural communities [27]. A proper regulatory framework has to be designed to allow microgrid and localised energy systems to bring expected benefits to the various stakeholders.

\subsubsection{Smart grids technical details}

According to IEA "a smart grid is an electricity network that uses digital and other advanced technologies to improve reliability, security, and efficiency of the electric system" [28]. Smart grids co-ordinate the needs and capabilities of all generators, grid operators, end-users and electricity market stakeholders to operate all parts of the system efficiently [29]. The process of "smartening" the electricity grid, which has already begun in many countries, involves significant additional upfront investment, though this is expected to reduce the overall cost of electricity supply to end users over the long term [30]. Smart-grid technologies are evolving rapidly and will be deployed at different rates around the world, depending on local commercial attractiveness, compatibility with existing technologies, regulatory developments and investment frameworks [31].

There are a number of different types of smart-grid technology all of which make use of information and communication technology. Smart grids involve the gathering, by means of sophisticated metering systems and exchange of large amounts of information in real time at different levels of the supply chain. Sensors can be installed on each device on the network (such as power meters, voltage sensors and fault detectors) to gather and transmit data, while two-way digital communication between the device in the field and the utility's network operations centre, which enables the utility to adjust and control each individual device remotely. A key feature of the smart grid is automation technology, which lowers the cost and increases the efficiency of load-management operations. Importantly, information flows between suppliers and end users can also be bi-directional, 
allowing both parties to adjust their behaviour in response to changes in pricing at short notice.

Smart-grid technologies are at varying levels of maturity. Some of the technologies are considered mature in both their development notably the integration of information and communication technology, transmission network enhancements and advanced metering and are already being deployed actively, while others require significant further development or demonstration on a large scale. The development and largescale installation of customer-wide systems are probably the least advanced of the major technology areas. EV battery-charging and discharging technologies are also still at the development stage, but as with customer-wide systems are developing rapidly [32].

The deployment of smart grid pilot and demonstration projects around the world has accelerated in recent years with the help of government funding. For example, USD 4.5 billion was allocated to smart-grid projects under the American Recovery Reinvestment Act of 2009, including USD 435 million for regional demonstrations. According to the Microsoft Worldwide Utility Survey, carried out in 2011, around three-quarters of the 215 utilities polled are at least at the stage of preparing plans to install smart-grid technologies, while 39\% are already at the deployment stage [33]. In Europe, smart-grid deployment is being boosted by a $2006 \mathrm{EU}$ directive that mandates the use of smart meters that are able, at a minimum, to record time-of-use information in all households by 2020 [34]. Smart grids can be a significant tool used to optimise electricity systems by monitoring and managing electricity flows from generation to demand, but it is essential to understand the range of technologies across the entire electricity system as shown in Table 2.1. Some of the technologies shown are specific to electrical systems; some cross over into the energy systems and others still are common information and communication technology (ICT) [29]. 
Table 2.1 Principal smart grid technologies [28].

\begin{tabular}{|c|c|c|}
\hline $\begin{array}{l}\text { Technology area } \\
\text { (level of maturity) }\end{array}$ & Hardware & Systems and software \\
\hline $\begin{array}{l}\text { Wide area monitoring } \\
\text { and control } \\
\text { (developing) }\end{array}$ & $\begin{array}{l}\text { Phasor measurement units } \\
\text { (PMU) and other sensor } \\
\text { equipment }\end{array}$ & 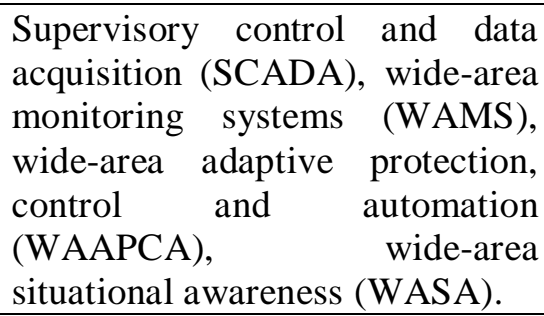 \\
\hline $\begin{array}{l}\text { Renewable and } \\
\text { distributed generation } \\
\text { integration (developing) }\end{array}$ & $\begin{array}{l}\text { Power conditioning } \\
\text { equipment for bulk power } \\
\text { and grid support, } \\
\text { communication and } \\
\text { control hardware for } \\
\text { generation and enabling } \\
\text { storage technology } \\
\text { Superconductors, }\end{array}$ & $\begin{array}{l}\text { Energy management system } \\
\text { (EMS), distribution management } \\
\text { system (DMS), SCADA, } \\
\text { geographic information system } \\
\text { (GIS) }\end{array}$ \\
\hline $\begin{array}{l}\text { Advanced metering } \\
\text { infrastructure (mature) }\end{array}$ & $\begin{array}{l}\text { Smart meters, in-home } \\
\text { displays, servers, relays }\end{array}$ & $\begin{array}{l}\text { Meter data management system } \\
\text { (MDMS) }\end{array}$ \\
\hline $\begin{array}{l}\text { Information and } \\
\text { communication } \\
\text { technology integration } \\
\text { (mature) }\end{array}$ & $\begin{array}{l}\text { Communication } \\
\text { equipment (power line } \\
\text { carrier, WIMAX, LTE, } \\
\text { RF mesh network, } \\
\text { cellular), routers, relays, } \\
\text { switches gateway, } \\
\text { computers (servers) } \\
\end{array}$ & $\begin{array}{l}\text { Enterprise resource planning } \\
\text { software } \\
(\text { ERP), customer information } \\
\text { system (CIS) }\end{array}$ \\
\hline $\begin{array}{l}\text { Transmission } \\
\text { enhancement (mature) }\end{array}$ & $\begin{array}{l}\text { Superconductors, } \\
\text { FACTS, HVDC }\end{array}$ & $\begin{array}{l}\text { Network stability analysis, } \\
\text { automatic recovery systems }\end{array}$ \\
\hline $\begin{array}{l}\text { Distribution grid } \\
\text { management } \\
\text { (developing) } \\
\text { Advanced }\end{array}$ & $\begin{array}{lr}\text { Automated re-closers, } \\
\text { switches and capacitors, } \\
\text { remote r controlled } \\
\text { distributed generation and } \\
\text { storage, transformer } \\
\text { sensors, wire and cable } \\
\text { sensors }\end{array}$ & $\begin{array}{lrr}\text { Geographic } & \text { information } & \text { system } \\
\text { (GIS), distribution management } & \text { system (DMS), } & \text { outage } \\
\text { management system } & \text { (OMS), } \\
\text { workforce management } & \text { system } \\
\text { (WMS) } & & \end{array}$ \\
\hline $\begin{array}{l}\text { EV battery charging } \\
\text { infrastructure } \\
\text { (developing }\end{array}$ & $\begin{array}{l}\text { Charging equipment } \\
\text { (public and private), } \\
\text { batteries, inverters } \\
\text { Smart }\end{array}$ & $\begin{array}{l}\text { Energy billing, smart grid-to- } \\
\text { vehicle charging (G2V) and } \\
\text { discharging vehicle-to-grid } \\
(\mathrm{V} 2 \mathrm{G}) \text { methodologies }\end{array}$ \\
\hline $\begin{array}{l}\text { Customer-side systems } \\
\text { (developing) }\end{array}$ & $\begin{array}{l}\text { Smart appliances, routers, } \\
\text { in-home display, building } \\
\text { automation systems, } \\
\text { thermal accumulators, } \\
\text { smart thermostat }\end{array}$ & $\begin{array}{l}\text { Energy dashboards, energy } \\
\text { management systems, energy } \\
\text { applications for smart phones and } \\
\text { tablet }\end{array}$ \\
\hline
\end{tabular}

Sources: Based on IEA (2011a) 


\subsubsection{Scope of a smart grid}

The structure of smart grid scope from a different team may not be the same, due to analysis differences and the aim differences between designers [35]. However, the basic elements and considerations of each scope appear to be similar. In [36], Department of Energy, USA, provides a smart grid scope in Fig 2.1. The figure provides a pictorial view of the many aspects of the electric system touched by smart grid concerns.

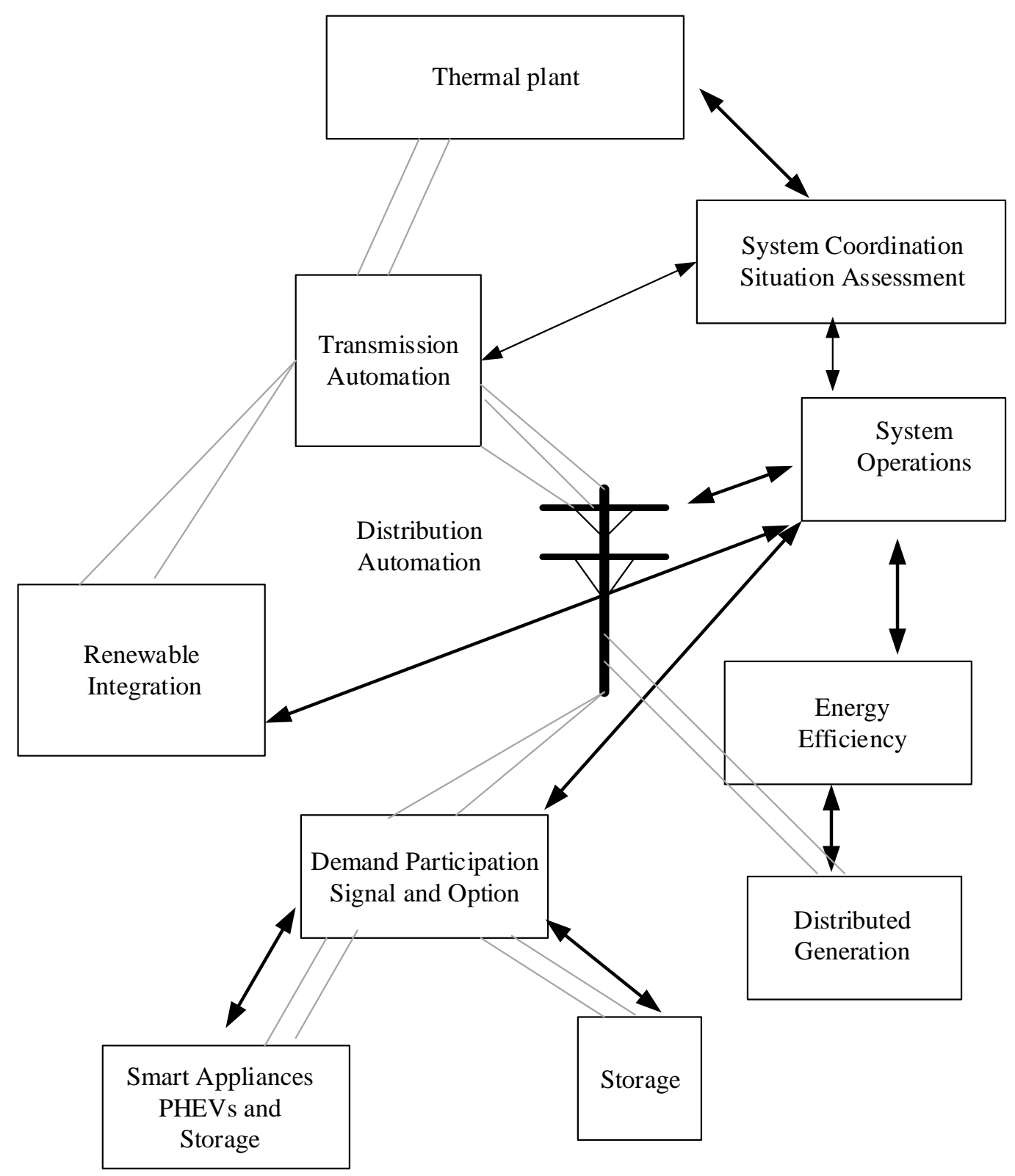

Fig 2.1 Scope of a smart grid concerns 
The following areas of the electric system cover the scope of a smart grid namely: the delivery infrastructure (e.g., transmission and distribution lines, transformers and switches), management of the generation and delivery infrastructure at the various levels of system coordination (e.g., transmission and distribution control centres, regional reliability coordination centres, national emergency response centres), the end-user systems and related distributed-energy resources (e.g., building and factory loads, distributed generation, storage, electric vehicles), the financial and regulatory environment that fuels investment and motivates decision makers to procure, implement, and maintain all aspects of the system (e.g., stock and bond markets, government incentives, regulated or non-regulated rate-of-return on investment), and the information networks themselves (e.g., remote measurement and control communications networks, inter and intra-enterprise communications, public internet).

Among the significant challenges facing the development of a smart grid is the cost of implementing a smart grid and the regulations that allow recovery of such investments [37]. Major technical barriers include developing economical storage systems; these storage systems can help solve other technical challenges, such as integrating renewable-energy sources with the grid and addressing power-quality problems and strengthen asset utilization [38]. Without. Another challenge facing a smart grid is the uncertainty of the path that its development will take over time with changing technology, changing energy policy, and developing climate change policy [39].

\subsubsection{Comparison of microgrids and localised energy system}

The comparison between microgrid and localised energy systems is presented in Table 2.2. The comparison is based on size of the generated power, storage requirements, consumers, voltage level and mode of connection to the grid. The most fascinating feature of a microgrid is the ability to separate and isolate itself from the utility's distribution system during grid disturbances, i.e., faults, voltage collapses, and black-outs [24]. It may also intentionally disconnect during grid maintenance and also when the quality of power from the grid is deteriorated [24]. Whereas, LES are mostly connected to the grid. 
Table 2.2 Comparison between microgrids and localised energy systems

\begin{tabular}{|c|c|c|}
\hline Value & Microgrids & Localised energy systems \\
\hline Power & $\begin{array}{l}\text { Small-sized, (few MW) [40] } \\
\text { Mainly controllable power; } \\
\text { small PV,wind, etc. }\end{array}$ & $\begin{array}{l}\text { Medium-sized, (less than 50MW) } \\
\text { mainly distributed energy; PV, } \\
\text { Wind, small-hydro etc }\end{array}$ \\
\hline Storage & $\begin{array}{l}\text { Required storage } \\
\text { (battery) }\end{array}$ & $\begin{array}{l}\text { Required storage } \\
\text { (Flywheel, Battery) }\end{array}$ \\
\hline Cost & Low variable cost & $\begin{array}{l}\text { Low variable cost ( higher than } \\
\text { microgrid) }\end{array}$ \\
\hline Consumers & Small community, village & Local government, state or region \\
\hline $\begin{array}{l}\text { Voltage } \\
\text { level }\end{array}$ & Connect at low voltage & Connect at medium voltage \\
\hline Connection & $\begin{array}{l}\text { Connect to the grid or } \\
\text { operate independently }\end{array}$ & Mostly connect to the grid \\
\hline
\end{tabular}

\subsection{RENEWABLE ENERGY TECHNOLOGY STATE OF ART}

The future power networks operation will be influenced greatly by the proliferation of electricity generation from renewable energy sources [41]. Reasons that have prompted their widespread include ever-increasing power demand in the face of overall low power generation, environmental concerns, and market liberalisation. Levels of penetration are expected to keep on growing as a pathway to achieve Government emission reduction targets. Fig 2.2, is the estimated renewable energy share of the global electricity production at the end of the year 2016 [42]. 


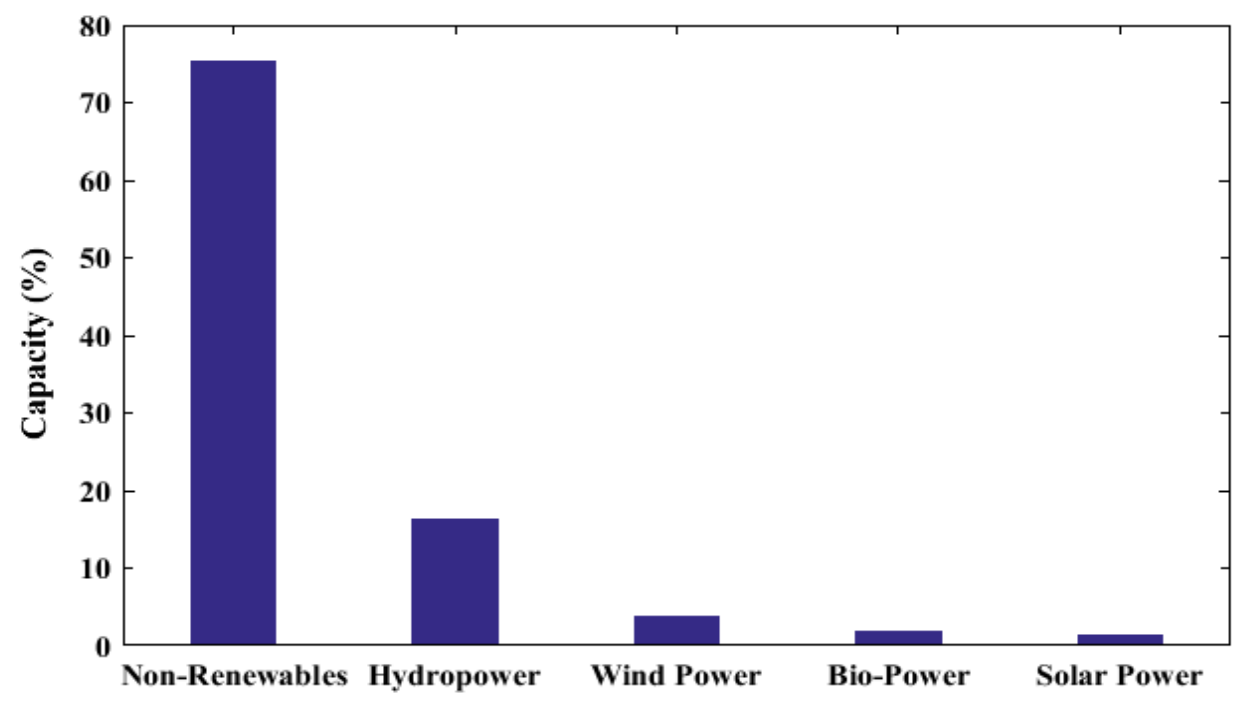

Fig 2.2 Renewable energy share of global electricity production [42].

Grid-connected renewable energy systems receive support mostly through financial incentives, feed-in tariffs, tenders or net metering, which have contributed to the deployment of renewable generation. Many countries are moving away from or reducing their use of, traditional centrally fixed, price-based mechanisms. Developed countries have followed the lead of emerging economies such as Brazil and South Africa by turning to more competitive systems, such as renewable energy tenders. In Europe, a multi-tiered system has developed, through which large-scale renewable projects or specified power supply profiles are awarded through tenders, while smallerscale projects continue to be supported through feed-in policies. In Germany, Renewable Energy Act amendments first released in 2016 entered into force in 2017, extending tendering mechanisms to cover offshore wind power and introducing financial support for solar PV systems on residential multi-apartment buildings. The feed-in tariff (FIT) remains for solar PV and wind power projects less than $750 \mathrm{~kW}$ and for biomass projects less than $150 \mathrm{~kW}$.

In 2012, renewable energy provided an estimated $19 \%$ of global energy consumption, and it increased to $23.7 \%$ in 2014 [11]. It has been observed that, among various renewable energy sources, the hydropower share is on the top at $16.6 \%$, the wind followed at $4 \%$ and bio-power power is other renewable energy sources, concentrated solar photovoltaic is $1.5 \%$. 
Renewable energy plays a vital role in providing energy services in a sustainable manner in the sense that they are abundant and inexhaustible without any environmental challenges. Renewable energy is derived from resources that are regenerative and do not deplete over time. This can be energy from wind, waves, the sun and geothermal heat from the ground.

Renewable energy ensures increase security of supply and reduced energy price since they can be produced locally or available on site [43]. Although renewable energy has many benefits, the major limitation is in the intermittent nature of certain renewable technologies. For example, solar electricity cannot be generated at night, just as wind turbines will not provide electricity when it is not windy. The intermittency problem associated with renewable energy source could also be avoided through demand response management. This method involves using energy in periods of high renewable energy supply, such as summer daytime for solar energy. Likewise, transmitting large amounts of energy over a long distance could also be partly avoided by shifting industry to regions of high renewable energy potential. Once the appropriate renewable energy technologies have been identified, feasibility studies can then be undertaken to determine the stability of the technology in terms of its technical, economic and environmental performance.

\subsection{OVERVIEW OF LOCALISED ENERGY INTEGRATION}

Most electricity distribution systems were designed for a one-way flow of electricity. The addition of LES into the distribution system in increasing amounts might change the dynamic behaviour of the distribution systems by introducing new sources of energy that intermittently change the amount and direction of power flow in the grid. These changes in grid behaviour create new challenges for the utility in determining how to plan, design, and operate delivery systems that were not designed for the application of localised energy systems. This addition of LES that can, at times, push electricity onto the distribution system, can require operational or even hardware modifications to the distribution system. A few countries (notably Germany) have successfully integrated large amounts of distributed renewable technologies into their distribution networks, but most electricity systems worldwide are still dominated by centralized generation and utility experience with LES is still quite limited. How 
distribution systems handle distributed generation, what problems DG might cause, and how to solve them are all questions currently being examined.

Localised energy systems will enhance the security and efficiency of the energy system and also reduce the energy lost in transmission [44]. Cheaper electricity could be provided to the communities living close to this medium-sized electricity generation system. Localised energy systems such as solar PV and wind turbines if well planned, could bring considerable benefits to local communities and the country as a whole [45], [46]. Other advantages of LES is the ability to match energy supply and demand within a defined area to the benefit of a range of stakeholders. Allowing local communities to participate in the LES project has the potential to encourage energyconscious behaviour and greater public engagement in carbon reduction initiatives.

Localised energy systems could help to boost energy security by increasing diversity and provide greater flexibility within the system [47]. It may have the potential to reduce demand on the main grid, providing they can demonstrate the required reliability and predictability to support the power network at a national level. Medium-sized electricity system could provide opportunities for new sources of investment from the independent generator, community groups and housing associations to invest in energy infrastructures [48]. Localised energy systems could bring down the cost in some ways. For examples, businesses using "onsite" generation are able to avoid transmission and balancing charges and would not be subject to levies, such as the Renewables Obligation (RO) or Energy Company Obligation (ECO), which suppliers pass on to their customers. This could lead to additional savings.

\subsubsection{Localised energy systems in the UK}

The UK energy system is undergoing a period of significant change. It is changing from a passive, one-directional system where power is produced in a centralised large generator to an active, multi-directional one where power is generated at different levels within the system and consumers produce, manage and own generation assets. Localised energy systems are a key focus in the UK's power system revolution and are considered to facilitate faster decarbonisation than centralised power systems [49]. Although it is unlikely that localised energy systems will eliminate the need for larger, centralised power stations, with some Government support they could provide a significant proportion of the UK's energy capacity [29]. The LES is a rapidly growing sector, with an important role to play in 
helping the UK meet its renewable energy and carbon reduction targets and ensuring the security of supply. It is widely acknowledged that obtaining a grid connection can be a difficult and expensive process that can be the determining factor between the success and failure of localised energy systems.

This research has identified a number of particular issues that cause problems for localised energy systems and hinder their development. In the UK the distribution network operators (DNOs) vary significantly in terms of timeliness and consistency and this can have a significant impact on the timescales and costs of projects [50]. Connection processes are slow, high and variable connection cost quotations, dependent upon location, can cause surprises and derail this technology. The grid reinforcement can also present a very large problem to localised energy developers as it has the capability of significantly increasing costs [50].

The DNOs have made some positive progress in improving communication with distribution generation (DG) customers through annual DG Forum meetings, largely as a result of a new licence condition imposed on them in 2010. But further improvement is needed to improve the transparency and predictability of grid connection processes and charges. Another area the industry is making progress is primarily through the Low Carbon Network Fund (LCNF) and for reducing the need for grid reinforcement measures by assessing less expensive network management alternatives to reinforcing the grid.

Both Germany and Denmark have more focused policies than the UK that aim to specifically facilitate localised energy, and consequently, they have a high proportion of localised energy systems. In Denmark, the reinforcement costs are socialised and renewables are given priority access to the grid. Germany also offers priority grid access, and its connection procedure is transparent and predictable. These approaches have delivered high levels of build-out in local energy schemes.

According to the UK localised energy survey, most localised energy projects are influenced by a desire to save money on energy bills and to reduce greenhouse gas emissions [45]. Other reasons include empowerment and providing income for the community. Many localised energy schemes are co-operatives that are owned and run by and for their members. Examples of community-owned local energy systems are Lochcarnan Community Windfarm, Westmill Solar Co-operative and Westmill Wind Co-operative [47]. 
There are a few different models for medium-sized electricity systems that are owned by private companies. These models include independent generators looking to sell the electricity they generate for a profit company investing in on-site assets for their own use, so as to manage energy price risk, to protect themselves from rising energy costs and/or to meet environmental commitments and companies investing in off-site assets (for the same reasons as above). For example, Cornwall Energy believed there was potential for energy-intensive companies to benefit from investing in LESs [45], [46].

Joint-ownership projects are mostly between local communities and commercial developers. In the UK, the community and local equity in medium-sized projects are split between joint ventures with developers (53\%) and wholly-owned (47\%) [47]. Joint ventures can help community groups address many barriers and partnerships between commercial developers and communities can provide a good mix of knowledge, skills, access to finance and local contacts to enable developments.

According to IEA, Feed-in Tariff (FiT) scheme was introduced on 1st April 2010 to encourage the growth of renewable generations and is a financial support scheme for eligible low-carbon electricity technologies, aimed at small-scale installations up to a maximum capacity of $5 \mathrm{MW}$. This tariff further enhances the development of LES in the UK. For example, electricity generated from LES (renewable sources) increased by 19 per cent between 2016 and 2017 to 99.3 TWh. Wind generation increased by 34 per cent to $50.0 \mathrm{TWh}$, hydro generation rose by 9 per cent to $5.9 \mathrm{TWh}$, generation from solar photovoltaics increased by 11 per cent, to $11.5 \mathrm{TWh}$, due to increased capacity. Renewable electricity accounted for $29.3 \%$ of electricity generated in the UK during 2017, 4.8 percentage points higher than in 2016. Onshore wind now has the largest capacity, marginally ahead of solar photovoltaics. The contribution of renewable sources to electricity generated in the UK from 1990 to 2017 is shown in Fig 2.3. 


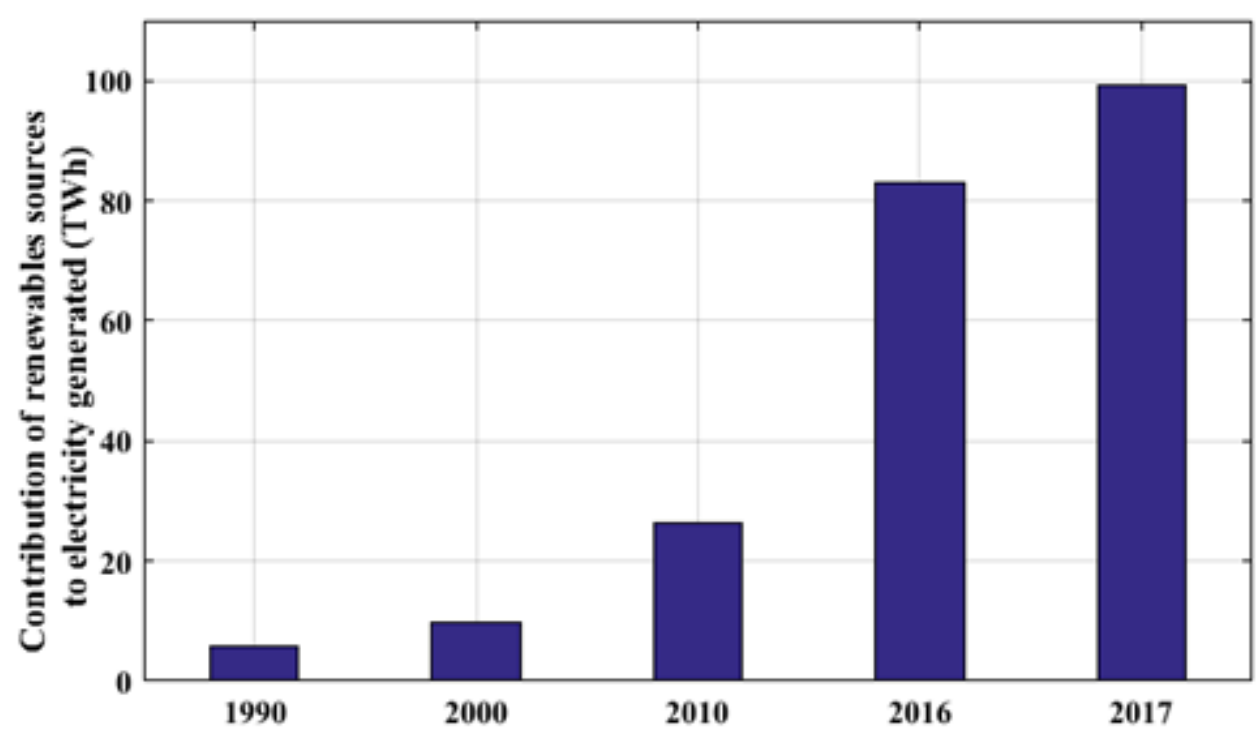

Fig 2.3 Renewable energy contribution to electricity in the UK

Despite some barriers, there have been significant developments in LES in the UK. Networks such as that set up by Woking Borough Council, alongside energy efficiency measures have reduced emissions by $77 \%$ and cut energy prices for low-income households, offering important lessons for UK policy-makers [41]. While Ofgem has recently taken some small steps in support of localised energy system, it should be given an explicit obligation to deliver a fully sustainable energy system within a few decades. The electricity market needs fundamental reform, to promote meaningful competition and to stimulate technological advances. At the same time, the economic regulation of the electricity sector must be overhauled, abolishing the present system under which network operators are rewarded for continued investment in outdated grid assets, and instead incentivising them to connect localised generation and to become active managers of efficient local networks.

Removing the barriers to LES will facilitate the emergence of new enterprise models, particularly energy services companies (ESCOs) focused on the efficient delivery of local low-emission energy offering a genuinely competitive and innovative alternative to business-as-usual in the electricity sector [47].

\subsubsection{State of the power sector in other developing countries}

Power sector from developing countries such as China, India, and those of subSahara Africa are faced with common challenges of non-sustainable primary sources, ageing grid infrastructure and inadequate grid capacity to meet current demands [51]. 
The rate of integration into the energy mix is inadequate even where renewable energy sources are available as such cannot meet their target time frame owing to the low investment being made into grid upgrades [52].

In most of these developing countries, a careful study of their power sectors over past years has reveals risen fossil fuel usage and has continued to provide the bulk of the energy requirements. While countries like China and India rely majorly on fossil fuels for their primary electricity needs, for sub-Saharan Africa, the large parts of the population rely on biomass for cooking and heating, low fossil fuel usage and low level of industrial activities [52]. That means Sub-Saharan Africa is less faced with challenges of $\mathrm{CO} 2$ emission than China and India. That is why power policy in subSahara must be aimed at improving generation capacity than reducing GHG emissions. However, typical biomass usage has poor efficiency and implications for public health and the environment. It is obvious a new direction is needed to increase and improve energy usage in this part of the world. Local renewable energy sources must be integrated into the national efforts for expanding electricity access to align with global sustainability efforts [51].

Currently close to $80 \%$ of the communities in sub-Saharan Africa lack connection to the power infrastructure [53]. While efforts are on to develop the transmission and generation infrastructure, it is clear that population growth will continue to outstrip supply and distribution capacity addition. Effort should be channel toward renewable generation and has to be coupled with energy storage to even out intermittency in supply. Some of the options available for EES include batteries - for energy-intensive applications (e.g. renewable integration) storage devices with low power/capacity ratio are preferable, for instance, lead-acid batteries; while for power intensive applications (e.g. primary frequency regulation) high power/capacity may be preferred, such as lithium-ion batteries. Since grid access will continue to be an issue in the very near future, Hybrid Systems (Solar PV with Diesel Generating sets) are also being looked at as viable means to increase access to power in some remote areas in Africa [54].

Most of the African countries have high solar radiation intensity for the most part of the year with the highest intensity in the Sahara and Kalahari deserts. Therefore, the power sector in sub-Sahara Africa can be sustained by solar energy. Most of the subSahara African countries are part of the Sunshine Countries that are likely going to enjoy the support of the International Solar Alliance on sustainability [52]. However 
low population density and hence low demand in these areas means a significant improvement in transmission capabilities and storage capabilities would be needed to transmit most of the generated power out to where the bulk of consumers might be. Lack of growth in these capabilities could mean large solar projects may not be economically viable due to curtailments.

According to the International Energy Agency report, India is to contribute more than any other country to the projected rise in global energy demand by 2040. Over $50 \%$ of new generation capacity in 2040 will come from renewables and nuclear. With an average of 300 days of sunshine every year, India is massively endowed with solar energy potentials in the developing world. Current installed on-grid capability is around 8.5 GW per data available end of September 2016. India has announced plans to source at least $40 \%$ of its energy needs from renewable sources by 2030 including $100 \mathrm{GW}$ of solar energy by 2022 .

India made an early start in wind power with the first wind farm installation in 1986 on the western coast [55]. Potential for wind power generation for the grid in India is estimated at over $100 \mathrm{GW}$. Current installed capacity is close to $28 \mathrm{GW}$ which puts India in the 4th place after China, USA and Germany in terms of grid-connected wind power installations [54]. Going forward plans for renewables include a target of $60 \mathrm{GW}$ of installed wind power by 2022 .

China may see an increase in the near term before a slowdown in economic growth and improvement in efficiencies cause total energy usage to level off and then decline. Under a high RES penetration scenario, it is projected that by $2050,85 \%$ of Chinas total power generation will be provided by renewable power and $60 \%$ by variable renewable power such as solar and wind. Large parts of northern and western China have excellent potential for wind energy, and reports suggest China has added over $20 \mathrm{GW}$ of capacity every year in the recent past [54].

Current plans are to add another $100 \mathrm{GW}$ of installed wind power capacity by 2020 , and data suggest the country could well be on track to generate more than a quarter of its electricity from wind power by 2030. Though there are indications of challenges with integrating wind power into the grid. Last year China became the world's largest producer of PV power surpassing Germany. China also leads the world in PV module 
manufacturing and plans to triple its solar capacity by 2020 adding about $15-20 \mathrm{GW}$ capacity per year for the next few years taking its installed capacity to $140 \mathrm{GW}$ [54].

\subsection{REVIEW OF THE NIGERIAN ENERGY SYSTEMS AND ITS POWER NEEDS}

The history of electricity development in Nigeria began in 1896 when the first generating power plant was installed to serve the Colony of Lagos [56]. By Act of Parliament in 1951 [56], the Electricity Corporation of Nigeria (ECN) was established, and in 1962, the Niger Dams Authority (NDA) was also built for the development of Hydro Electric Power [57]. However, in 1972, both ECN and NDA were merged to form the National Electric Power Authority (NEPA). Therefore, NEPA was in charge of the generation, transmission and distribution of electric power in Nigeria.

The power sector did not experience significant investment in infrastructural development for over twenty years prior to 1999 [17]. During that period, there was a lack of funds to acquire new plants, and the existing ones were not properly maintained making the power system unreliable and poor. In 2001, power generation drops from the installed capacity of about $5,600 \mathrm{MW}$ to $1,750 \mathrm{MW}$, as compared to a load demand of $6,000 \mathrm{MW}$ [17]. Also, only nineteen out of the seventy-nine installed generating units were in operation [58].

In March 2000, the president of the Federal Republic of Nigeria, Chief Olusegun Obasanjo took charge of the affairs of PHCN and set up a nine-man Technical Board with full executive powers. The mandate of the board is to ensure uninterrupted power supply by December 31, 2001. In the year 2001, the reform of the electricity sector began with the promulgation of the National Electric Power Policy which had as its goal the establishment of an efficient electricity market in Nigeria [59]. It had the overall objective of transferring the ownership and management of the infrastructure and assets of the electricity industry to the private sector with the consequent creation of all the necessary structures required to forming and sustaining an electricity market in Nigeria.

The power sector reform bill was signed into law in March 2005 to enable private companies to participate in electricity generation, transmission, and distribution [60]. The government has separated PHCN into eleven distribution firms, six generating 
companies, and a transmission company [61]. In this restructuring process, the Federal Government retains the ownership of the transmission assets, while the generation and distribution sectors were fully privatised [62]. The reform in the Nigeria Power sector is to produce radical expansion of the existing grid network. It is expected that in the next few years, a much larger, fortified and stable grid will replace the scanty, unstable and fragile grid that exists presently. This restructuring process was unable to provide a tangible solution to the problem in the power sector.

Currently, Nigeria power system is faced with so many challenges such as; inability to effectively dispatch generated energy to meet the load demand, generating plants are outdated, lack of maintenance of power infrastructure, low revenues, high losses, power theft and poor tariffs [63], [64]. This resulted in an unreliable and unstable electric power supply situation in the country with customers exposed to frequent power cuts and outages. In addition, some of the transmission lines are also fragile and radial nature, which is prone to frequent system collapse. Poor network configuration in some regional work centres and large numbers of overloaded transformers in the grid system [65].

In 2010, $83 \%$ of firms surveyed by the World Bank identified access to power as the primary constraint on their business [66],[67]. Nigerian businesses experienced an average of 239 hours of power outage per month, leading to about 7\% in lost sales in 2010 [68]. The Africa Development Bank estimates that power outages result in a loss equivalent to $3 \%$ of the country's GDP [69]. Table 2.3 shows the cost of unserved energy in Nigeria compared to South Africa. South Africa has ten times the available generation capacity of Nigeria despite having only one-third of the population. Electricity consumption is nearly seven times greater in South Africa than Nigeria despite the former having a lower national GDP [70].

Table 2.3 Cost of unserved energy in Nigeria, benchmarked to South Africa

\begin{tabular}{|c|c|c|c|c|}
\hline Country & $\begin{array}{c}\text { Population } \\
\text { (million) }\end{array}$ & $\begin{array}{c}\text { 2016 GDP } \\
\text { (billion US\$) }\end{array}$ & $\begin{array}{c}\text { Available } \\
\text { Generation } \\
\text { Capacity (MW) }\end{array}$ & $\begin{array}{c}\text { Annual Electricity } \\
\text { Consumption*(billion } \\
\text { KWh) }\end{array}$ \\
\hline Nigeria & 170.5 & 405.1 & 4,000 & 35 \\
\hline $\begin{array}{c}\text { South } \\
\text { Africa }\end{array}$ & 55.91 & 294.8 & 40,000 & 237 \\
\hline
\end{tabular}

[Source: CSL Research] 
In Nigeria, individuals are allowed to install and run an off-grid power generator, however with a capacity below $1 \mathrm{MW}$; all forms of the generation above this must obtain a generation license and a Power Purchase Agreement (PPA) from NERC [70].

In 2012, NERC signed two regulations namely, Independent Electricity Distribution Network (IEDN) and Embedded Generation. The IEDN allows for communities, local and state government to invest in electricity distribution networks in areas with little or no access to the grid, poorly serviced areas or bad distribution network [71]. While embedded generation allows communities, investors, local and state government to generate and distribute electricity solely for their consumption, utilizing the facilities of electricity distribution companies or independent electricity distribution networks that already exist.

It is essential to understand Nigeria's power system in order to fully appreciate the extent of the challenges facing the sector and the need to address the challenges facing the sector urgently.

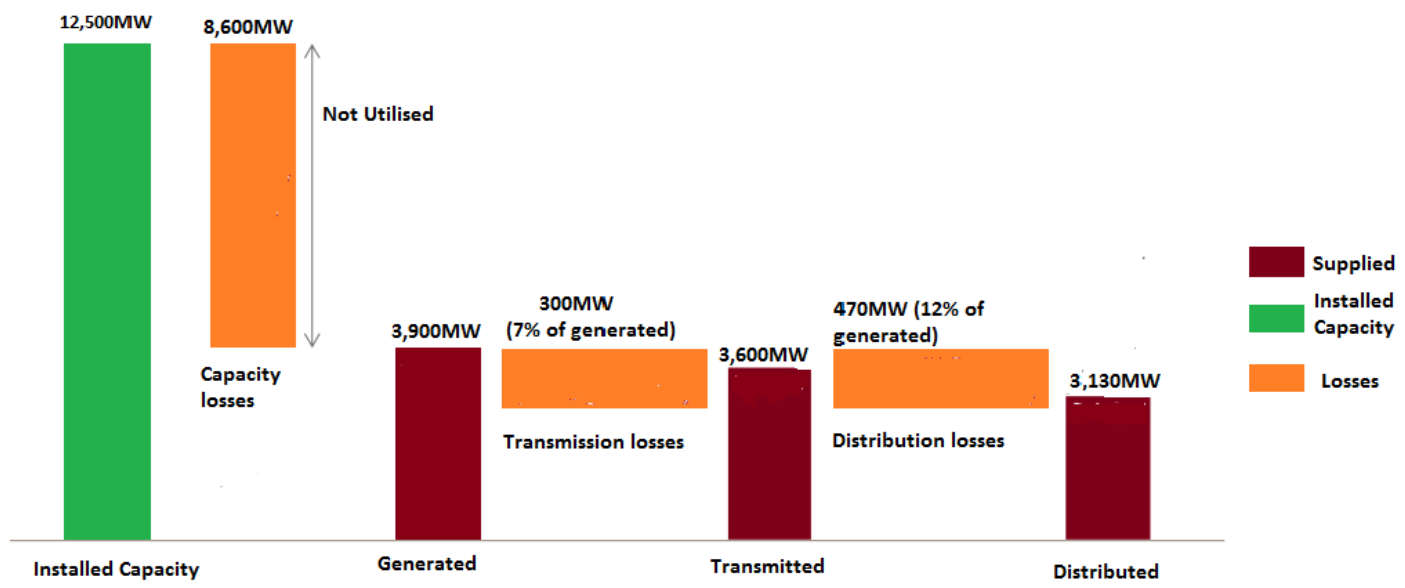

Fig 2.4 Installed capacity and losses across the Nigeria power system [14].

A summary of the losses across Nigeria's power system, along with the categories of players in each segment, is presented in Fig 2.4. The installed generation capacity was $12,500 \mathrm{MW}$ in 2015 . The available generation capacity was $3,900 \mathrm{MW}$ and the total network losses were 19\% (7\% of the generated power was lost through the transmission lines and a further 12\% through distribution network) [14].The total losses across the power network can be attributed to two key causes - technology limitations and outdated infrastructure. 
Nigeria's power generation capacity utilisation is approximately $31 \%$ which is very low, given the country's urgent need for reliable power supply. Whereas, developing countries such as Malaysia and South Africa have relatively higher average utilisation rates of approximately $50 \%-60 \%$ as a result of significant efforts to attract investment in new technologies. Table 2.4 show the generation capacity, utilisation factor and network losses for some developing country.

Table 2.4 generation capacity, utilisation factor and network losses

\begin{tabular}{|c|c|c|c|}
\hline Country & $\begin{array}{c}\text { Generation } \\
\text { capacity }(\mathrm{MW})\end{array}$ & $\begin{array}{l}\text { Utilisation } \\
\text { factor }(\%)\end{array}$ & $\begin{array}{l}\text { Network } \\
\text { losses (\%) }\end{array}$ \\
\hline Nigeria & 12,500 & 31 & 19 \\
\hline Brazil & 121,700 & 55 & 21 \\
\hline Equador & 5400 & 49 & 15 \\
\hline Egypt & 27000 & 63 & 16 \\
\hline India & 254700 & 55 & 22 \\
\hline Malaysia & 28500 & 53 & 14 \\
\hline New Zealand & 9500 & 54 & 10 \\
\hline South Africa & 44200 & 66 & 10 \\
\hline Peru & 9700 & 47 & 13 \\
\hline Norway & 32300 & 47 & 9 \\
\hline Ukraine & 55200 & 40 & 10 \\
\hline
\end{tabular}

[Sources: Nigeria power baseline report (2015) BMI research, Pwc analysis]

Nigeria must look towards improving capacity utilisation (currently at $31 \%$ ) significantly by investing in new and efficient power generation technology, as well as revamping existing power plants. This is explored further in chapter four of this thesis. 
Power system losses in Nigeria further reduce generated power output by $19 \%$. While this is lower than a few other developing countries where power losses are greater than 20\%, the benchmarks set by countries such as South Africa, Malaysia, Peru and Ukraine are much better [14]. These losses are more pronounced in rural areas due to ageing infrastructure and irregular maintenance. The possible methods to address these challenges are discussed later in chapter four of this thesis.

\subsection{RENEWABLE ENERGY POTENTIAL IN NigERIA}

Nigeria is endowed with abundant renewable energy resources such as solar energy, hydro-power, biomass, wind etc. But the share of renewable energy in Nigeria energy mix is insignificant compared with other developing countries of the world [72], [73]. Aside from biomass and waste used traditionally in the rural areas, the current state of exploitation and utilization of renewable energy resources is very low; limited largely to pilot and demonstration projects developed by research centres [74]. At present, there has not been a single grid generation of electricity from renewable energy sources. The efforts by the Energy Commission of Nigeria in promoting renewable energy into Nigeria's energy mix through the installation of solar energy for rural electrification, street lighting, etc. and the role of private commercial renewable energy importers are important but are largely fragmented and undocumented. Renewable energy potential and utilisation is shown in Table 2.5 . 
Table 2.5 Renewable energy potential and utilisation in Nigeria [74].

\begin{tabular}{|c|c|c|c|}
\hline Resource type & $\begin{array}{c}\text { Reserves } \\
\text { (natural units) }\end{array}$ & Production & $\begin{array}{c}\text { Domestic } \\
\text { utilization } \\
\text { (natural units) } \\
\end{array}$ \\
\hline $\begin{array}{c}\text { Small } \\
\text { hydropower }\end{array}$ & $3500 \mathrm{MW}$ & $30 \mathrm{MW}$ & $30 \mathrm{MW}$ \\
\hline $\begin{array}{c}\text { Large } \\
\text { hydropower }\end{array}$ & $11,250 \mathrm{MW}$ & $1938 \mathrm{MW}$ & $1938 \mathrm{MW}$ \\
\hline Wind & $\begin{array}{c}2-4 \mathrm{~m} / \mathrm{s} \text { at } 10 \mathrm{~m} \\
\text { height (mainland) }\end{array}$ & - & - \\
\hline Solar radiation & $\begin{array}{c}3.5-7.0 \\
\mathrm{kWh} / \mathrm{m}^{2} / \text { day }\end{array}$ & $6 \mathrm{MWh} /$ day & $6 \mathrm{MWh} /$ day \\
\hline Fuel wood & $\begin{array}{c}11 \text { million } \\
\text { hectares of forest } \\
\text { and wood }\end{array}$ & $\begin{array}{l}0.120 \text { million } \\
\text { tonne/day }\end{array}$ & $\begin{array}{l}0.120 \text { million } \\
\text { tonne/day }\end{array}$ \\
\hline Animal waste & $\begin{array}{c}211 \text { million } \\
\text { assorted animals }\end{array}$ & $\begin{array}{c}0.781 \text { million } \\
\text { tonnes of } \\
\text { waste/day } \\
\end{array}$ & None \\
\hline $\begin{array}{c}\text { Energy crop and } \\
\text { Agric. residue }\end{array}$ & $\begin{array}{c}28.2 \text { million } \\
\text { hectares of arable } \\
\text { land }\end{array}$ & $\begin{array}{c}0.256 \text { million } \\
\text { tonnes of assorted } \\
\text { crops/day }\end{array}$ & None \\
\hline
\end{tabular}

\subsubsection{Hydropower}

Hydropower is the most developed and exploited renewable energy in Nigeria. Hydropower is derived from the potential energy available from water due to the potential energy difference between the levels of water in reservoirs, dams or lakes and the tailwater to which it is discharged. Power is generated by mechanical conversion of the energy into electricity through a turbine, at a usually high-efficiency rate. Depending on the volume of water discharged and height of fall (or head), hydropower can be large or small. Nigeria's hydropower currently accounts for about $32 \%$ of the total installed commercial electric power capacity [75].

About two-thirds of Nigeria lies in the watershed of the Niger River, which empties into the Atlantic at the Niger Delta, with its major tributaries; the Benue in the Northeast, the Anambra in the Southeast and Kaduna in the Northwest. The Niger is Africa's third longest river and fifth largest in term of discharge.

The installed grid-connected hydropower in Nigeria is $1,977 \mathrm{MW}$ consisting of major stations at Kainji (760MW), Jebba (578MW) and Shiroro (600MW) [76], While 
$98 \%$ of the hydropower stations have capacities greater than $30 \mathrm{MW}, 2 \%$ have capacities less than 30MW [76]. However, studies carried out in twelve states and four river basins show that over 278 unexploited Small Hydro Power (SHP) sites with a total potential of 734.3MW exist [73]. SHP which based on Nigeria's level of hydropower development is defined as follows: small (2MW to $10 \mathrm{MW}$ ), mini ( $\leq$ $2 \mathrm{MW})$ and micro $(\leq 100 \mathrm{~kW})$ sites exist in virtually all parts of Nigeria with an estimated capacity of $3,500 \mathrm{MW}$ [73]. As at 2010, it was estimated that the total contribution of hydropower to the total energy consumption is $0.4 \%$ [77], while it currently contributes approximately $30 \%$ of the total installed grid-connected generated electricity [78].

\subsubsection{Wind}

Wind, which is an effect from the uneven heating of the earth's surface by the sun and its resultant pressure inequalities is available at annual average speeds of about $2.0 \mathrm{~m} / \mathrm{s}$ at the coastal region and $4.0 \mathrm{~m} / \mathrm{s}$ at the far northern region of the country. Assuming an air density of $1.1 \mathrm{~kg} / \mathrm{m}^{3}$, wind energy intensity, perpendicular to the wind direction, range between $4.4 \mathrm{~W} / \mathrm{m}^{2}$ at the coastal areas and $35.2 \mathrm{~W} / \mathrm{m}^{2}$ at the far northern region.

Wind energy conversion systems (wind turbines, wind generators, wind plants wind machine, and wind dynamos) are devices which convert the kinetic energy of the moving air to rotary motion of a shaft, that is, mechanical energy. The technologies for harnessing this energy have, over the years been tried in the Northern parts of the country, mainly for water pumping from open wells in many secondary schools of old Sokoto state and Kano states as well as Katsina, Bauchi and Plateau state.

Even though there is a reasonable level of use of renewable in the country, a significantly higher level could be attained. Nigeria surely needs technical assistance from pro-active countries, especially from the industrializing developing nations.

\subsubsection{Solar}

Solar energy or power is the utilization of sunlight for the generation of electricity. Solar energy is the most abundance of renewable resources in Nigeria due to the visible abundance of sunlight [79]. Nigeria is located in the equatorial region with direct sun rays and high temperature, hence the potential solar energy generation is high. According to [80], solar radiation in Nigeria can generate approximately $3.8 \times 10^{23} \mathrm{~kW}$, 
an equivalent of 1,082million ton of oil (Mtoe) worth of energy in a day. This is about 4,000 times the crude oil production and 13,000 times the gas production per day as of 2009. Fig 2.5 shows the map of the daily averages of global solar radiation in Nigeria. Furthermore, to generate the same amount of solar energy which is equal to the country's conventional energy reserves, only about $3.7 \%$ of Nigeria's land area is needed.

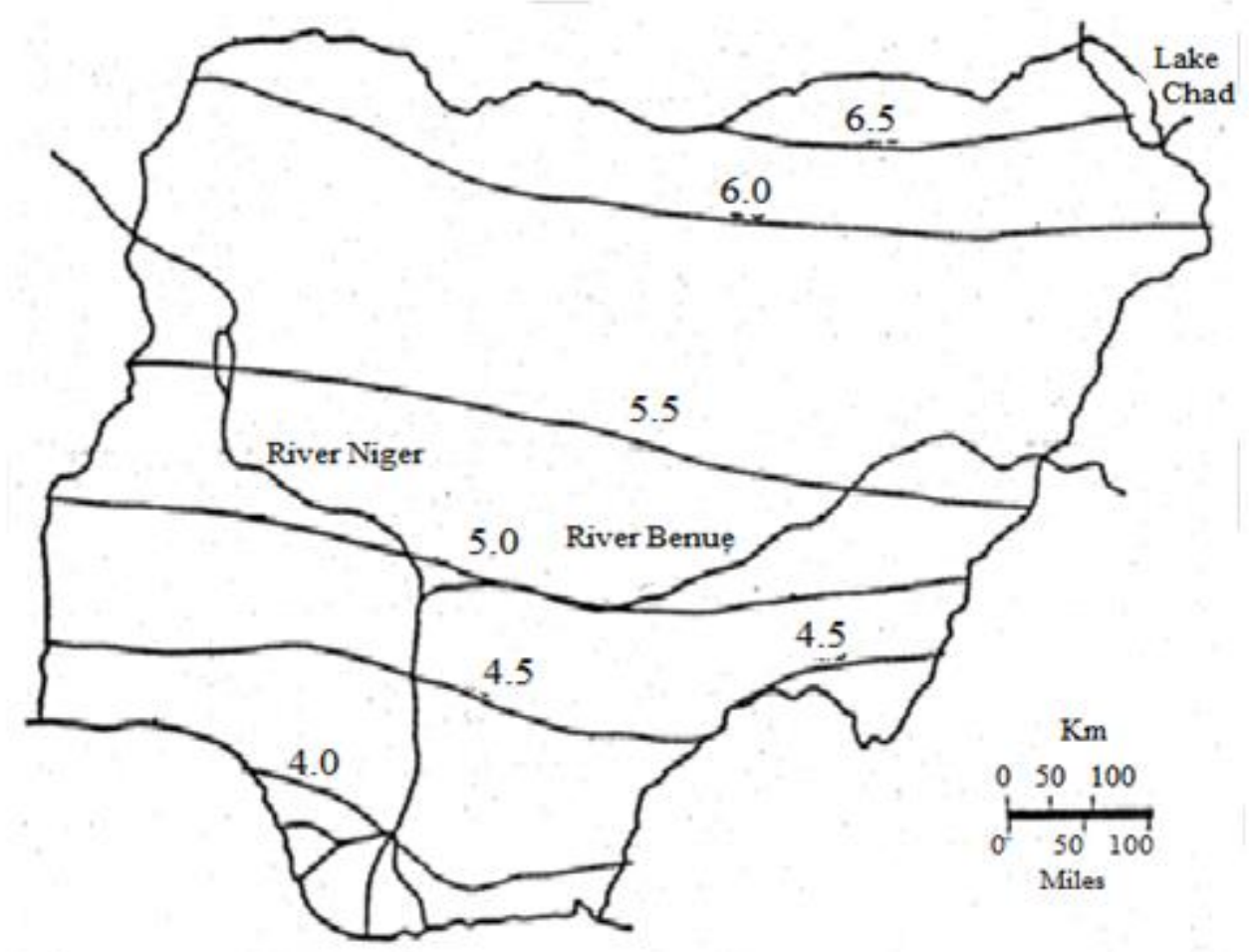

Fig 2.5 The daily average of global solar radiation in Nigeria [81]

Also [80] noted that, though Nigeria has sufficient solar radiation to generate energy that can meet its local demand; there is high variation in solar radiation across the country with the North having higher solar radiation than other parts of the country. The variation in the total solar radiation ranges from about $3.5 \mathrm{kWh} / \mathrm{m}^{2} /$ day in the coastal region to $7.0 \mathrm{kWh} / \mathrm{m}^{2} /$ day in the far north [82]. Based on these, an average of about $1,770 \mathrm{TW} / \mathrm{h}$ of solar energy falls on the entire land area and this is about 120,000 times the total electricity generated in the country [83].

With average solar radiation of $5.5 \mathrm{kWh} / \mathrm{m}^{2} /$ day in Nigeria and the general productive level of commercial solar electric generators, [83] speculates that if solar collectors or modules occupy only $1 \%$ of Nigeria's land area of $923,773 \mathrm{~km} 2$, approximately $1.850 \times 10^{3} \mathrm{GWh}$ of solar electricity can be generated per year. The 
generated solar electricity can be used through off-grid solutions to provide power especially to the rural areas that are not connected to the national grid. This can be done through low and medium power applications such as vaccine refrigeration, rural clinic and school power supply, village electrification. Solar energy can also be used as a primary energy resource to facilitate other renewable energy sources like hydro, wind, biomass, etc. In summary, the solar energy potential in Nigeria is endless and it's not fully harnessed.

\subsubsection{Biomass}

Biomass resources available in the country include fuelwood, agricultural waste and crop residue, sawdust and wood shavings, animal dung/ poultry droppings, industrial effluents/ municipal solid waste [84]. Fig 2.6 shows the estimated biomass resources in Nigeria.

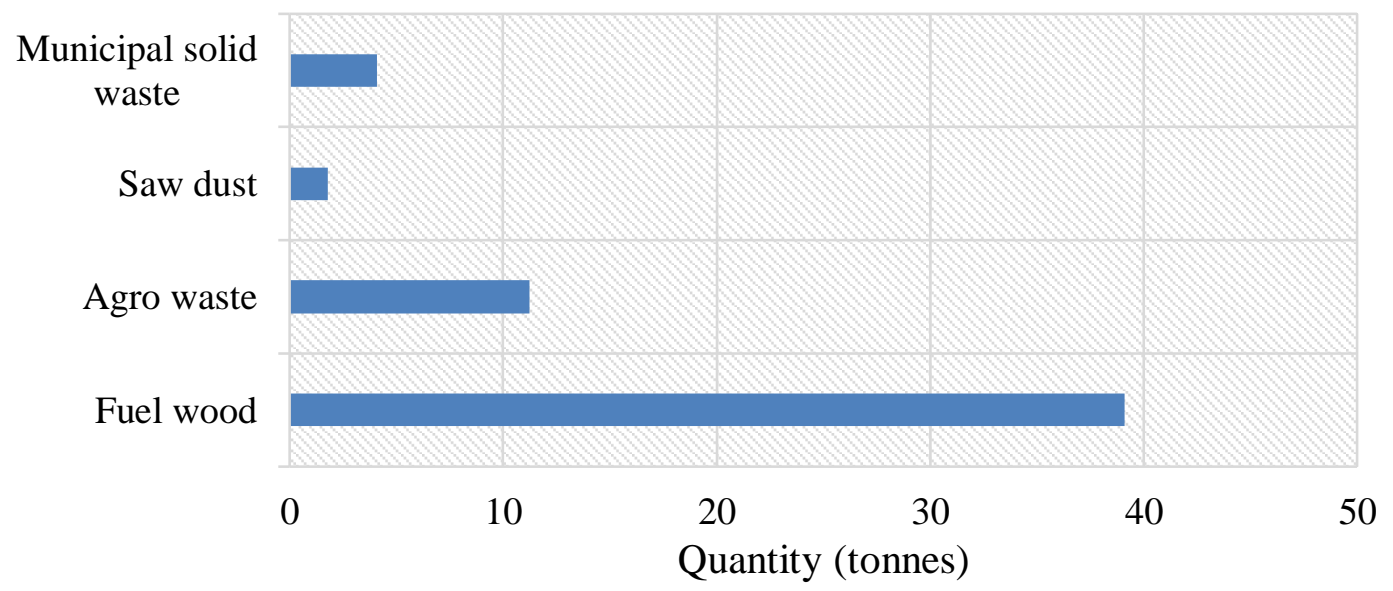

Fig 2.6 Biomass resources and the estimated quantities in Nigeria [84].

\subsubsection{Policy on renewables energy generation}

The Nigerian National Energy policy came into effect in April 2003. It recognises the use of renewable energy sources, such as hydro, solar, wind, biomass among other renewable energy sources. The policy recognizes the need for the nation to integrate renewable generation into the country's energy mix [74]. Apart from the deregulation of the power sector, in furtherance of the ongoing power sector reform, the Federal government is encouraging the development of renewable generation to overcome the current challenge from the conventional energy source. 
To encourage investments in the renewables energy, the Renewables Energy Research and Development Division of NERC developed the Renewables Energy Feed-in-Tariffs (REFiTS) that were included in the Multi-Year Tariff Order (MYTO) II issued in June 2012 [74]. In addition to the very attractive REFiTS, the government set a $10 \%$ target for renewables energy usage in the country until the year $2017,20 \%$ renewable energy usage has been set for the year 2020 and 30\% target for 2030. In addition, there is a five-year tax-free period for renewables investments.

Government involvement in the Nigerian renewable energy market has been limited to making policies intended to encourage renewable energy development. The current Minister of Power, Babatunde Fashola, in 2016, released a Road map for steady, incremental and uninterrupted power supply, which buttressed the government readiness to participate in renewable energy development and to increase generation capacity in the country by the use of renewable energy sources [85]. Also, in 2016 the National Energy Efficiency Action Plan, which sets out the strategy for achieving Nigeria's electricity vision of attaining 30,000MW of electric power by the year 2030 with at least 30 per cent renewable energy in the electricity mix. If faithfully implemented by the government, relevant agencies and stakeholders, the renewable energy market in Nigeria will experience unprecedented growth [85].

\subsection{FREQUENCY REGULATION}

The electric power system must maintain a balance between generation and load, and also adjust generation (or load) to manage power flows through individual transmission facilities [86]. A mismatch between power generation and usage causes the grid frequency to change. If demand is higher than supply, the frequency will fall, leading to brownouts and blackouts. If utilities generate more power than consumers are using, the frequency goes up, potentially damaging the grid or the electric devices plugged into it [87].

Therefore, for the satisfactory operation of a power system, the frequency should remain nearly constant. In an interconnected power system with two or more independently controlled areas, in addition to control of frequency, the generation within each area has to be controlled so as to maintain scheduled power interchanged. The control of generation and frequency is commonly referred to as load-frequency control (LFC) [88]. Significant frequency deviations can cause under/over frequency 
relaying to disconnect some loads and generations. Under unfavourable conditions, this may result in cascading failure and system collapse [88].

The electric power industry typically considers frequency regulation to consist of two subcategories: primary (on the time scale of a few seconds and below), and secondary (on time scales ranging from a few seconds to several minutes), illustrated in Fig 2.7 [89]. The network frequency is maintained in the following ways.

\subsubsection{Primary frequency response}

Primary frequency response consists of the inertia response and mechanical governor control of rotating electric generators [89]. Inertia response is the immediate response to a power disturbance that causes a frequency change, such as a large loss of load or the loss of a large generator [89]. Inertia response is important because it reduces the rate of change of frequency after a disturbance, which can lead to avoidance of underfrequency load shedding or worse issues, including blackouts. Conventional synchronous generators provide inertia response naturally from stored energy in the rotating mass of their turbines. Because inertia response is nearly immediate (occurring on a sub-second time scale) it is sometimes considered a category separate from the primary response. This distinction is less relevant in relation to inverter-based frequency response because inverter control responds much faster than mechanical governors [88]. Primary frequency response follows the inertia response. Fig 2.7 shows the difference between inertia, primary and secondary control following a frequency disturbance. 


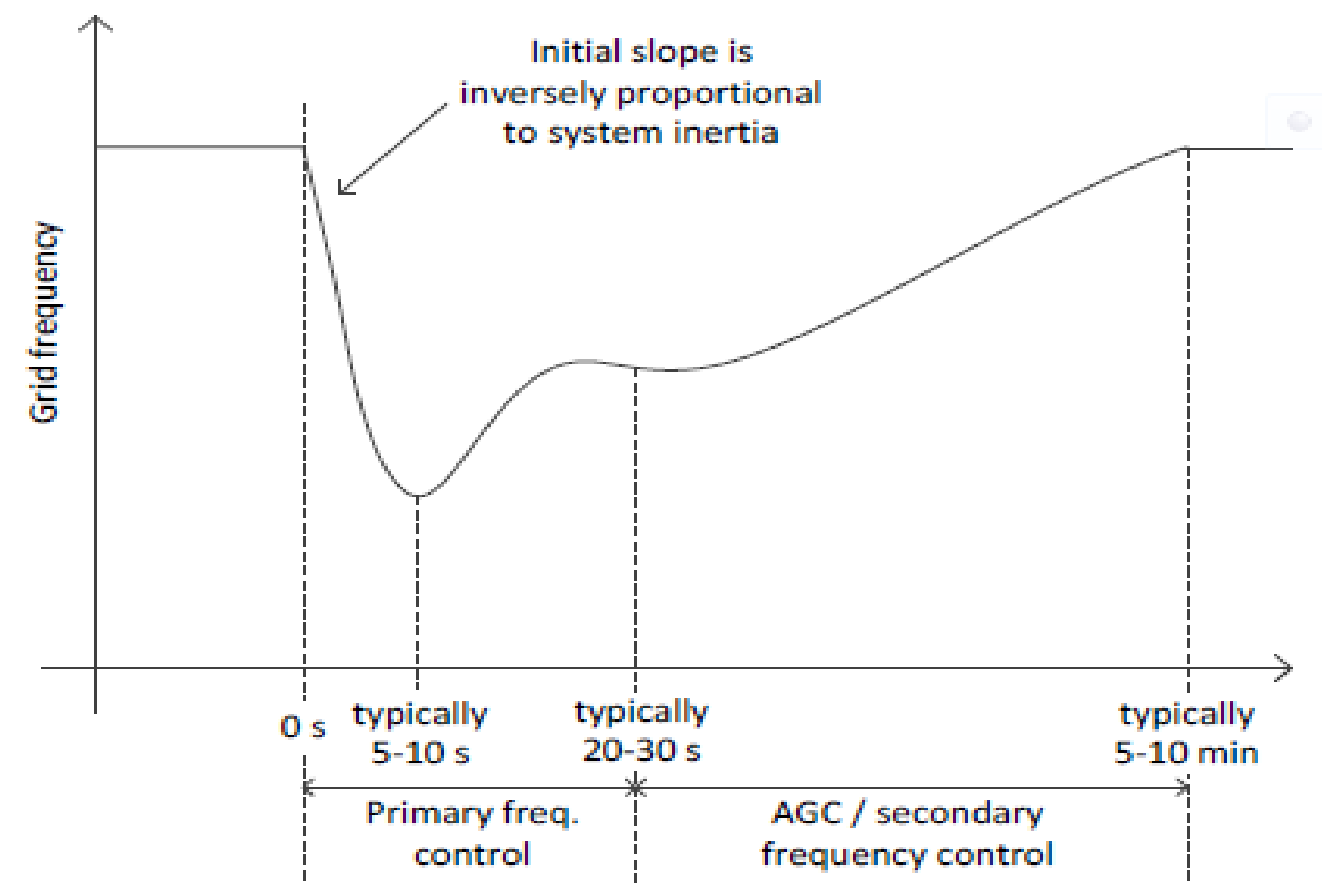

Fig 2.7 Frequency control following a frequency disturbance [89].

It is the action by turbine governor controls to change the output to balance generation and load and ensure system frequency returns to a stable level following a disturbance. If the frequency deviates too far from its nominal set point (which, in Nigeria, is $50 \mathrm{~Hz} \pm 0.5 \%$ ), the reliability of the grid is threatened, under-frequency load shedding relays can trigger an involuntary load tripping, and equipment can be harmed.

\subsubsection{Secondary frequency response}

Automatic generation control is used to help continuously balance the system, maintain a constant frequency and eliminate area control error. Secondary frequency response is controlled centrally; commands are sent to various generators via an automatic generation control (AGC) signal [89]. The generators adjust their real power set points based on the AGC signal, thereby bringing the grid frequency back towards its nominal value. Conventional frequency regulation from rotating machines ramps slowly, responding to AGC signals on a time scale of several minutes [90].

Generators that provide regulation reserve increase or decrease output to meet the constantly changing load, thereby maintaining a balance between the load and generation on the system and acceptable frequency levels. They do so by responding to automatic generation control signals from a system operator every four to six seconds to determine how much to increase or decrease output. 
This section reviews the following work reported in the literature on frequency control in the Nigerian power system. In [91], an adaptive neural network based load frequency control design of Nigeria hydrothermal system in which load disturbance with great similarities are represented by one load disturbance using an unsupervised neural network. A variable technique of managing load frequency control of the Nigerian power system after deregulation was described in [92]. The methods incorporate factors which represent a bilateral contract between Gencos and the Discos in a state space formulation into the traditional load frequency control schemes. In [93], a reviewed of system collapse incidences comprising the series of system collapse experienced by the Nigeria power system since 1987 to 2014 were presented and analyzed to view the frequency of the occurrence of the collapse. Also, suggestions were given on the ways to reduce the incidence of system collapse on the power system.

In [94], the estimation of the Nigerian power system electromechanical modes using frequency disturbance recorder measurement was discussed. Two previous papers [95], [96] reported on FDR data analysis from disturbance events and proposed a university-based frequency monitoring network for the Nigerian power system. It presented the initial results of the joint work between Rensselaer Polytechnic Institute (RPI) and Abubakar Tafawa Balewa University (ATBU) to study the frequency dynamics of rapidly growing power systems. The implementation of the FDR at ATBU has provided background information on possible future problems of GPS signal drop and data retrieval.

None of these previous work examine the impact of PV on systems frequency regulation in the Nigeria power systems. This research work is an initial effort on frequency regulation with PV penetration in the Nigeria power system. In the following section, frequency regulation in a two-area system is considered, which the focus of this study.

\subsubsection{Interconnected power system}

Fig 2.8 is an equivalent network for two area power system showing two equivalent generating units interconnected by a lossless tie line with reactance $X_{T}$ [97]. Each area is represented by a voltage source behind an equivalent reactance. Equation (2.1) is the real power transfer over the tie line during normal operation.

$P_{12}=\frac{\left|V_{1}\right|\left|V_{2}\right|}{X_{12}} \sin \delta_{12}$ 
Where $X_{12}=X_{1}+X_{T}+X_{2}$, and $\delta_{12}=\delta_{1}-\delta_{2}$

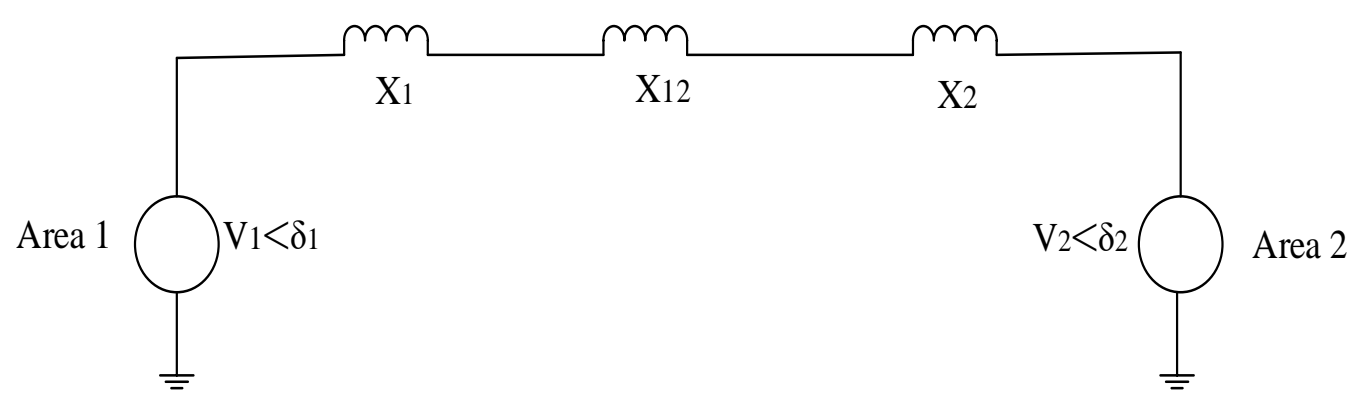

Fig 2.8 Equivalent network for two-area power system [97].

Equation (2.1) can be linearized for a small deviation in the tie-line flow $\Delta P_{12}$ from the nominal value, i.e.

$$
\begin{aligned}
& \Delta P_{12}=\frac{d P_{12}}{d \delta_{12}} \mid \delta_{12_{0}} \Delta \delta_{12} \\
& \Delta P_{12}=P_{S} \Delta \delta_{12}
\end{aligned}
$$

Where $P_{S}$ is the slope of the power angle curve at the initial operating angle and $\delta_{12_{0}=} \delta_{1_{0}-} \delta_{2_{0}} \quad($ Synchronizing power coefficient $)$

Thus we have

$$
P_{S}=\frac{d P_{12}}{d \delta_{12}} \mid \delta_{12_{0}}=\frac{\left|V_{1}\right|\left|V_{2}\right|}{X_{12}} \cos \Delta \delta_{12_{0}}
$$

The tie-line power deviation then takes on the form

$$
\Delta P_{12}=P_{s}\left(\Delta \delta_{1}-\Delta \delta_{2}\right)
$$

The tie-line power flow appears as the load increase in one area and a load decrease in the other area, depending on the direction of the power flow. If $\Delta \delta_{1}>\Delta \delta_{2}$, the power flow from area1 to area 2. A block diagram representation for two-area power system with LFC containing only the primary loop is shown in Fig 2.9. 


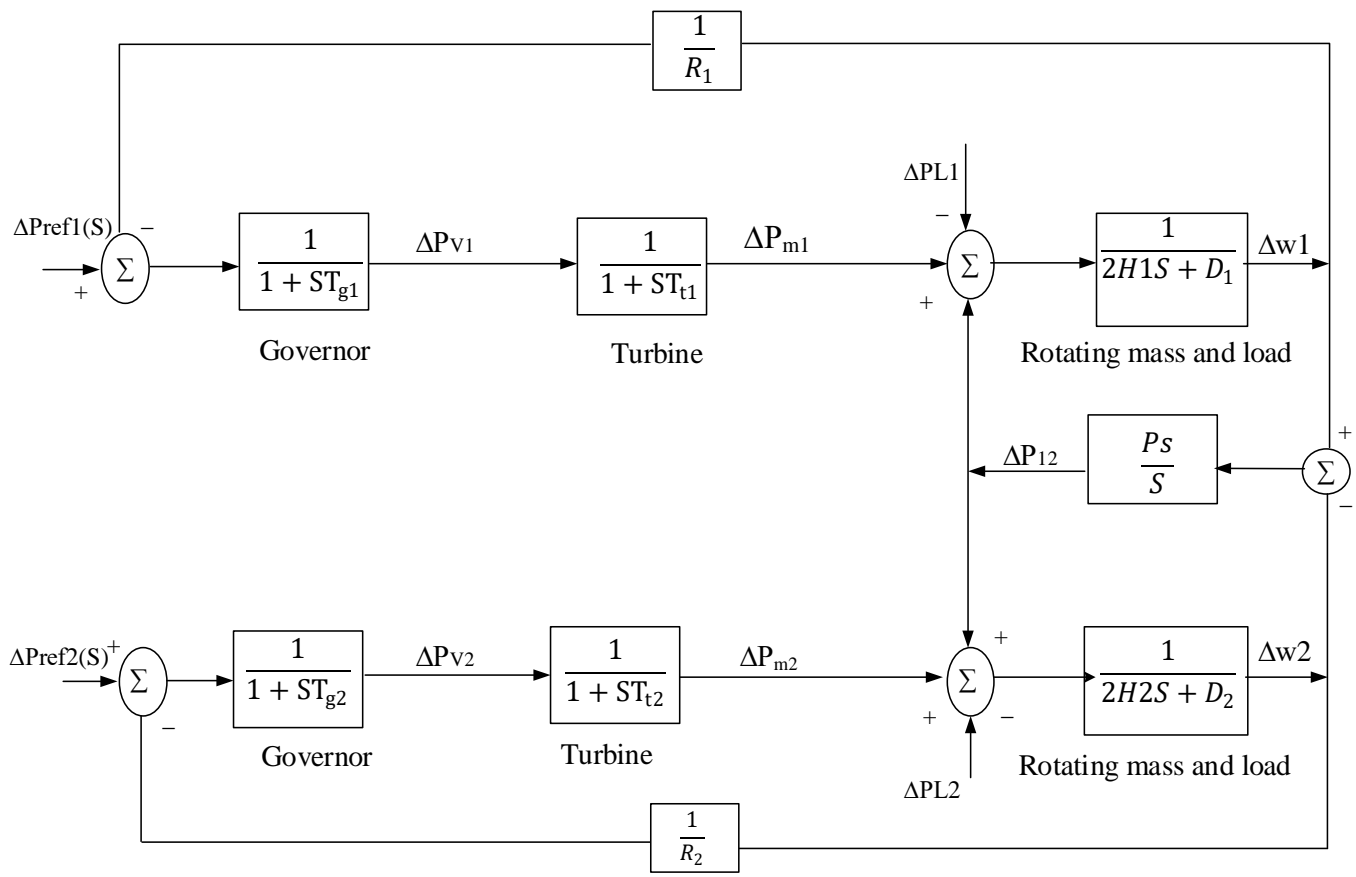

Fig 2.9 Two-area power system with only primary LFC loop [97]

Let consider a load change $\Delta P_{L 1}$ in area $1 . \Delta_{w}$ is the steady state frequency deviation. $R_{1}$ and $R_{2}$ are the governor speed regulation. In the steady state both areas will have the same steady-state frequency deviation, i.e.

$\Delta_{w}=\Delta_{w 1}=\Delta_{w 2}$

and

$\Delta P_{m 1}-\Delta P_{12}-\Delta P_{L 1}=\Delta w D_{1}$

$\Delta P_{m 2}+\Delta P_{12}=\Delta w D_{2}$

The change in mechanical power is determined by the governor speed characteristics, given by

$\Delta P_{m 1}=\frac{-\Delta w}{R_{1}}$

$\Delta P_{m 2}=\frac{-\Delta w}{R_{2}}$

Substitute from (7) into (8), and solving for $\Delta w$, we have.

$$
\begin{aligned}
\Delta w & =\frac{-\Delta P_{L 1}}{\left(\frac{1}{R_{1}}+D_{1}\right)+\left(\frac{1}{R_{2}}+D_{2}\right)} \\
\Delta w & =\frac{-\Delta P_{L 1}}{B_{1}+B_{2}}
\end{aligned}
$$


where

$B_{1}=\frac{1}{R_{1}}+D_{1}$

$B_{2}=\frac{1}{R_{2}}+D_{2}$

$B_{1}$ and $B_{2}$ are the frequency bias factors. The change in the tie line power is

$\Delta P_{12}=-\frac{\left(\frac{1}{R_{2}}+D_{2}\right) \Delta P_{L 1}}{\left(\frac{1}{R_{1}}+D_{1}\right)+\left(\frac{1}{R_{2}}+D_{2}\right)}$

$\Delta P_{12}=\frac{B_{2}}{B_{1}+B_{2}}\left(-\Delta P_{L 1}\right)$

For instance, the two-area system in Fig 2.9 is equipped with only the primary control loop, a change of power in area1, will be met by the increase in generation in both areas associated with a change in the tie-line power, and a reduction in frequency.

\subsubsection{Frequency regulation and solar PV}

The generation of electrical power from renewable energy sources is developing rapidly due to growing electrical demand and the rising concerns with environmental issues for the reduction of greenhouse gases and carbon dioxide $\left(\mathrm{CO}_{2}\right)$. Solar PV was the worlds leading source of additional power generating capacity in 2016 and is considered a cost-competitive source of a new generation in many emerging markets across the world [87]. The annual market increased by nearly $50 \%$ to at least $75 \mathrm{GWdc}$ -equivalent to more than 31,000 solar panels installed every hour raising the global total to at least $303 \mathrm{GWdc}$ [87].

The Nigerian government targeted to supply $30 \%$ of the electricity demand from renewable sources by 2030. The federal government of Nigeria and the ministry of power are calling for significant increases in renewable generation within the next few years [18]. PV is likely to be the generation technology of choice in answering this call because of the low cost and relative maturity of the technology.

However, as a result of varying solar conditions, solar PV facilities generate varying amounts of electricity [98]. From a grid operations perspective, other generation resources must offset these changes in output [98]. One important feature of PV generation systems is that, unlike wind and conventional generators, they do not 
involve any rotating mechanical parts, fully relying on the power electronic inverter/converter interface to be interconnected to the grid. To date, it has not been necessary for small PV generators to provide frequency regulation services to the power system [98]. The current practice is that they are disconnected from the power system in the event of network disturbances. In the future, with increasing penetration of PV generation, their impact on the overall control of the power system will become significant.

The Nigeria Power System of the future incorporating solar PV will look very different from what it is today. The renewable energy revolution has already commenced in many countries, as evidenced by the growth of renewable energy sources in response to the climate change challenge. Renewable energy currently provides more than $14 \%$ of the world energy supply [5].

It is important that the solar PV systems must meet technical requirements with respect to voltage, frequency, and have a reasonable ability to withstand abnormal system operating conditions.

\subsection{ELECTRICAL ENERGY STORAGE}

Electrical Energy storage systems (ESS) can be used to balance electrical energy supply and demand. The process involves transforming and storing electrical energy from an available source into another form of energy, which can be converted back into electrical energy when needed. The forms of energy storage conversion can be mechanical, chemical, magnetic, or thermal [99]. Whenever the generation exceeds the demand, storage stores energy and produces it when demand exceeds supply. Storage is beneficial when there is low demand, low generation cost, or when the available energy sources are intermittent. Also, the stored energy can be consumed at times of peak demand, high generation cost, or when no alternative generation is available [100], [101].

The growing energy demand has led to increases in energy prices, and traditional centralised energy generation methods are less able to cope with this increase. This issue is further worsened by market deregulation, power quality problems and pressures to reduce carbon dioxide emissions [100]. Renewable energy sources are considered as a viable replacement for traditional centralised generation methods [101]; however, there are challenges with energy supply coming from renewables, due 
to their intermittent nature [102]. Renewable sources could be sufficient during offpeak demand hour but peak demand period might exceed renewable energy production [100]. Also, there are fluctuations in renewable energy supply, as their availability is always subject to weather conditions. On the other hand, the energy demand differs from time to time, which does not necessarily match the intermittences of re, thus creating reliability problems [101]. Energy storage systems are essential to aggregate traditional centralised generating plants in order to meet an excessive demand, and support intermittent renewable generation sources for their integration into the electrical network [103].

According to the [104], the world's energy storage technology up through 2016 is overwhelmingly comprised of pumped hydro storage, as shown in Fig 2.10. Molten salt thermal energy storage comes in seconds in terms of cumulative global capacity, with projects are mainly centred in Spain, Italy, the United States, South Africa, Morocco, and Chile. Electrochemical energy storage capacity comes in third, with a total capacity of $1769.9 \mathrm{MW}$. The existing storage technologies are discussed next.

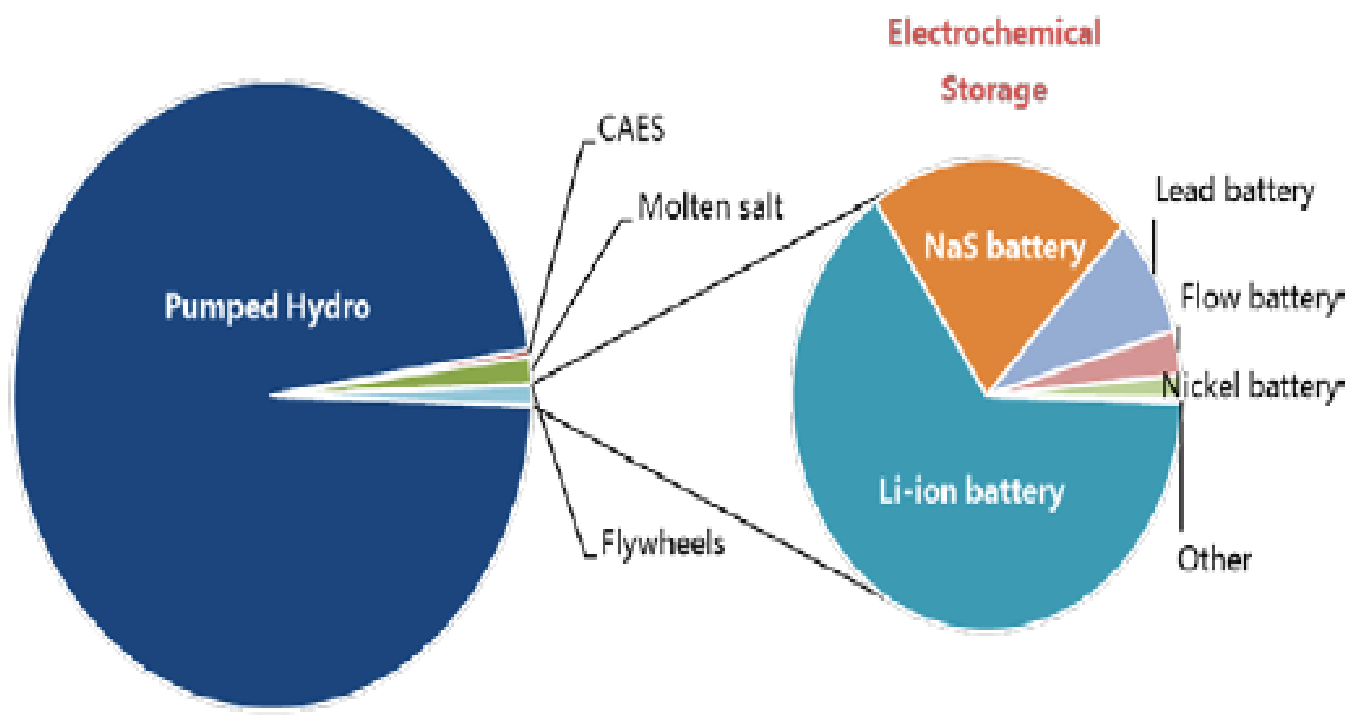

Fig 2.10 Global energy storage capacity by technology type [104].

Source: CNESA White Paper 2017 


\subsubsection{Li-ion battery}

Li-ion battery chemistries represent an array of systems with lithium-based electrolytes. They are used from small electronics, electric vehicles, and even in multimegawatt grid-scale energy storage projects. The battery's energy density and voltage vary across electrode materials. The most common cathodes include cobalt $\mathrm{LiCoO}_{2}$, however, cobalt is expensive to source and has low thermal stability. Manganese-based $\mathrm{LiMn}_{2} \mathrm{O}_{4}$ is attractive due to its low cost and durability, but manganese is known to dissolve into the electrolyte decreasing performance.

Li-ion batteries are sensitive to temperature and as such battery must include appropriate heating and ventilation systems. Lithium is also highly reactive and shortcircuiting can result in fires or explosions.

\subsubsection{Flow battery}

A flow battery differs from traditional batteries in that the energy is not stored on the electrodes, but rather in a liquid electrolyte solution [105]. The electrolyte is stored in external tanks and run through a flow cell where the chemical energy is converted to electricity. A flow battery's capacity thus is dependent on the electrolyte volume and surface area of the electrodes. Flow batteries have dual properties able to behave like a rechargeable battery, and as a fuel cell by replacing the "spent" discharged liquid electrolyte solution with a previously "charged" electrolyte.

The flow battery family has various subtypes such as redox flow batteries, hybrid flow batteries and membraneless batteries. One of the most expensive and fragile components of a flow battery is the membrane since many membrane materials corrode easily when exposed to the battery reactants. The membraneless flow battery design uses laminar flow allowing for the electrodes to slide past each other, unmixed, with no need for a membrane. This eliminates this need for membranes and can provide a high-energy density, and a more cost-effective solution when compared to other flow battery chemistries[106].

In general, flow batteries are long-lasting batteries that operate at much higher power densities than Li-ion battery systems, making them an ideal solution for largescale energy storage[107]. Since flow batteries require storage of liquid electrolytes, current technology limitations translate to a lower energy density compared to Li-ion 
making, today's flow batteries poorly suited for mobile applications, such as in electric vehicles.

\subsubsection{Na-S battery}

Sodium sulphur (Na-S) battery is a high-temprature battery. It uses a molten sulphur positive electrode and molten sodium as the negative electrode [104]. With molten components, the system operates at extremely high temperatures between $300-350^{\circ} \mathrm{C}$, usually requiring an external heating device to reach the necessary operating temperatures [104]. Although sodium reactant, can behave explosively, modern cells are generally reliable. They are well suited to the integration of renewable energy generation sources and are capable of ramping their power output from $0 \%$ to $100 \%$ of maximum power in less than 10s. However, a fire was reported in 2012 at a sodiumsulphur installation in Japan [108]. Fig 2.11 shows the structure of sodium-sulphur battery technology.

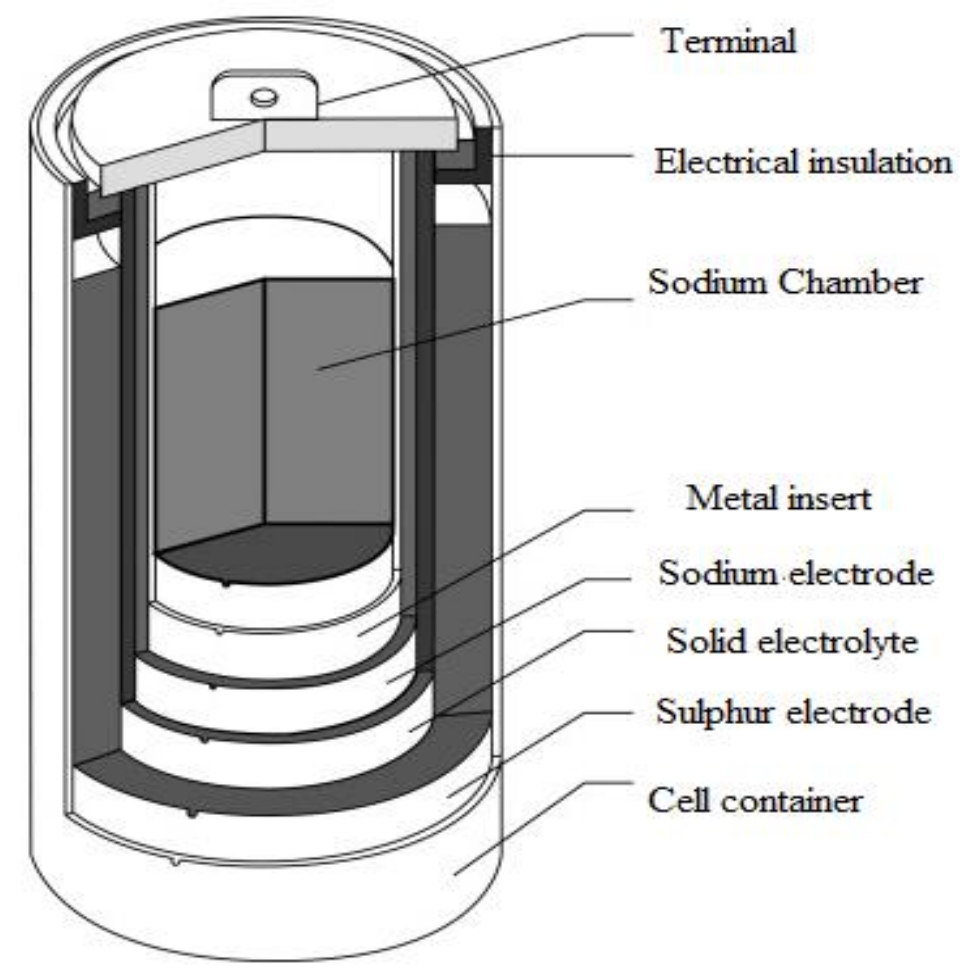

Fig 2.11 Sodium-sulphur battery

Source: NASA John Glenn Research Centre

Na-S batteries are made in cylindrical and block-shaped configurations. They are well-suited for high-power, long discharge applications in providing power quality 
control for renewable energy projects along with grid services. Grid-scale Na-S batteries are unique, in that, unlike other newly developed battery technologies, they have been in commercial operations for a relatively long time, with around 10-years of operating experience on a grid-level scale.

\subsubsection{Pumped hydro storage}

Currently, the most mature form of storage technology, pumped hydro storage accounts for around 95\% of global energy storage capacity [104]. Most commonly, water held in two reservoirs at different heights is pumped up against gravity, stored, and then released to run through a turbine generating electricity. More traditional openloop systems connect with a natural water formation that refills either the upper or lower reservoir. Pumped hydro storage is at currently the most utilised method of large-scale grid energy storage. It comprises 3\% of global installed power energy storage. They are really only applicable for large-scale applications due to their low energy density. The main drawbacks include geographic limitations along with impacts on aquatic life and stream flows [104]. To overcome these challenges, many recent design concepts and demonstration projects favour closed-loop schemes separate from naturally flowing water, including underground systems with a smaller footprint and environmental concerns.

Current pumped hydro projects can serve many functions for the electricity grid to provide energy-balancing, reserve power, and stability functions. Modified pumped hydro set-ups with variable-speed turbines are better suited for renewable generation and providing frequency regulation services. Most existing projects with variable speed turbines currently exist in Japan and Europe.

Pumped hydro technology has been in use since the 1920s, but improvements continue to be made to turbine technology and project engineering.

\subsubsection{Lead-acid battery}

The lead-acid battery, the oldest type of rechargeable battery, is a low initial cost energy storage solution [107]. It involves reversible electrochemistry between lead oxide in sulphuric acid [111]. Lead-acid battery technology is more than 100 years old, and in this context, it is "proven" technology. However, the energy storage capability of the lead-acid battery varies with battery design and use, and in all cases, the practical discharge capacity is best only about $60 \%-70 \%$ of the theoretical capacity. 
According to [104], lead-based battery technology makes up 6\% of operational global energy storage. While lead-based batteries provide a low initial cost investment, their durability remains inferior to other battery such as Li-ion, and with the decreasing costs of other battery, long-term high-power applications favour other battery forms. Safety and environmental concerns have spurred research into how to safely recycle lead components and ensure they do not leak into the environment.

\subsubsection{Compressed air energy storage}

Compressed air energy storage (CAES) uses the expansion of compressed air to drive a turbine and produce electricity [104]. Relatively few projects are currently operating in the world, but reported capital and operating costs can be competitive to pumped hydro. Due to the low storage density, a major consideration in CAES systems is how to store the compressed air [104]. Underground CAES has been to date mostly applied in a constant volume.

Table 2.6 Energy Storage technologies

\begin{tabular}{|l|l|l|}
\hline & \multicolumn{1}{|c|}{ Technologies } & \multicolumn{1}{c|}{ Characteristics } \\
\hline Physical storage & $\begin{array}{l}\text { Pumped Hydro } \\
\text { Compressed Air (supercritical } \\
\text { CAES } \\
\text { Flywheel }\end{array}$ & $\begin{array}{l}\text { Uses water/air as storage } \\
\text { medium } \\
\text { No chemical change } \\
\text { Mechanical to electric } \\
\text { energy }\end{array}$ \\
\hline Chemical Storage & $\begin{array}{l}\text { Lead-acid Battery } \\
\text { Li-ion Battery } \\
\text { Flow Battery (Vanadium Zn-Br) } \\
\text { Na-S Battery }\end{array}$ & $\begin{array}{l}\text { Battery charges/ } \\
\text { discharges with chemical } \\
\text { change/valence change } \\
\text { medium }\end{array}$ \\
\hline $\begin{array}{l}\text { Electromagnetic } \\
\text { Storage }\end{array}$ & Super-capacitor & $\begin{array}{l}\text { Fast response, can release } \\
\text { large amounts of electric } \\
\text { power in a short time, } \\
\text { high number of cycles }\end{array}$ \\
\hline Other Storage & $\begin{array}{l}\text { Fuel Cell } \\
\text { Metal-air Battery }\end{array}$ & $\begin{array}{l}\text { Does not possess } \\
\text { charging characteristics }\end{array}$ \\
\hline
\end{tabular}

Source: CNESA 
Underground salt caverns, introducing, of course, geographic limitations. Emptied natural gas wells and abandoned mines are also other options. Some projects have also used the above-ground piping system to store compressed air, presenting an increase in cost but offering greater site flexibility. Table 2.6 shows the energy storage technologies and characteristics. Air can also be stored under constant pressure with a variable volume vessel, for example, the Canadian CAES company, Hydrostor, achieves this through constructing an underwater cavern with a changing volume of water to keep the air at constant pressure. Isobaric systems can achieve even greater efficiencies as pumping equipment works optimally under constant pressure.

\subsubsection{Flywheel storage}

The flywheel energy storage system is a mechanical energy storage technology that absorbs energy from the grid and converts it into a spinning disc. The disc is connected to a central shaft and rotates on two magnetic bearings that are placed in a vacuum to reduce windage losses occurring due to air resistance against moving parts. The flywheel can be sped up to take in electricity from the grid or slowed down to rapidly utilize the energy. Fig 2.12 is a schematic of a flywheel storage system showing the components.

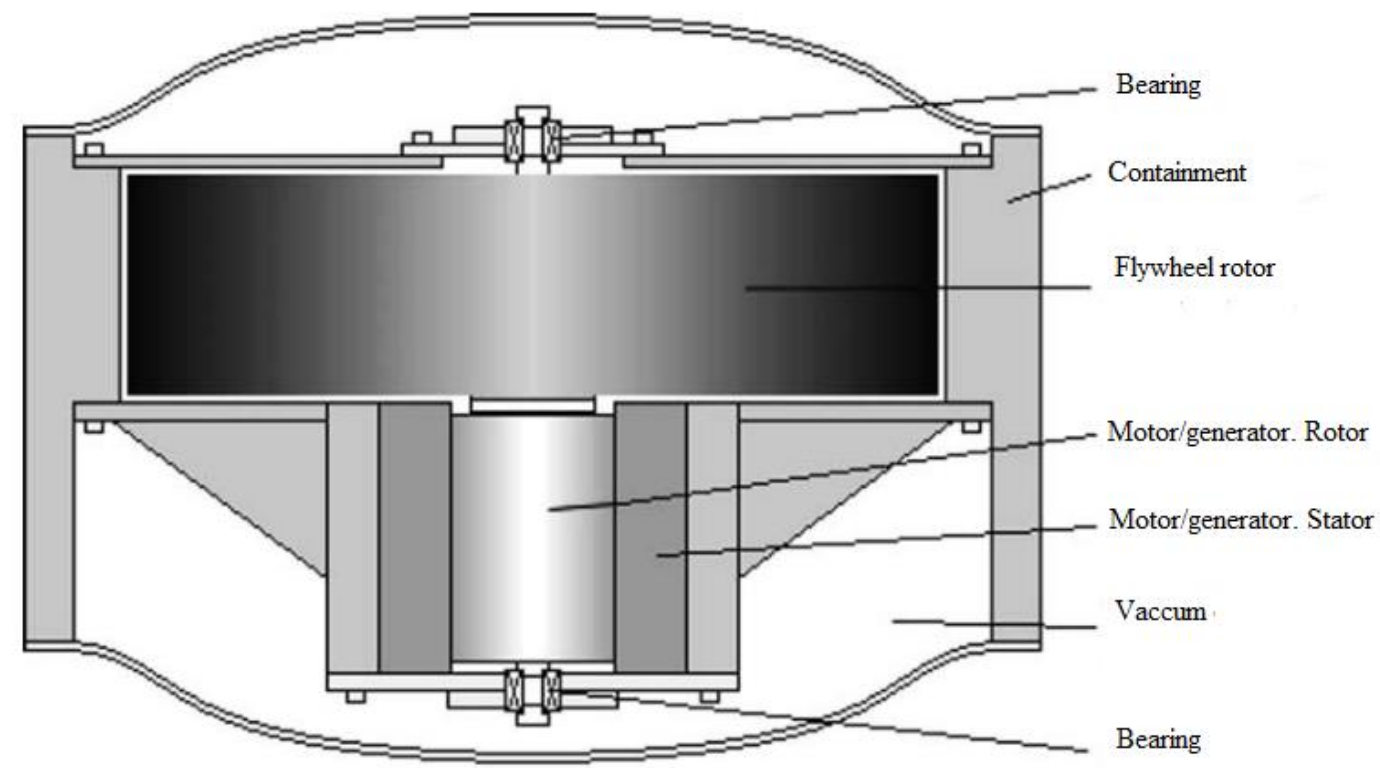

Fig 2.12 A schematic of a flywheel storage system 
The faster a flywheel rotates the more energy it can store. The material used for the rotating mass has a great effect on the cost, weight, and performance often either steel or carbon composite, carbon composite outperforming steel being lighter and stronger.

The amount of kinetic energy E stored in a spinning object is a function of its mass and its velocity as the following equation:

$E=\frac{1}{2} I \omega^{2}$

Where $I$ the moment of inertia of the rotating is mass $\left(\mathrm{kg} \cdot \mathrm{m}^{2}\right)$ and $\omega$ is the rotational velocity $(\mathrm{rad} / \mathrm{sec})$. In the case of a flywheel with a solid disc, the stored kinetic energy can be expressed by

$$
E=\frac{1}{4} M r^{2} \omega^{2} \approx \frac{1}{4} M v^{2}
$$

Where $M$ is the mass of the rotating disc, $V$ is the linear velocity of the outer rim of the cylinder, and $r$ is the radius of the disc. Equation (6) shows that increasing the rim speed is more effective than increasing the mass of the disc for increasing the energy capacity of a flywheel system. However, a flywheel system is limited by the strength of the disc material to withstand the stresses caused by rotation [109]. Although the power density of the flywheel is very high, its energy density is relatively low. Thus, in grid applications, they are only suitable for frequency regulation and short-time power quality services. Moreover, the flywheel energy storage can be utilized in a hybrid configuration with a high-energy storage device such as a battery or fuel cell. Examples include aircraft powertrains and shipboard power systems, where the system requires a very high-power for a short period in order of a few seconds and even milliseconds [110].

Other advantages of flywheels compared to battery systems include fast response speed and durability [105]. Flywheels can charge/discharge on a scale of seconds and most systems can last in 170,000 full depth of discharge cycles. Several flywheel units can be integrated together to provide a longer discharge duration [106]. In particular, they are well-suited to high power, low energy uses such as an intermediate resource while slower generations ramp up, ensuring power reliability, and frequency response. Their use is also being explored in regenerative brake systems in vehicles. 


\subsection{FLYWHEEL STORAGE SYSTEM STATE OF ART}

There is a high demand for reliable, cost-effective and environmentally friendly energy storage systems to support different energy storage applications. With advances in materials technology, power electronics, and bearings the technology of flywheels for energy storage has significantly developed [103], [112]. Flywheels with the main attributes of high power, energy density and high energy efficiency compete with other storage technologies in energy storage applications [113]. With storage capabilities of up to $500 \mathrm{MJ}$ and power ranges from $\mathrm{kW}$ to $\mathrm{GW}$, they perform a variety of important energy storage applications in a power system [114]. The most common applications of flywheels in electrical energy storage are for uninterruptible power supplies (UPS), frequency control and power quality improvement [115]. For these applications, the electrochemical battery might be unsuitable [116]. This is not necessarily true for some UPS with highly reliable grids, so storage is seldom called upon. Particularly for power quality improvement, electrical disturbances are frequent but short, with the vast majority of them lasting for less than $5 \mathrm{~s}$. Such disturbances are effectively managed by flywheels. Supercapacitors have been tested for these types of applications; however, with more or less the same capital cost as flywheels [117], their operational lifetime is relatively low [118].

A number of reviews of flywheel storage systems have been presented by several papers in the literature. A comparison of energy storage technologies is made in [116], where a graphical and numerical review demonstrates the problems and improvements associated with FESS. A comparative analysis of energy storage technologies for high power applications is carried out in [119] and a survey of FESS for power system applications is provided in [120]. FESS is briefly reviewed in [121] and an overview of some previous projects is presented in [107]; however, such sources offer a scarcity of information. The control of high-speed FESS in space applications is discussed in [102]. In [122] there is a focus on the developments of motor-generator for FESS, where the common electrical machines used with flywheels, along with their control, is reported in [123]. A simulation and review of FESS for an isolated wind power system is presented in [114].

A lot of work reported in the literature to improve the performance of LFC. Prominent among them is the introduction of an energy storage system during the peak 
load period [124]. Also, in [125] the effect of 30MW battery on the frequency regulation in the Isreali isolated power system was studied. The study was carried out on a single area model representing the whole power system. In [126] the effect of the battery energy storage system on two areas reheat thermal system considering conventional tie-line bias control strategy is studied. In the following section, the author will discuss the existing storage technologies in details. This review uses the most recent literature in the research study.

\subsection{SUMMARY}

This chapter provided a brief literature review of technologies of smart grids, microgrids and localised energy systems in electricity distribution systems. It also reported a literature review on renewable energy technology in distribution systems. The concept and application of localised energy system in the UK were also reviewed in this chapter. The literature review presented in this chapter showed the shift from traditional centralised generation toward a low carbon emission and environmentally friendly distributed renewable technologies (LES, microgrids and smart grid). However, this move towards distributed renewable technologies is popular in UK, USA, Europe, and other developed nations but the developing nations and sub-Sahara Africa are yet to adopt these changes. The ability to connect renewable resources, storage, and distributed generation is becoming more regulated and cost-effective. While the penetration level remains low, the area is experiencing high growth. Several other concepts associated with a smart grid are in a nascent phase of deployment these include the integration of microgrids, demand response, and electric vehicles. Without a smart grid, high penetrations of variable renewable resources may become more difficult and expensive to manage due to the greater need to coordinate these resources with dispatchable generation and demand.

This chapter reviews the Nigerian energy systems and its power needs due to poor investment in power generation and also other technical challenges in the network. With the level of renewable potential in Nigeria implementing LES will not be a problem. The knowledge obtained in this chapter will help in the research studies in chapter three, four and five. 


\section{ChApter 3}

\section{A STUDY OF LOCALISED ENERGY SYSTEM IMPACTS IN THE UK}

\subsection{BACKGROUND}

This chapter provided a comprehensive study of LES impact using Neplan on low voltage UK generic distribution network. The aim of the study is to determine the effect and opportunities of LES penetration on the UK distribution network. Some of the technical challenges caused by LES connection to electric utilities were analysed and discussed in this chapter namely network voltage changes, network losses and overloading of network components (e.g. transformers and cables). Maintaining network operating conditions within acceptable limits is necessary to ensure adequate power quality for electricity customers.

Furthermore, a methodology for evaluating the allowable DG capacity that could be installed by individual customers within an LES was presented. The local distribution network area considered in this chapter is a low voltage part of the UK Generic Distribution Network (UKGDN) model described in [127] with local generators added

However, with significant penetration of LES, the power flow in the distribution network may become reversed [128]. This power flow reversal depends on the relative magnitudes of the real and reactive network loads compared to the generator outputs. This change in grid behaviour creates a new challenge for the Distribution Network Operator (DNO) in determining how to plan, design, and operate distribution systems that were not designed for the connection of local generation. Effective integration of LES in the distribution networks requires effective planning with the aim of reducing the adverse impact on the distribution systems. 


\subsubsection{Network voltage change}

In a traditional distribution system, the voltage profile is normally stable [128]. The flow of power is always from the higher to the lower voltage level. Due to the high impedance in the distribution network, the voltage drop is from the primary substation to the point of connection of the customers.

When DGs are connected to the distribution system, the voltage profiles and the power flow may change. This voltage variation may influence power quality in the network. It is the obligation of the DNO to supply its customers at a voltage within specified limits. These specified voltage values vary from country to country. In the UK the electricity supply limit is $+10 \%-6 \%$ of $230 \mathrm{~V}$ [129].

The voltage at each network node of a low voltage distribution network depends on the voltage at the substation, the current in the lines and the line properties. The difference between the lower voltage limit and the upper voltage limit is the available voltage band within which the node voltages may vary in a network. This requirement often determines the design of the distribution circuits.

For a lightly loaded distribution network, the approximate voltage rise $(\Delta \mathrm{V})$ due to the generator connection is given approximately by[129],[130].

$\Delta \mathrm{V}=\frac{P R+X Q}{V}$

Where: $\mathrm{V}=$ nominal voltage of the circuit,

$\mathrm{P}=$ active power output of the generator,

$\mathrm{Q}=$ reactive power output of the generator,

$\mathrm{R}=$ resistance of the circuit,

$\mathrm{X}=$ inductive reactance of the circuit.

\subsubsection{Network losses}

Electricity transported to the distribution network is lost within the resistance of the network components. The estimate of electrical losses on distribution network is calculated as the difference between power entering and exiting the network. Power losses across the distribution system is considered as the electrical loss. Power losses in the distribution networks are affected by the parameters of the lines [131]. Losses 
on the power system depend upon the square of the current flow in the line and line parameters. All system losses are unavoidable but can be minimised.

The Distribution losses are important from the DNO point of view since power losses are an economic concern and have to be minimised [132]. Power losses can be minimised by techniques like feeder reconfiguration, capacitor placement, DG placement, increasing the voltage of the distribution system and conductor grading.

\subsubsection{Transformer loading}

Transformers are normally rated in kVA or MVA. They have long thermal time constants and thus can be overloaded for short periods of time without causing overheating or significant damage [133]. Transformers are usually chosen to match the expected maximum demand and are generally operated at a significant proportion of their thermal limit because the no-load losses are significant and so the efficiency of a lightly loaded transformer is poor. Thus, in areas with high penetrations of LES, thermal limits of transformers can restrict further installation of LES.

Most transformers can allow reverse power flow, up to the normal forward rating, without a problem. However, there are some on-load-tap changers that have limited reverse-power capability. Furthermore, some automatic voltage regulators associated with on-load tap-changers can be affected by reverse power flow [134].

The output of the power lines losses is used in the calculation to determine if a backup generator is required to achieve an energy balanced local area, as shown in the following section.

\subsubsection{Maximum allowable DG capacity in the LES}

As the capacity of the installed DGs in the LES increased, some measurable problems (reverse power flow and voltage rise) on the system operation, power regulation and power quality start to arise. To solve these problems, many research papers have been published on how to reduce the adverse effects. An assessment of voltage profiles in residential neighbourhoods in the presence of PV systems is published in [135]. A study to assess the impact of fluctuating solar irradiance on the grid is provided in [136]. In this research, a deterministic analysis was performed. In order to assess a network's ability to accommodate LES technology, 
A deterministic steady-state analysis is performed in order to assess network limitations. The analysis is carried out by introducing LES to a test network for a given worst-case scenario. Depending on the particular type of technology under investigation, a worst-case scenario can be defined as a period of time whereby the demand on the network is at either its lowest or its highest level. The method investigates the effects of increasing LES penetration, as well as the effect of the location, on the network and is assessed in terms of the resulting network voltage levels and thermal loading of components. The method provides insight into the limitations of a given network's capability to accommodate LES without the need for active control on the demand side or upgrading of the network.

When assessing the limitations of a distribution system, it is normal practice to test models of the system for a worst-case scenario. For LV residential distribution networks, this typically implies that the network is examined under conditions of maximum load. However, this may not be the case in future networks where there is a large penetration of local micro-generation units. The maximum or minimum, system demand is usually determined from historical load data. The main concern from a distribution system operator's point of view is that a network operates in a safe and reliable manner under all loading conditions.

With an increase in LES on the network in future years, the level of electricity demand that will define a network's 'worst case scenario' will undoubtedly change significantly. This method assesses the potential impact on the distribution network due to the introduction of LES. This is achieved by incrementally adding LES units to the network for a given time period, i.e. maximum or minimum demand. In order to perform this analysis, a model of a section of LV distribution network was developed using power system analysis software (NEPLAN). Details of the model are given in Section 3.3. Steady-state analyses were performed using unbalanced load-flow calculations, with the changes in voltage and thermal loading levels at various parts of the network recorded. The load-flow solutions were calculated using the NewtonRaphson method employing 3-phase current injection equations [137].

\subsubsection{Charging of electric vehicles in the LES}

Using EV instead of conventional vehicle is a great way to reduce our dependence on fossil fuels. However, charging EVs at homes will increase the residential 
electricity demand. Consequently, this will lead to problems such as: overloading distribution transformers, overloading distribution cables, and violating limits of the voltage magnitude [138].

The charging and discharging of EV can be timed to match low and peak network demand respectively. EV charging could have a significant impact on the loads applied to the grid at certain times and locations, and this could affect the quality and availability of power supply, resulting in cost increases for consumers and negative feedback on transport electrification prospects [139].

\subsection{Methodology}

Deterministic analysis is carried out on the modelled UK generic distribution network to assess a network's ability to accommodate LES technology. The analysis is carried out by introducing LES to a test network for a given worst case scenario. A worst case scenario can be defined as a period of time whereby the demand on the network is at either its minimum or its maximum level depending on the particular type of technology under investigation. The method investigates the effects of increasing LES penetration, on the network and is assessed in terms of the resulting network voltage levels, network losses and transformer loading. The method provides insight into the limitations of a given network's capability to accommodate LES without the need for network upgrade. When determining the limitations of a distribution system, it is normal practice to test models of the system for a worst case scenario. For instance, in the LV residential distribution networks, the network is examined under conditions of maximum load. However, this may not be the case in future networks where there is a large penetration of LES units. The maximum, or minimum, system demand is usually determined from historical load data. The main concern from a distribution system operator's point of view is that a network operates in a safe and reliable manner under all loading conditions. With an increase in LES on the network in future years, the level of electricity demand that will define a network's ‘worst case scenario' will undoubtedly change significantly.

This method assesses the potential impact on the distribution network due to the introduction of LES. This is achieved by incrementally adding DG units to the network for a given time period, i.e. maximum or minimum demand. In order to perform this analysis, a model of a UK generic LV distribution network with localised energy 
systems was developed using power system analysis software (Neplan). Details of the model are given in Section 3.2.1. Steady-state analyses were performed using unbalanced load-flow calculations, with the changes in voltage, losses and thermal loading levels at various parts of the network recorded. The load-flow solutions were calculated using the Newton-Raphson method.

\subsubsection{The UK distribution network}

The UK generic network (UKGDN) model that is representative of the UK distribution networks is used for this study [140]. This distribution network model is used by many DNOs. It consists of a 500 MVA three phase $33 \mathrm{kV}$ ideal voltage source, connected to two $33 / 11.5 \mathrm{kV}$ 15MVA YY0 transformers, and eight $11 \mathrm{kV}$ outgoing feeders substation. Each feeder supplies $11 / 0.433 \mathrm{kV}$ transformer which ultimately feeds the LES. The network was modelled in NEPLAN software environment defining all the parameters as provided in [127]. NEPLAN is a versatile power system analysis tool that can perform load flow analysis for multiple bus networks. Fig 3.1 is a low voltage distribution network that is used for this research.

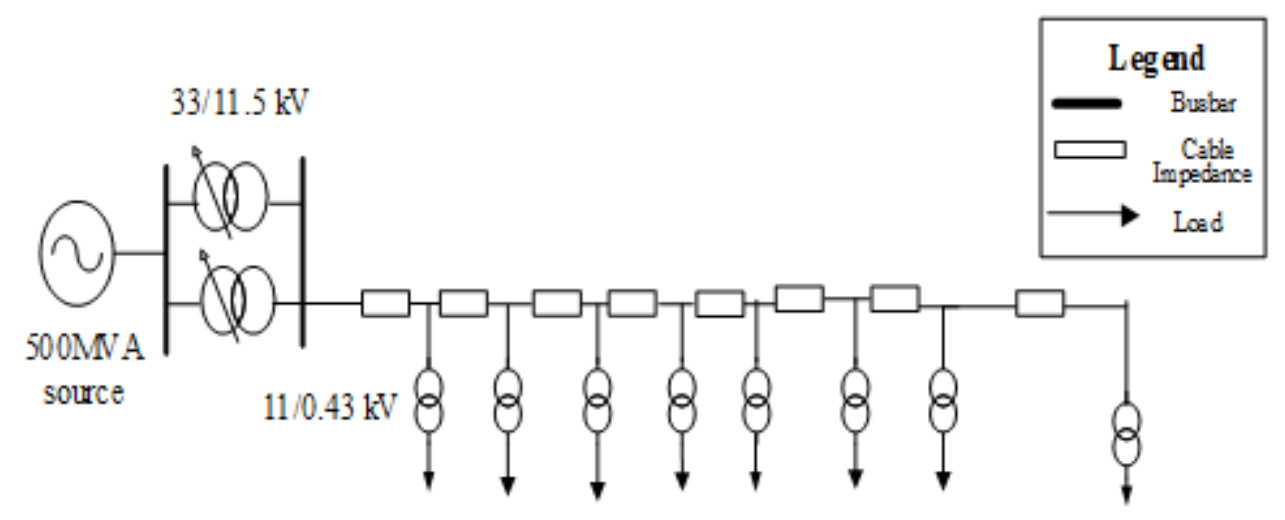

Fig 3.1 UK generic low voltage distribution network [127].

\subsubsection{Localised energy systems}

In this research, three different LES were defined and modelled as LES1, LES2 and LES3. The first localised energy system, LES1, is a residential distribution network with 384 homes and arranged into four segments of 96 houses as shown in Fig 3.2. The model is based on the 2003 report by PB power for the Department of Trade and Industry [127]. The first localised energy systems LES1 was created by replacing 400V feeder of the UK generic distribution network with residential load described earlier with local generations. The load profile has been provided by Electricity 
Association (supplied by Elexon Ltd). It consists of a time-series residential demand data over a 24-hour period as shown in Fig 3.3. This load is assumed to be uniformly distributed among each customer. Each residential consumer is denoted as a type 1 consumer by UKERC. This specific type is known as unrestricted domestic and has an annual consumption of $4000 \mathrm{kWh}$. The network cable data is shown in Table 3.2.

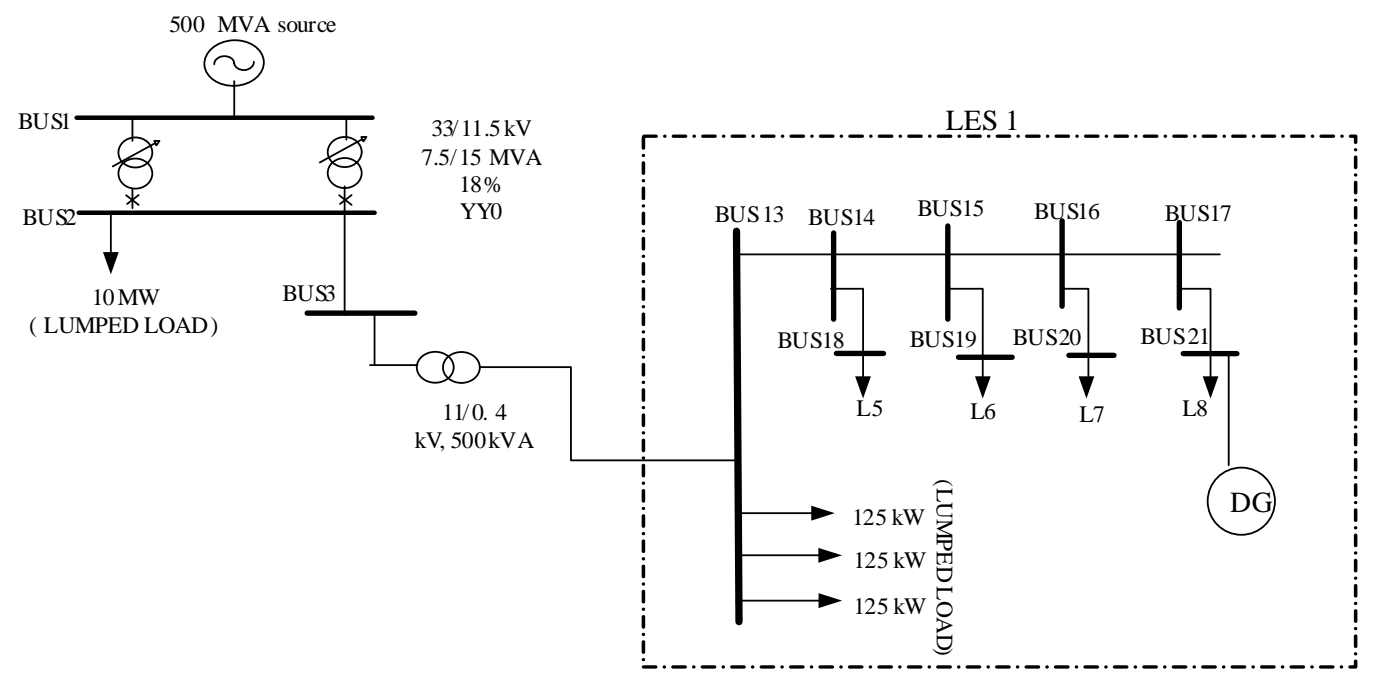

Fig 3.2 UK generic low voltage network with localised energy system

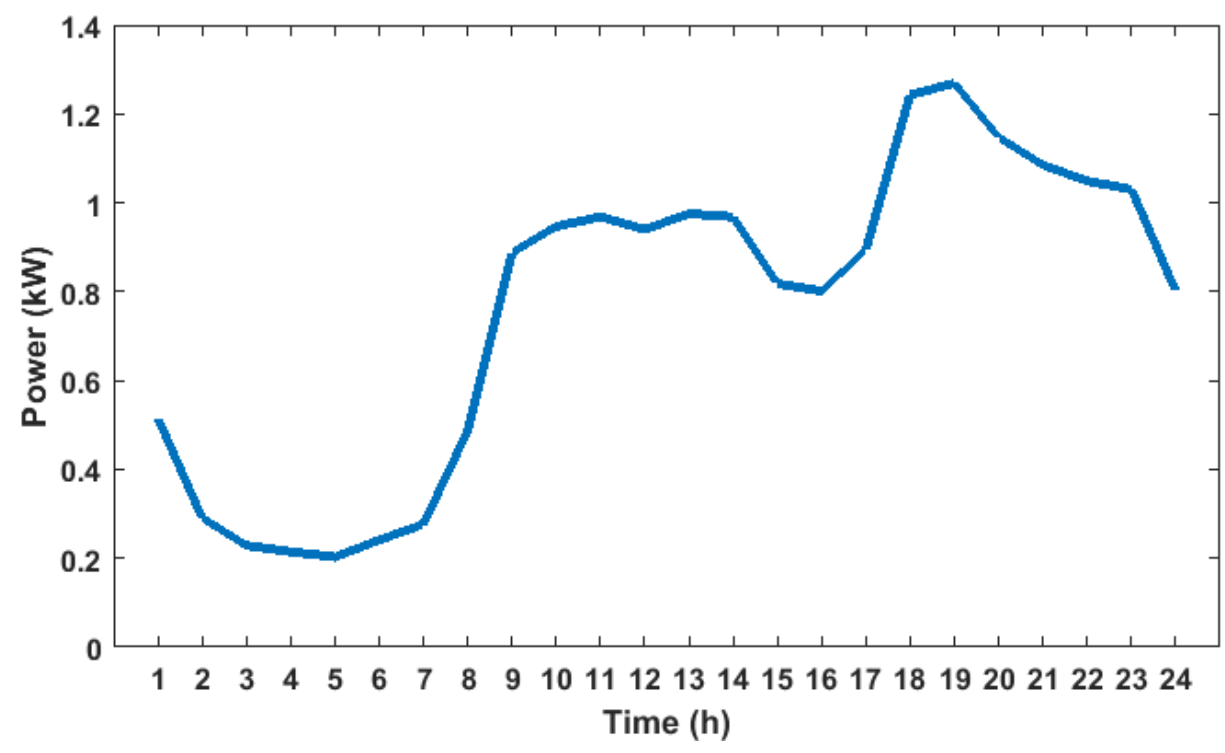

Fig 3.3 A residential hourly load profile [141]

Source: Electricity Association, (supplied by Elexon Ltd) 
Table 3.1 Network model cable data

\begin{tabular}{|c|c|c|c|c|c|}
\hline Construction & $\begin{array}{l}\text { Voltage } \\
(\mathbf{k V})\end{array}$ & $\begin{array}{l}\text { Diameter } \\
(\mathbf{m m} 2)\end{array}$ & $\begin{array}{l}\text { Maximum } \\
\text { current (A) }\end{array}$ & $\begin{array}{l}\text { Inductance } \\
(\Omega / \mathbf{k m})\end{array}$ & $\begin{array}{l}\text { Lengths } \\
(\mathbf{k m})\end{array}$ \\
\hline PICAS, $\mathrm{Cu}, 3$ & 11 & 185 & $355-420$ & 0.164 & 0.375 \\
\hline PICAS, $\mathrm{Cu}, 3$ & 11 & 95 & $245-290$ & 0.320 & 0.375 \\
\hline XPLE, Al, 3 & 11 & 70 & 195 & 0.568 & 1.000 \\
\hline XPLE, $\mathrm{Cu}, 2$ & 0.4 & 300 & 741 & 0.0802 & 0.200 \\
\hline XPLE, $\mathrm{Cu}, 2$ & 0.4 & 120 & 410 & 0.197 & 0.200 \\
\hline XPLE, $\mathrm{Cu}, 3$ & 0.4 & 50 & 192 & 0.494 & 0.050 \\
\hline XPLE, $\mathrm{Cu}, 3$ & 0.4 & 185 & 347 & 0.164 & 0.075 \\
\hline XPLE, Al, 2 & 0.4 & 95 & 257 & 0.320 & 0.075 \\
\hline XPLE, Al, 2 & 0.4 & 35 & 135 & 0.851 & 0.030 \\
\hline
\end{tabular}

The second localised energy system, LES2, is a commercial distribution network with sixteen offices with a maximum and minimum loading of $19.275 \mathrm{kVA}$ and $5 \mathrm{kVA}$ as shown in Fig 3.4

The $400 \mathrm{~V}$ of the UK generic distribution network was replaced with commercial loads of sixteen offices and local generation. These sixteen offices are distributed evenly between four segments of the LV network. The load profile has been provided by Electricity Association (supplied by Elexon Ltd) to enable the modelling of office 
buildings within this study (as shown in Fig 3.5). The average office has a power factor of approximately 0.85 [142].

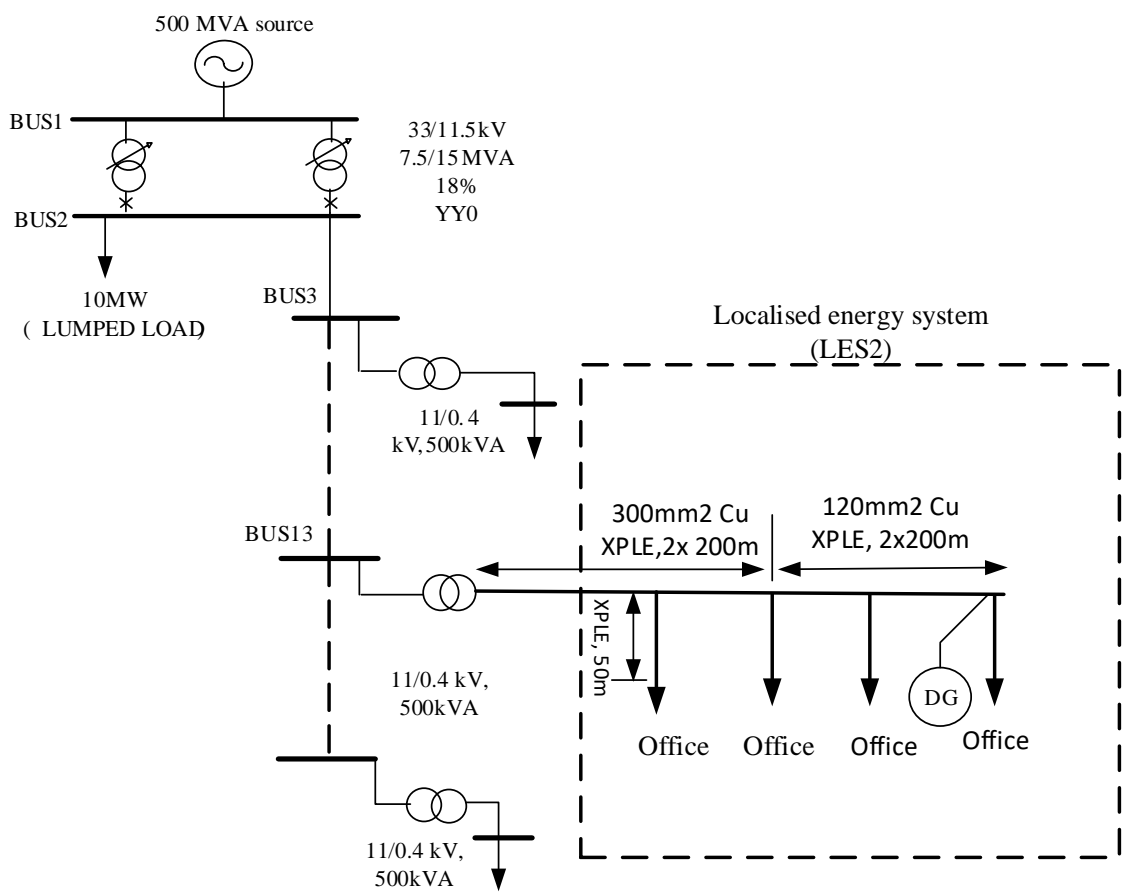

Fig 3.4 UK generic distribution network with LES2

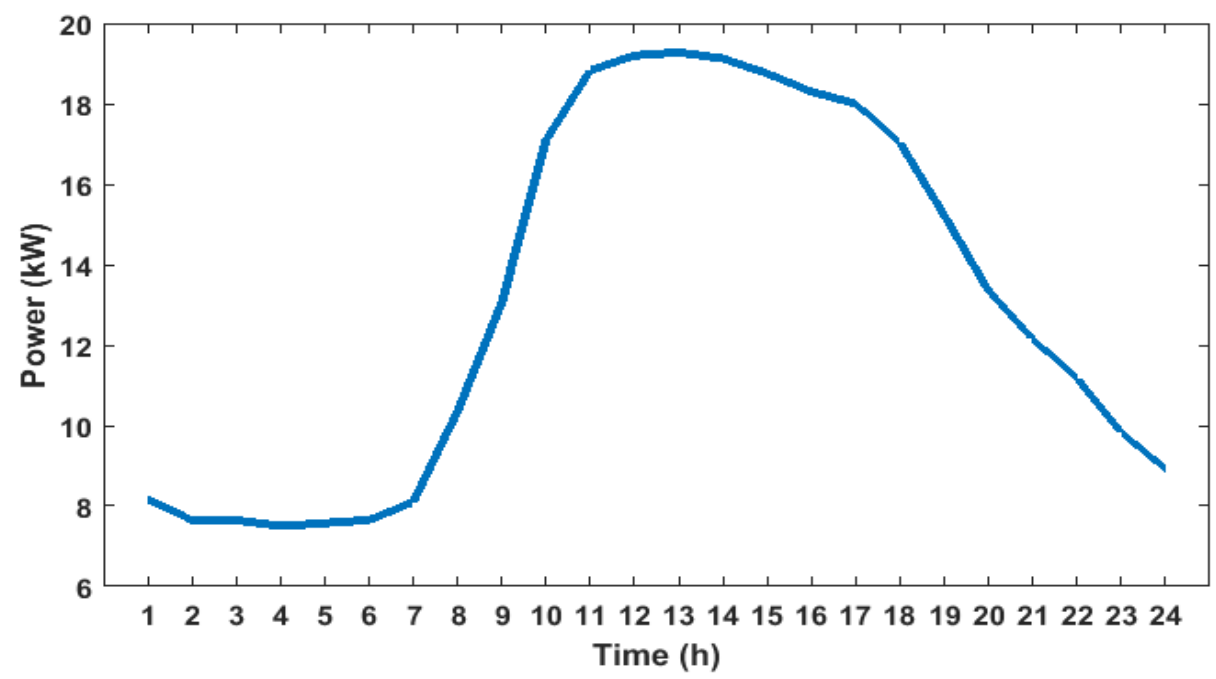

Fig 3.5 Commercial load profile [141]

Source: Electricity Association, (supplied by Elexon Ltd) 
The third localised energy system, LES3, is a housing estate, having 63 residential homes and 1 commercial building and is based on a real Cardiff network. It is an urban area, so the network was connected by underground cable (copper underground and wavecon). As shown in Fig 3.6 the network consists of 15 nodes and a distribution transformer (500kVA). The commercial load in the network is represented by node 35 . The network cable data is given in Table 3.2. The LES3 is connected in the modelled UKGDN by replacing 400V feeder with a mixed load (residential and commercial) with local generations to create a localised energy systems. The load profile has been provided by Electricity Association (supplied by Elexon Ltd). It consists of 30-minute time-series residential and commercial demand data over a 24-hour period as shown in Fig 3.3 and Fig 3.5. This load is assumed to be uniformly distributed among each customer.

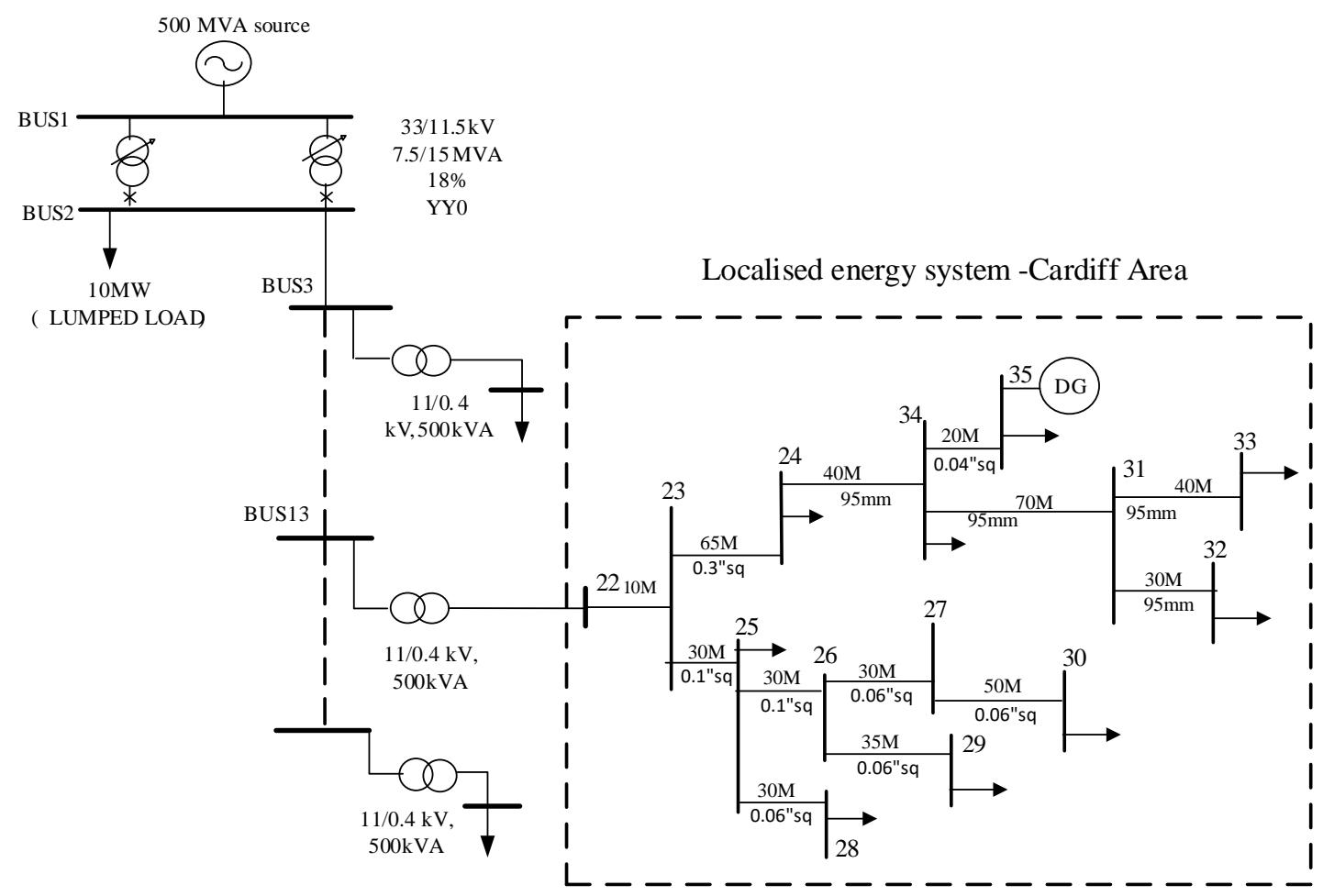

Fig 3.6 UK generic distribution network with LES3 
Table 3.2 Network cable data

\begin{tabular}{|c|c|c|c|c|c|c|c|}
\hline & & & & & Ope & ating Resis & tance \\
\hline & & & & Ratings & Phase & Neutral & Phase \\
\hline Nodes & $\begin{array}{l}\text { Length } \\
\text { (M) }\end{array}$ & $\begin{array}{l}\text { Cable } \\
\text { Type }\end{array}$ & Size & (AMPS) & $\Omega / 1000 M$ & $\Omega / 1000 M$ & $\Omega / \mathbf{M}$ \\
\hline 5 and 8 & 50 & $\mathrm{CU}$ & 0.06 "sq & 197 & 0.4637 & 0.4637 & 0.023185 \\
\hline 4 and 7 & 35 & $\mathrm{CU}$ & 0.06 "sq & 197 & 0.4637 & 0.4637 & 0.0162295 \\
\hline 3 and 6 & 30 & $\mathrm{CU}$ & 0.06 "sq & 197 & 0.4637 & 0.4637 & 0.013911 \\
\hline 4 and 5 & 30 & $\mathrm{CU}$ & 0.06 "sq & 197 & 0.4637 & 0.4637 & 0.013911 \\
\hline 3 and 4 & 30 & $\mathrm{CU}$ & 0.1 "sq & 270 & 0.2758 & 0.2758 & 0.008274 \\
\hline 2 and 3 & 30 & $\mathrm{CU}$ & 0.1 "sq & 270 & 0.2758 & 0.2758 & 0.008274 \\
\hline 1 and 2 & 10 & $\mathrm{CU}$ & 0.36 "sq & 514 & 0.0928 & 0.0928 & 0.000928 \\
\hline 1 and SUB & 10 & $\mathrm{CU}$ & 0.3 "sq & 514 & 0.0928 & 0.0928 & 0.000928 \\
\hline 12 and 13 & 30 & WC & $95 \mathrm{~mm}$ & 251 & 0.32 & 0.32 & 0.0096 \\
\hline 11 and 12 & 70 & WC & $95 \mathrm{~mm}$ & 251 & 0.32 & 0.32 & 0.0224 \\
\hline 12 and 14 & 40 & WC & $95 \mathrm{~mm}$ & 251 & 0.32 & 0.32 & 0.0128 \\
\hline 10 and 11 & 40 & WC & $95 \mathrm{~mm}$ & 251 & 0.32 & 0.32 & 0.0128 \\
\hline 2 and 10 & 65 & $\mathrm{CU}$ & 0.3 "sq & 514 & 0.0928 & 0.0928 & 0.006032 \\
\hline 11 and 15 & 20 & $\mathrm{CU}$ & 0.04 "sq & 156 & 0.7027 & 0.7027 & 0.014054 \\
\hline
\end{tabular}

CU: copper wire WC: wavecon 


\subsection{CASE STUDIES OF LOCALISED ENERGY SYSTEMS}

In order to determine the impact of LES on the low voltage distribution systems, a steady-state power flow analysis is performed to assess network limitations. The analysis is carried out in each LES for a different level of DG penetration.

This method assesses the potential impact on the distribution network due to the introduction of LES. This is achieved by incrementally adding DG units to the network for a given period. Five case studies were defined to analyse the impacts of DG on the distribution systems with localised energy systems:

- Case Study1 investigated the effect of DG penetration on the network voltage profile.

- Case Study 2 examined the impact of DG penetration on network losses.

- Case Study 3 investigated the effect of DG penetration on transformer loading.

- Case Study 4 evaluated the maximum capacity (units) of DG that could be connected by individual customers in the distribution system without violating the DNO permissible voltage limits.

- Case Study 5 evaluated the numbers of EVs that could be charged by individual customers in the localised energy systems.

\subsubsection{Assumptions and limitations}

A basic unit of DG is considered to be $1.1 \mathrm{~kW}$ for residential customers [140]. Thus for $100 \%$ penetration, each of the $24 \mathrm{x} 4$ residential load is connected with $1.1 \mathrm{~kW}$ of DG. The commercial customer each have $5.5 \mathrm{~kW}$ of DG connected per customers. There was uniform DG penetration among the four segments for both residential and commercial customers. Also, basic unit of EV is considered to be $6.6 \mathrm{~kW}$ [138]. Thus for $100 \%$ penetration, each of the $24 \times 4$ residential customers have an EV with $6.6 \mathrm{~kW}$ load. For commercial load, it is assumed for the purpose of this research study, a car park with $40 \mathrm{EVs}$. The EV is considered in Grid to Vehicle (G2V) more 


\subsubsection{Case study 1}

The first case study investigated the impact of DG penetration on the network voltage profile. Load flow analyses were carried out at various level of DG penetration. The first simulation was conducted with zero DG penetration (normal network operation). The second simulation utilised 100\% DG penetration, i.e. all customers installed DG on their premises. The voltage level at each connection point of the load is very important for the quality of the supply. In accordance with Electrical Safety, Quality and Continuity Regulation 2002, the statutory voltage limits are currently $+10 \% /-6 \%$ based on $230 \mathrm{~V}$ [143].

\subsubsection{Results of case study 1}

The simulation results for the load flow analyses are presented in this section.

LES1: The voltage profile at zero DG reflects the normal working voltage of the system. As shown in Fig 3.7, the minimum voltage of $0.435 \mathrm{kV}$ (1.06p.u.) occurred between hours 17:30 and 18:00 when customers arrived from work.

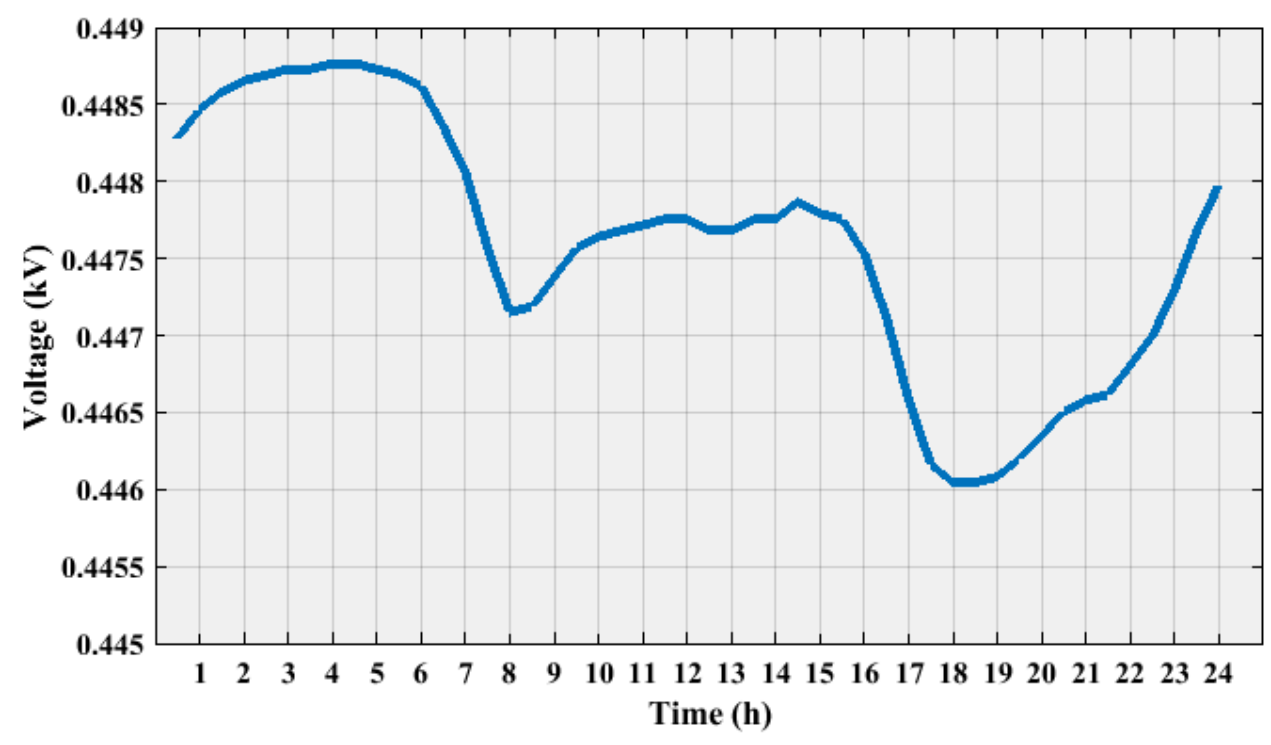

Fig 3.7 Voltage at bus 12 (without DG)

The maximum voltage of $0.438 \mathrm{kV}$ (1.02p.u.) happened at hour 3:30, and 4:00 during the night. The statutory voltage limit for low voltage levels being $0.404 \mathrm{kV}$ (0.94p.u.) and $0.473 \mathrm{kV}$ (1.10p.u.) respectively. Since the network is built to keep the voltage below the upper limit at minimum load, the case should not be a problem. 
In the second simulation, $1.1 \mathrm{~kW}$ of DG units were connected to each of the residential customers representing 100\% DG penetration. As shown in Fig 3.10, there was a significant increase in voltage when DG was connected. The minimum voltage increased to $0.446 \mathrm{kV}$ (1.06p.u.) between 17:30 and 18:00 and the maximum voltage increased to $0.449 \mathrm{kV}$ during the hour interval 3:30 and 4:00.

This increase in voltage is due to the DG power cancelling out some or all of the residential load, and some due to excess generator real power flowing back through a mainly resistive network to the distribution transformer.

LES2: The network consists of only commercial customers. The voltage profile at zero DG is shown in Fig 3.8. The minimum voltage at the point of observation is $0.417 \mathrm{kV}$ (0.97p.u.). This occurred at hour 11:30 when the customer's load is peak. Also, the maximum voltage of $0.425 \mathrm{kV}(0.99$ p.u.) was recorded at hour 4:00 when customers were out of office.

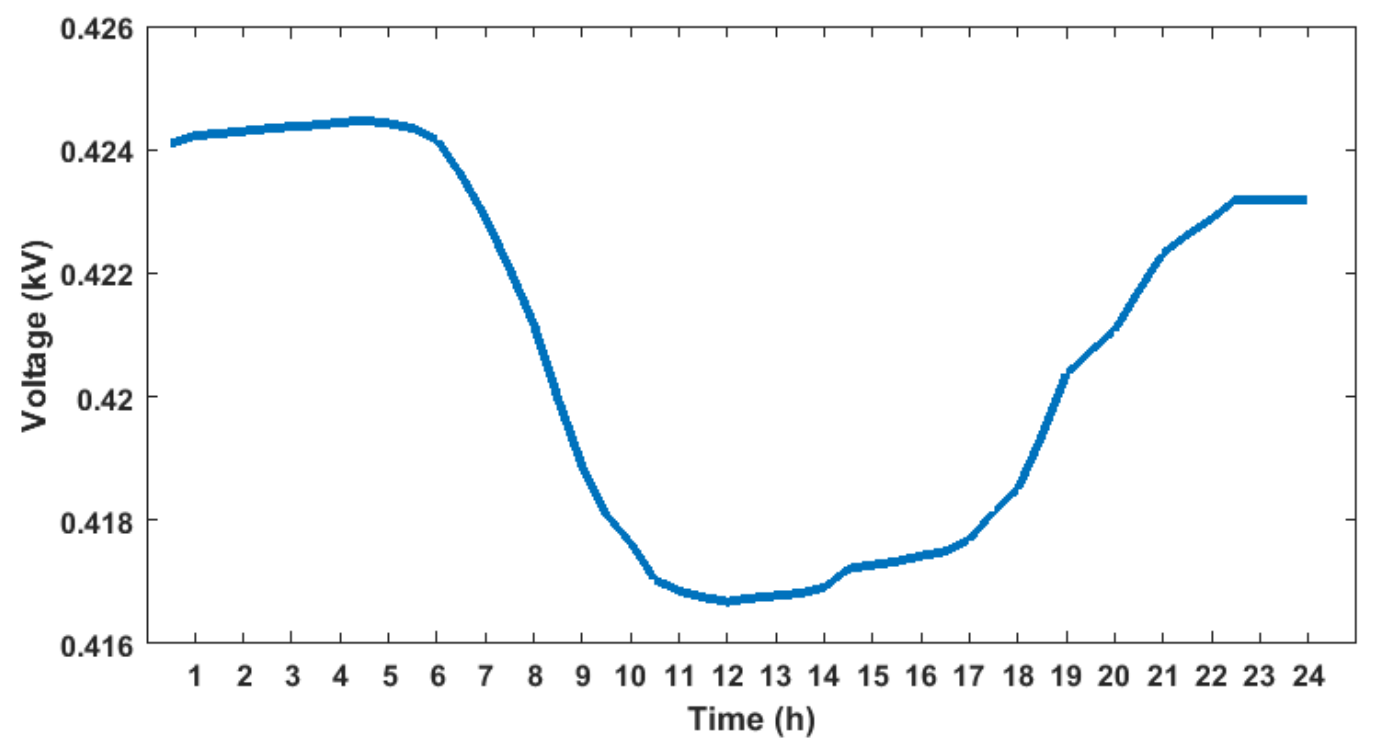

Fig 3.8 Voltage at bus 22 without DG (LES2) 


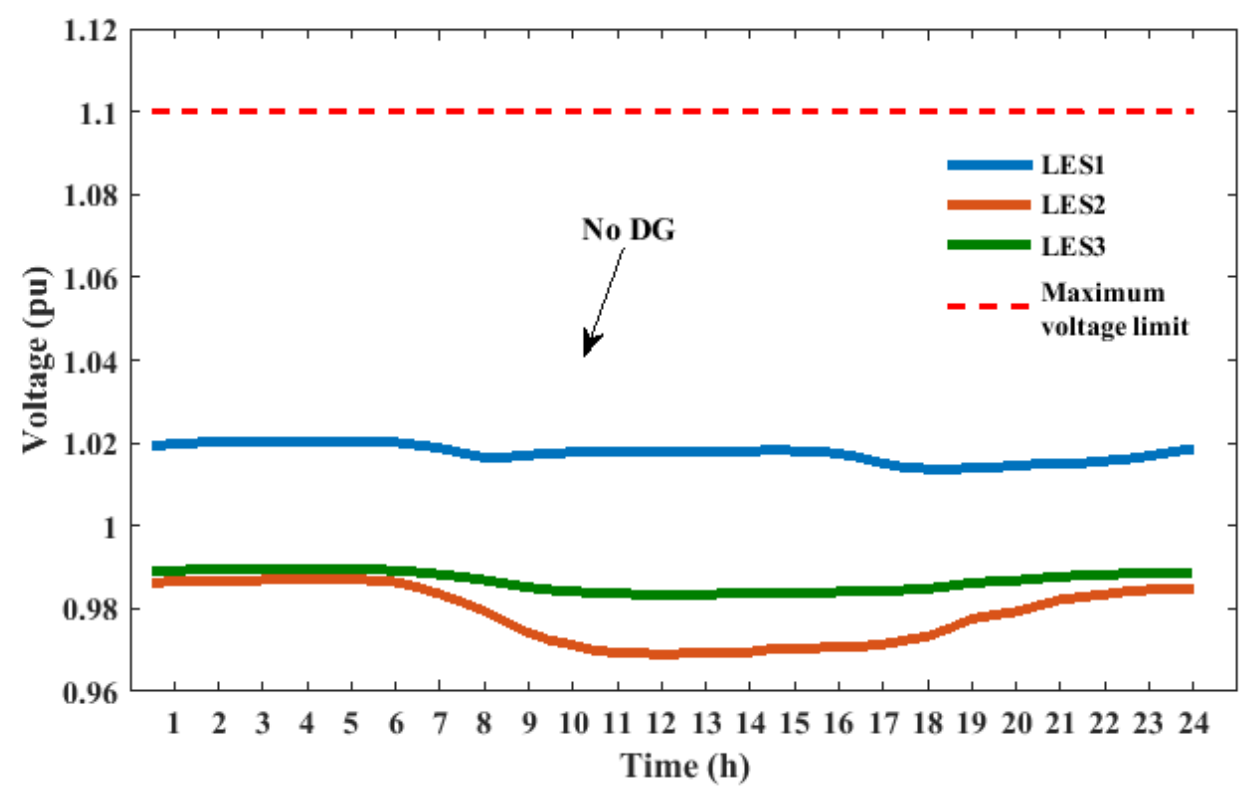

Fig 3.9 Network voltage without DG

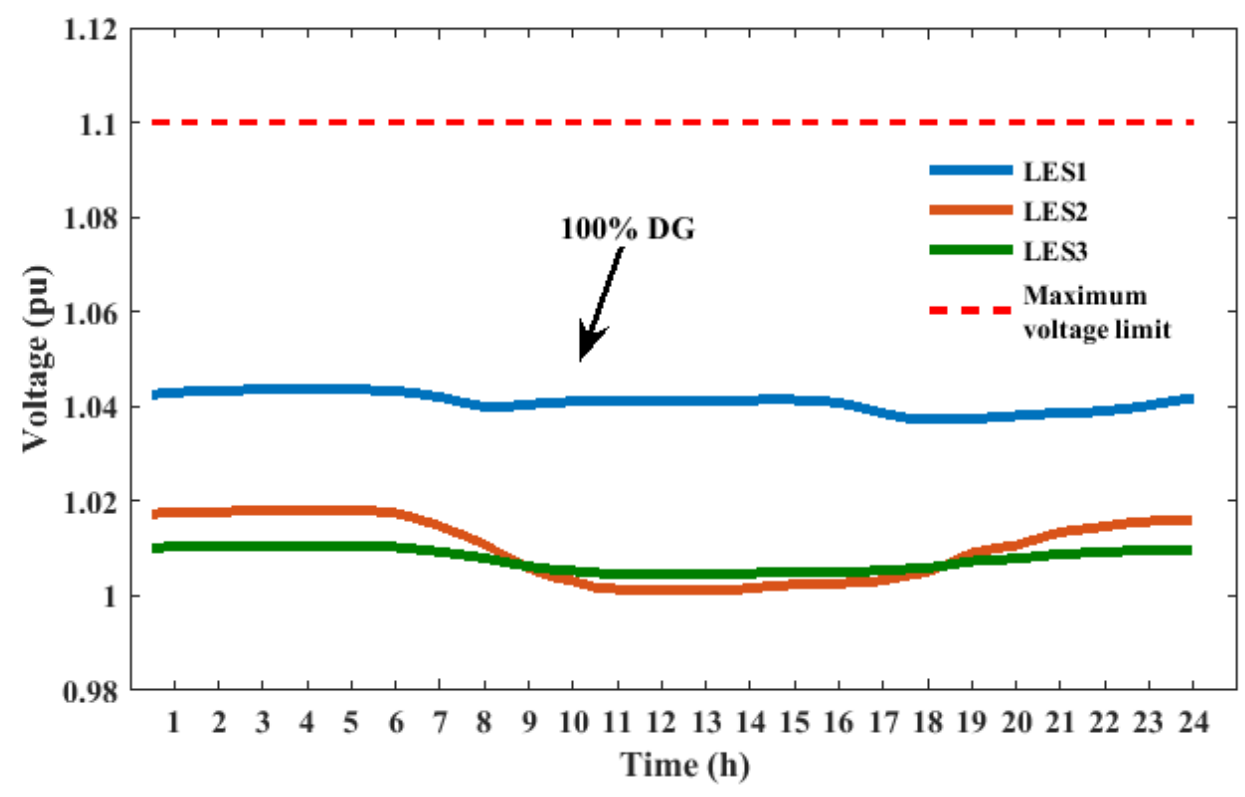

Fig 3.10 Network voltage with DG

When 5.5kW DG units were connected to each of the commercial customers is representing $100 \%$ DG penetration. The minimum voltage in the network rose to $0.430 \mathrm{kV}$ which is an increase of $13.7 \mathrm{~V}$ while the maximum voltage rose to $0.434 \mathrm{kV}$ representing an increase of $13.0 \mathrm{~V}$.

LES3: A mixed (residential and commercial) loads are connected to the distribution network, and the simulation was carried out. The voltage profile with and without DG penetration is represented in Fig 3.10. The maximum voltage rose from $0.429 \mathrm{kV}$ to 
$0.435 \mathrm{kV}$, an increase of $6 \mathrm{~V}$. The minimum voltage rose from $0.427 \mathrm{kV}$ to $0.432 \mathrm{kV}$ representing an increase of $5 \mathrm{~V}$.

\subsubsection{Case study 2}

Power losses in the distribution networks are caused by active and reactive power flows through line resistance. The magnitude of the losses depends on the amount of square of the current flow and the line resistance. The desire of every DNO is to minimise power losses while complying with the network voltage limit. In this section, power losses have been calculated for a distribution system having three different localised energy systems.

Losses are calculated with power flows using two sets of simulation to determine the network losses. The first simulation was conducted with zero DG penetration, and the corresponding losses are shown in Fig 3.11. The second simulation had 100\% DG penetration in the network.

\subsubsection{Results for case study 2}

LES1: Over the simulation time, without DG connected in the network, the maximum network losses is $19.3 \mathrm{kWh}$ at $18: 00$. With $100 \%$ DG connected to the network, the losses reduced to $15.4 \mathrm{kWh}$ at 18:00. Without DG, the active power losses over the day are summed to $884.9 \mathrm{kWh}$. When $100 \%$ DG penetration was added to the network the losses reduced to $730.2 \mathrm{kWh}$. The total loss reduction is $154.7 \mathrm{kWh}$ which correspond to $17.48 \%$. Fig 3.11 show losses in the LES with and without DG.

LES2: Without DG connected in the network, the maximum network losses is $16.34 \mathrm{kWh}$ at $12: 30$. With $100 \%$ DG connected to the network, the losses reduced to $13.22 \mathrm{kWh}$ at $12: 30$. Without DG, the total network losses without DG connected is $729 \mathrm{kWh}$. As shown in Table 3.3, the value reduced to $615.3 \mathrm{kWh}$ with $100 \%$ DG added to the network. The total loss reduction is $113.9 \mathrm{kWh}(15.61 \%)$.

LES3: Without DG connected in the network, the maximum network losses is 20.36 $\mathrm{kWh}$ at $12: 00$. With $100 \%$ DG connected to the network, the losses reduced to 15.31kWh at 12:00. Without DG, from Fig 3.11, it was shown that without DG the total losses in the network was $935.1 \mathrm{kWh}$. The losses reduced to $706.2 \mathrm{kWh}$ with DG connected to the distribution network. 

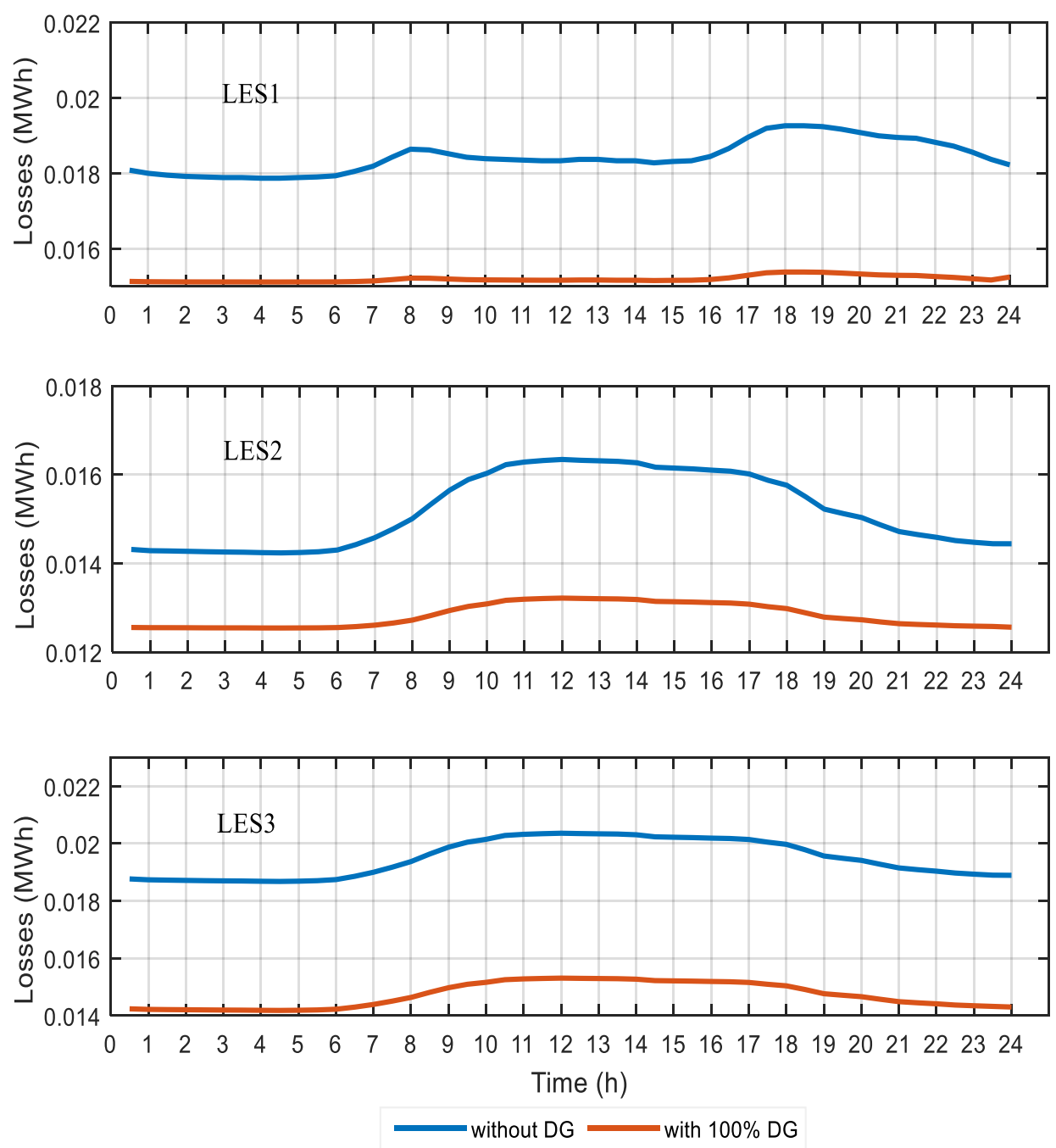

Fig 3.11 Network losses over 24 hours

Table 3.3 Network losses with and without distributed generation

\begin{tabular}{|c|c|c|c|c|}
\hline \multirow[b]{2}{*}{$\begin{array}{c}\text { Types of } \\
\text { LES }\end{array}$} & \multicolumn{3}{|c|}{ Power losses over the day $(\mathrm{kWh})$} & \multirow{2}{*}{$\begin{array}{l}\text { Loss } \\
\text { reduction } \\
(\%)\end{array}$} \\
\hline & $\begin{array}{l}\text { Without } \\
\text { DG }\end{array}$ & $\begin{array}{c}\text { With } \\
100 \% \text { DG }\end{array}$ & $\begin{array}{c}\text { Loss } \\
\text { reduction }\end{array}$ & \\
\hline LES1 & 884.9 & 730 & 154.6 & 17.48 \\
\hline LES2 & 729 & 615.3 & 113.7 & 15.61 \\
\hline LES3 & 935.1 & 706.2 & 228.9 & 24.47 \\
\hline
\end{tabular}




\subsubsection{Case study 3}

Distribution transformers connected in the distribution network have specific loading or utilisation capacity, and for smooth power supply to customers, it is essential to operate each distribution transformers within safe operating limits designated by DNO. Therefore, this section investigated the impact of DG penetration on LV distribution transformers that fed the LES. A power flow calculation for each of the 24 hours of the day is done in the evaluation of transformer loading. The maximum power in MVA or the maximum current in Amp (A) must be known for the calculation of transformer loading. For this simulation the rating of the transformer is 500kVA. The first simulation was carried out without DG while the second simulation was performed with $100 \%$ DG penetration. The simulation results are discussed next.

\subsubsection{Results for case 3}

LES1: The simulation results are shown in Fig 3.12. From the plot, it is shown that the transformer loading varies with time and increases as the customer's demand is increased. Without DG, the minimum transformer loading is $95.35 \%$ and it occurred between 3:30 and 4:00. The peak loading of the transformers is $100.47 \%$, which occurred between 5:30 and 6:00 hours.

When DG was connected to the network, the transformer's minimum loading reduced to $73.89 \%$, which occurred between hours 3:30 and 4:00. Most of the residential customers are still sleeping during the time. However, the maximum loading of the transformer $78.78 \%$ occurred between hours 17:30 and 18:00 when the customers demand is at the peak. There is an approximately $21.5 \%$ reduction in the transformer loading during the simulation period.

LES2: As shown in Fig 3.12, without DG, the transformer loading varied between $94.68 \%$ and $100.28 \%$. With DG installed, the loading varies between $56.72 \%$ and $61.11 \%$ for the 24 hours simulation time. From the plot in Fig 3.14, it is shown that the minimum transformer loading for the commercial customers (with DG installed) is $56.72 \%$ and occurred at $4: 00$, and the peak of $61.11 \%$ occurred at $11: 30$.

LES3: From Fig 3.12, it was shown that, without DG, the maximum loading of the distribution transformer is $91.85 \%$ at hour 4:00 and this situation occurred when the load demand is at maximum. With DG connected to the network, the transformer 
loading is reduced to $52.75 \%$ at hour $11: 30$, and $64.10 \%$ at hour $4: 00$ with DG connected to the distribution network.

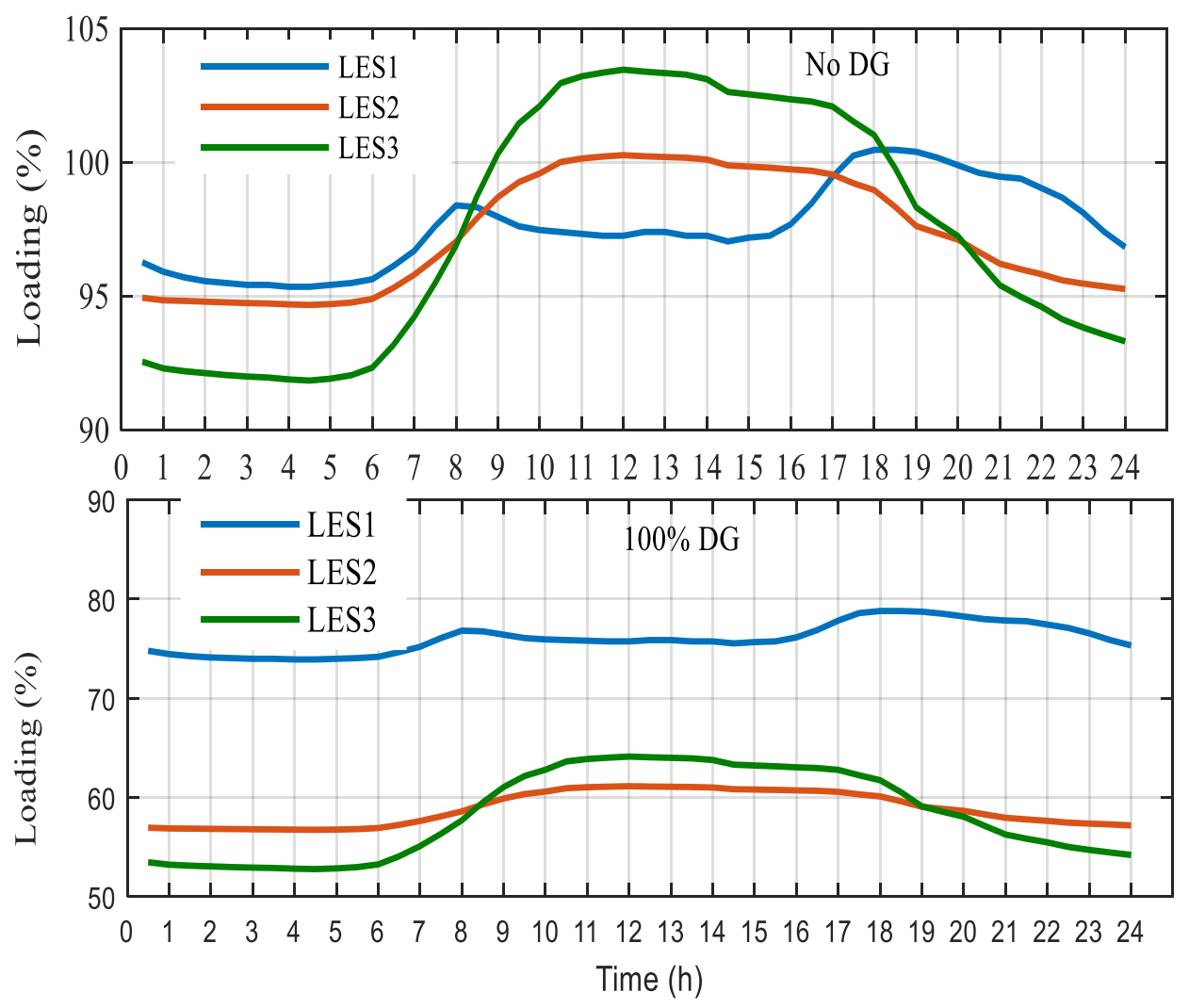

Fig 3.12 Transformer loading with and without DG

\subsubsection{Case Study 4}

To evaluate the maximum DG capacity that could be installed in an LES, the principle highlighted in section 3.1.4 is adopted. Load flow study was performed taking into considerations, important indices such as network voltage, transformers and cable loadings, and losses to ensure save network operation. In all the simulations and analysis, the voltage limit of $+10 \%$ and $-6 \%$ was strictly maintained. Thermal limit of the distribution transformers was not exceeded, and likewise, losses on the line were monitored. The results are presented in Table 3.4.

\subsubsection{Results for case study 4}

As shown in Table 3.4, each residential customer in LES1 can install three units of DG $(3 \times 1.1=3.3 \mathrm{~kW})$ which represent $300 \%$ DG penetration at maximum loading. 
However, at minimum loading each customer can install one unit of DG $(1 \times 1.1=$ $1.1 \mathrm{~kW}$ ) which denotes $100 \%$ DG penetration.

In the case of LES2, each of the sixteen commercial customers can install four units of DG $(4 \times 5.5=22 \mathrm{~kW})$ while each customer can install one unit of DG $(2 \times 5.5=11 \mathrm{~kW})$ which represents 200\% DG penetration as shown in Fig 3.13.

The results show that in LES3, each of the 63 residential customers can install 3 units of DG $(1.1 \times 3=3.3 \mathrm{~kW})$ and the commercial customer install 3units of DG $(5.5 \times 3=$ $16.5 \mathrm{~kW}$ ) at the maximum loading.

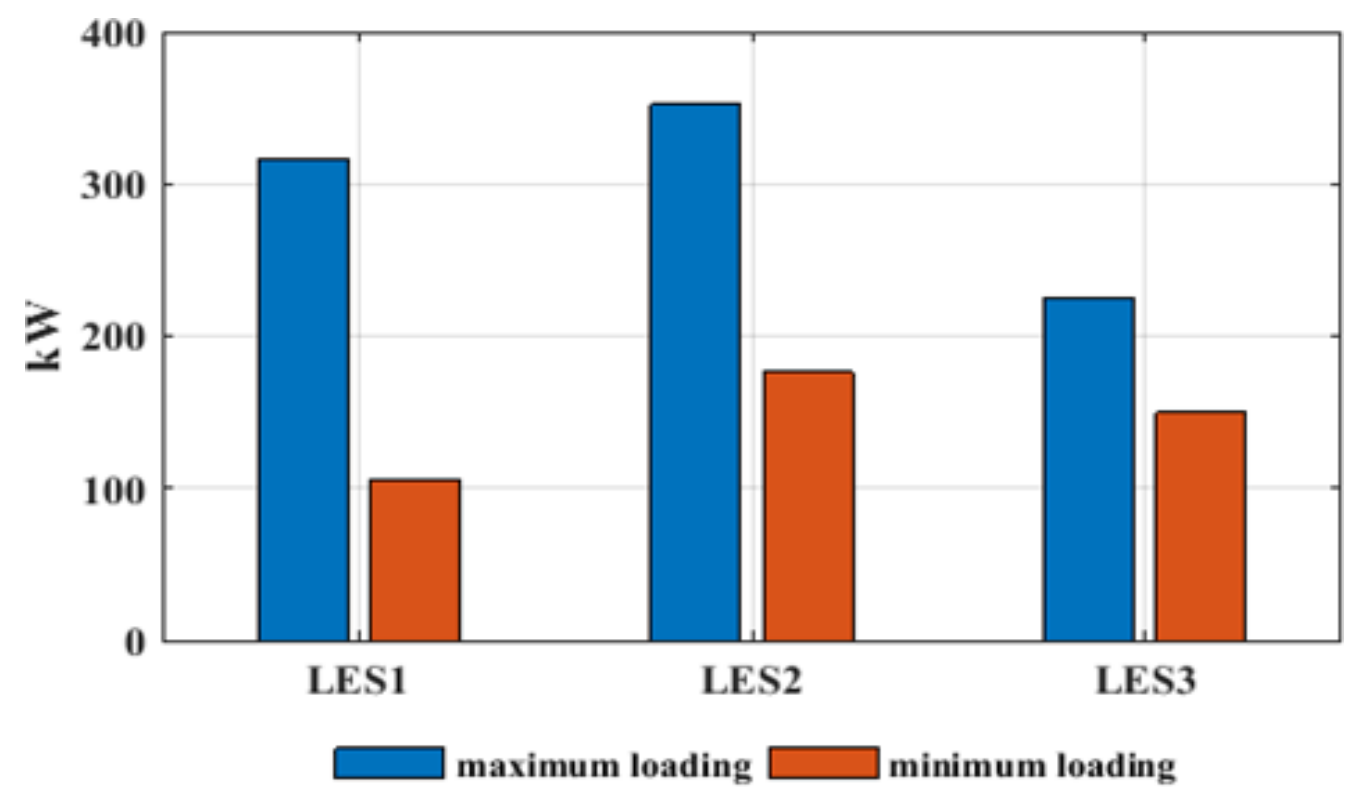

Fig 3.13 Maximum DG capacity installed in each LES

However, at minimum loading, each residential customer can install two units of DG $(1.1 \times 2=2.2 \mathrm{~kW})$ and each commercial customer can installed 2 units of DG $(2 \times 5.5=11 \mathrm{~kW})$ at minimum loading.

\subsubsection{Case study 5}

In this case study the total number of EV that could be charged in each LES were determined. Load flow study was performed to determine network voltage changes with EV penetrations. In all the simulations and analysis, the statutory voltage limit of $+10 \%$ and $-6 \%$ was strictly maintained.

\subsubsection{Results for case study 5}

Simulations in this case covers extreme condition at minimum load at both $50 \%$ and $100 \%$ EV penetration (charging mode) [28]. 
For residential customers, at $50 \%$ and $100 \%$ penetration of EV in charging mode is the condition that each load group is additionally loaded by $12 \times 6.6 \mathrm{~kW}=79.2 \mathrm{~kW}$ and $24 \mathrm{x}$ $6.6 \mathrm{~kW}=158.4 \mathrm{~kW}$ to an existing minimum load of $3.84 \mathrm{~kW}$. At $50 \%$ penetration, the resulting voltage is within the limit $(+10 \%$ and $-6 \%)$ permitted by DNO. However, at $100 \% \mathrm{EV}$ penetration, there is additional burden in the network, with effective loading of $6.6 \mathrm{~kW}$ per customers. Since there is no power injected into the network by a DG source, the voltage of the networks drops below the normal operating limit. The results show that a total of forty-eight customers in LES1, eighty customers in LES2 and thirty-two customers in LES3 can charge their EVs without violating permissible voltage limit.

Table 3.4 Summary of the results

\begin{tabular}{|c|c|c|c|c|}
\hline Network & $\begin{array}{c}\text { Voltage } \\
\text { Increase with } \\
\text { DG }\end{array}$ & $\begin{array}{c}\text { Losses } \\
\text { Reduction } \\
\text { With DG }\end{array}$ & $\begin{array}{c}\text { Transformer } \\
\text { loading reduction } \\
\text { with DG }\end{array}$ & $\begin{array}{c}\text { DG Unit per } \\
\text { customers in the } \\
\text { LES }\end{array}$ \\
\hline LES 1 & $\begin{array}{c}10.12 \mathrm{~V} \\
(2.32 \%)\end{array}$ & $17.48 \%$ & $21.5 \%$ & $3.3 \mathrm{~kW}(300 \%)$ \\
\hline LES2 & $13.7 \mathrm{~V}$ & $15.61 \%$ & $38.5 \%$ & $16.5 \mathrm{~kW}(300 \%)$ \\
& $(3.28 \%)$ & & & $4.4 \mathrm{~kW}(400 \%) /$ \\
& $(1.17 \%)$ & $24.47 \%$ & $39.2 \%$ & $22 \mathrm{~kW}(400 \%)$ \\
\hline
\end{tabular}

\subsection{SUMMARY DISCUSSION AND KEY FINDINGS}

The analysis presented in this chapter provides insight into the benefits and limitations of different LES within a distribution system for different loading scenarios. The results showed that the integration of DG led to voltage improvement and loss reductions in the UK distribution network. There is loss reduction in the network because the DGs are located very close to the loads, which prevent a large amount of power flowing from the substation to the loads. There is significant loss reduction in the three LES under study, but the extent of reduction depends on the squares of the current flows in the lines and the parameters of the lines. Another reason could be the size of the connected DGs. 
However, at $200 \%$ DG penetration, the generated excess power outside of the peak demand will be fed back into the grid. If the excess power is not consumed by other consumers during the peak demand periods a voltage rise occurs. This voltage rise may lead to the maximum voltage limits being violated which have adverse effects on consumer appliances. In order to mitigate this problem voltages control strategies such as, active power curtailment, smart grid design and implementation and reactive power compensation are employed.

Distribution transformers could be overloaded due to the growing power demand, but this could be avoided only if consumers are encouraged to avoid using electricity during peak hours or by connecting DGs in the network otherwise transformer upgrade will be required. Nigeria network is currently affected by a lack of funds due to the state of the economy; transformers upgrade cannot be recommended which buttress the needs for LES.

Three types of electricity customers are studied in this research namely residential, commercial and mixed customer. They have different behaviours and so have different impacts on the distribution network. Therefore, prior to LES integration, a comprehensive study must be carried out to determine the electricity consumption pattern of the customers for safe network operation.

The results of the research on the UK network is relevant in Nigeria and other developing countries in sub-Sahara Africa where power consumers are located mostly far away from the centralised generations.

The results obtained will help in successful planning and operation of a LES in a given distribution network. DG used in this study is Solar PV as such would help to achieve $\mathrm{CO} 2$ emission target.

Now that the performance and impacts of LES in a robust well-developed UK generic distribution system is understood, a similar study will be conducted on EkitiState distribution network

The results of this research in the UK networks is relevant in the Nigeria and other developing countries in sub-Sahara Africa where power consumers are located mostly far away from the centralised generations. 
The results obtained will help in successful planning and operation of a LES in a given distribution network. DG used in this study is Solar PV as such would help to achieve $\mathrm{CO} 2$ emission target.

Now that the performance and impacts of LES in a robust well-developed UK generic distribution system are understood, a similar study will be conducted on Ekiti-State distribution network. 


\section{CHAPTER 4}

\section{A STUDY OF LOCALISED ENERGY SYSTEM IMPACTS IN EKITI STATE}

\subsection{INTRODUCTION}

Nigeria power network is faced with many technical challenges such as, ageing infrastructure, inability to dispatch generated power to meet the load demand, large number of overloaded transformers in the grid systems, using the transmission lines beyond their limit [144], large number of uncompleted reinforcement and expansion projects in the power industry, inability of the existing transmission lines to wheel more than $4000 \mathrm{MW}$ of power leading to voltage and frequency control problems [145]. Some of the transmission lines are radial in nature and fragile which is prone to frequent system collapse [144].

The Federal Government of Nigeria had unbundled the National Electric Power Authority (NEPA) to encourage private participation in power generation and distribution [146]. It is expected to increase transmission strength because of the very high demand for the existing and ageing infrastructure, by building more power stations and transmission lines, through Independent Power Projects (IPP) [147]. The power supply in Nigeria remains poor and unreliable despite a history of restructuring [147].

Since most of the existing Nigerian generating stations are located far from the load centres, there is the possibility of experiencing low bus voltages, line overload, frequency fluctuations and poor system damping in the network. Thus, weakening the stability of the network when subjected to fault conditions.

Many research papers have been published on how to reduce the adverse effects of the problems in Nigeria power system. In [144], [148], [149], the use of FACTs devices and reactors is proposed. Construction of additional transmission lines and installation of VAR injection is recommended by [145]. Also, [150], [151] suggested that the network should be transformed from radial to ring, because of the high losses inherent in it and the violation of allowable voltage drop at $\pm 5 \%$ of nominal value. It 
is interesting to note that all the existing research work on Nigeria power system were carried out on $330 \mathrm{kV}$ high voltage (HV) transmission grid. Up till now the medium voltage and low voltage had not been investigated. The non-availability of comprehensive data at medium and low voltage level has restricted research effort to the high voltage level. This study aims to address the problem of low voltage and high network losses in the Ekiti state 33kv distribution network with localised energy systems over different season of the year, using the knowledge and experience obtained in chapter 3 of this thesis.

\subsection{METHODOLOGY}

Research in Nigeria power sectors is faced with the challenge of identifying reliable data. In the absence of central electronic data gathering unit in the power sector and conflicting statements made in the context of political agenda setting, data verification by comparison with at least one other dataset has been difficult. Moreover, sources are not always given in studies or papers that offer statistics, meaning citation of such sources is potentially problematic, especially if they are the only source. For the purpose of this study, I have consulted national and international data sets for each study case investigated in this research. In general, there is no comprehensive and commonly accepted database of power statistics, which is why this research work is using data from local source (PHCN, NERC, National Bureau of Statistics), own surveys and international sources (World Bank, IEA, United Nations) while effort was made to validate and harmonised the data, specific deviations across the information depicted are inevitable.

The model of the Ekiti State $33 \mathrm{kV}$ distribution network with localised energy system was developed using power engineering software called Neplan (Neplan is a software tool to analyse, plan, optimize and simulate networks). Power flow analysis is carried out with a standard load profile. The modelled network is simulated with and without PV system. The power flow analysis provides the steady state solution of the entire system voltage, real and reactive powers and line losses. It provides the solution to the network under steady state condition subject to certain inequality constraints such as nodal voltages, reactive power generation of the generators and gives the voltage magnitude and angles at each bus in the steady state. This is rather important as the magnitudes are required to be held within a specified limit. 


\subsubsection{Ekiti State test system overview}

Ekiti State is in the southwestern part of Nigeria [152]. The existing $33 \mathrm{kV}$ power grid covers sixteen local governments areas total land area of $5887.89 \mathrm{~km}^{2}$ presented in Fig 4.1. Like many other states in Nigeria, the electricity supply to the state is poor and unreliable. Currently, the state relied on the supply of less than $40 \mathrm{MW}$ to meet the electricity demand.

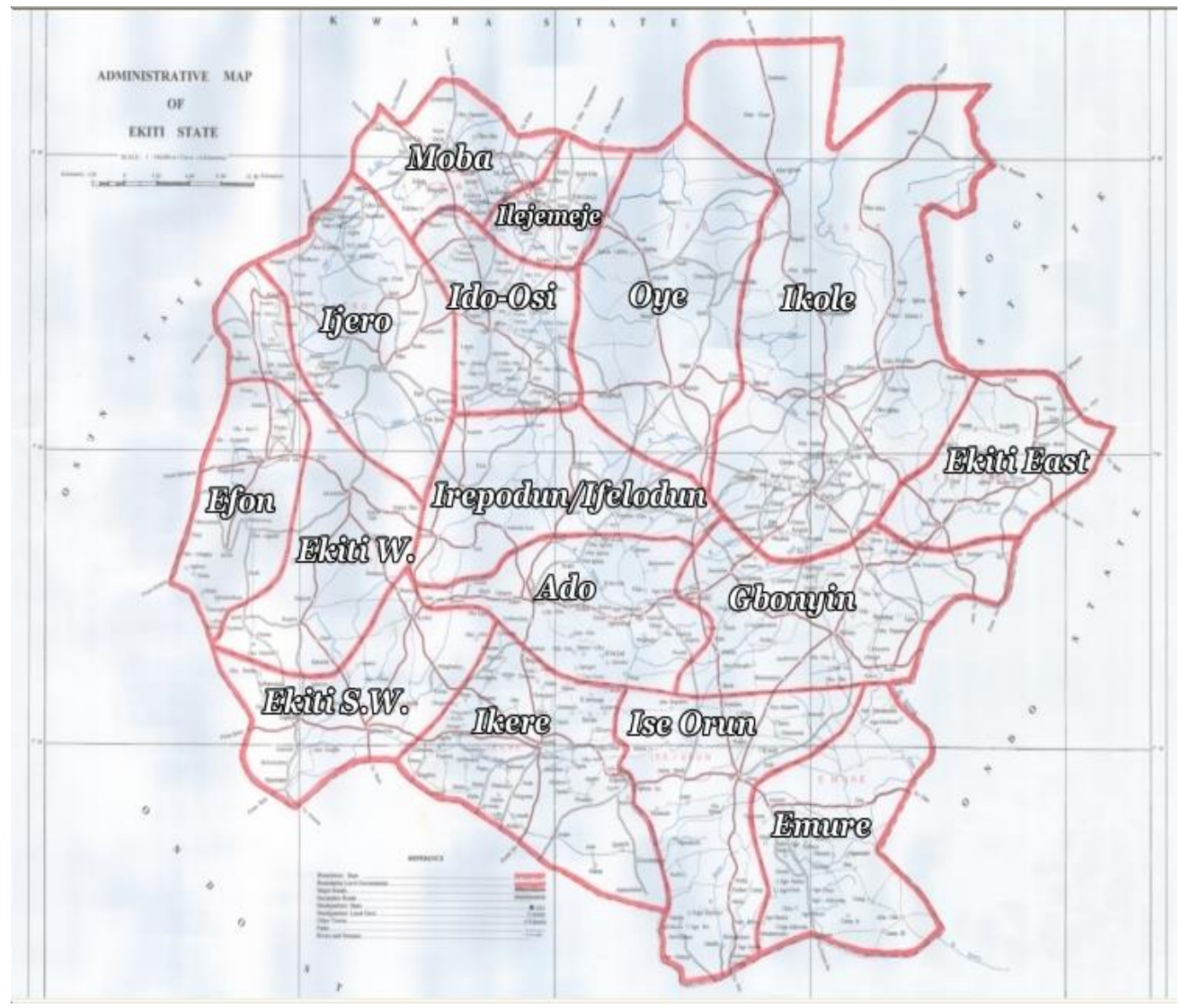

Fig 4.1 Map of Ekiti-State showing local government areas [27]

Recently, two new Universities were added to the existing institutions in the state namely, Federal University, Oye-Ekiti and Afe Babalola University, Ado-Ekiti. These Universities have campuses spread over three LGAs namely, Oye, Ikole, and Ado local governments. This increase in population has worsened the high demand for electricity in the state. There are more outages than uninterrupted power supply in most parts of Nigeria all year round. According to statistics obtained from National Control Centre (NCC) in Osogbo, Nigeria, there were 124 cases of systems collapse between 2009 and 2012, most of which were cases of total collapse with fewer cases of partial 
collapse. Also, Prof Chinedu Nebo, the Minister of Power, in June 2013, reported cases of over 15 system collapses in the previous five months [153]. This further buttress the need to address this problem urgently.

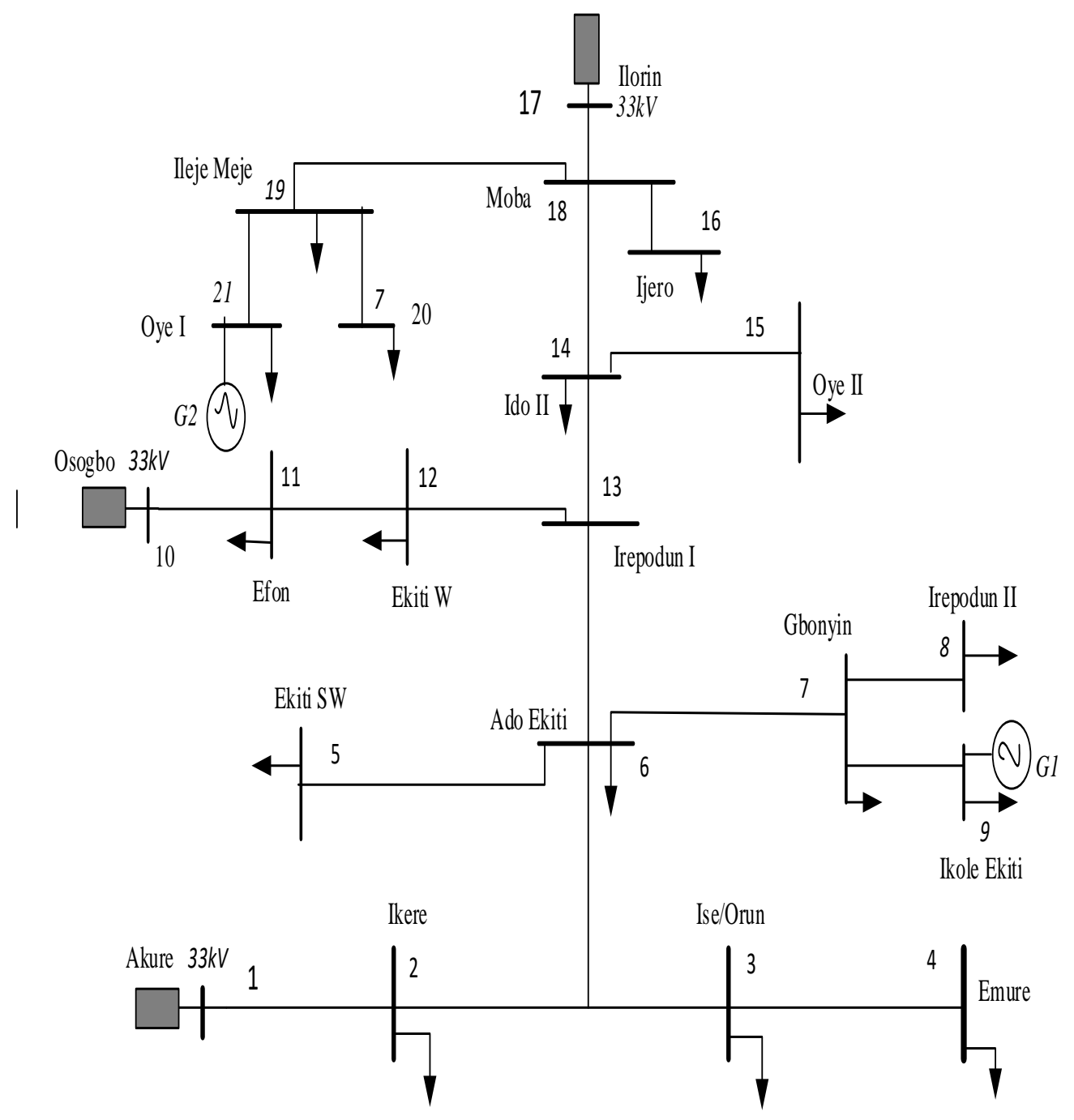

Fig 4.2 Ekiti-State $33 \mathrm{kV}$ power distribution network

The modelled network shown in Fig 4.2 is the Ekiti State $33 \mathrm{kV}$ grid which is an integral part of the existing Nigerian $330 \mathrm{kV}$ power system [9]. The network is fed from three (3) feeders namely, Akure, Osogbo, and Ilorin. The network data for the analysis was obtained partly from [152], [154] and partly by Power Holding Company of Nigeria and the rest by oral interviews with power systems specialists. The power injection to the state is presented in Table 4.1, and the network parameter is shown in 
Table 4.2. In Nigeria, the limits for the distribution voltage ( $11 \mathrm{kV}$ and $33 \mathrm{kV})$ are $\pm 6 \%$ of nominal [155].

Table 4.1 Injector- substation

\begin{tabular}{|c|c|c|c|}
\hline Injector-S/S & MW & Line Size $\left(\mathbf{m m}^{\mathbf{2}}\right)$ & $\begin{array}{c}\text { Thermal } \\
\text { Capacity (A) }\end{array}$ \\
\hline Akure & 15.8 & 100 & 300 \\
\hline Osogbo & 12.7 & 100 & 300 \\
\hline Ilorin & 10 & 100 & 300 \\
\hline
\end{tabular}

It is the obligation of the DNOs to ensure that the voltage limits are not violated. According to [17], [152], only about $40 \%$ of Nigeria population is connected to the power grid, and the remaining $60 \%$ are denied the benefits of reliable and quality electricity supply. According to [17], the estimated power demand for Ekiti-state is 224MW with less than forty per cent (40\%) connected to the grid. 
Table 4.2 Distribution network parameter

\begin{tabular}{|c|c|c|c|c|c|c|c|c|c|}
\hline $\begin{array}{l}\text { Bus } \\
\text { No }\end{array}$ & Bus i & Bus j & $\begin{array}{l}\text { Conductor } \\
\text { size }\end{array}$ & Lij(km) & Ro(ohm) & Xo(ohm) & Rij(ohm) & Xij(ohm) & Imax \\
\hline 1 & Ilorin & Moba & 100 & 11 & 0.233 & 0.4 & 2.56 & 4.40 & 300 \\
\hline 2 & Moba & ilejemeje & 70 & 14.4 & 0.266 & 0.4 & 3.83 & 5.76 & 255 \\
\hline 3 & Ilejemeje & Oye (1) & 100 & 18 & 0.233 & 0.4 & 4.19 & 7.20 & 300 \\
\hline 4 & Ilejemeje & Ido (1) & 70 & 13.5 & 0.266 & 0.4 & 3.59 & 5.40 & 255 \\
\hline 5 & Moba & Ido (2) & 100 & 10 & 0.233 & 0.4 & 2.33 & 4.00 & 300 \\
\hline 6 & Moba & Ijero & 100 & 12 & 0.233 & 0.4 & 2.80 & 4.80 & 300 \\
\hline 7 & Ido (2) & Oye (2) & 100 & 5.5 & 0.233 & 0.4 & 1.28 & 2.20 & 300 \\
\hline 8 & Ido (2) & $\begin{array}{l}\text { Irepodun } \\
\text { (1) }\end{array}$ & 100 & 15 & 0.233 & 0.4 & 3.50 & 6.00 & 300 \\
\hline 9 & $\begin{array}{l}\text { Irepodun } \\
\text { (1) }\end{array}$ & Ado & 100 & 10 & 0.233 & 0.4 & 2.33 & 4.00 & 300 \\
\hline 10 & Ado & Ekiti SW & 100 & 12.5 & 0.233 & 0.4 & 2.91 & 5.0 & 300 \\
\hline 11 & Ado & Gbonyin & 100 & 20.1 & 0.233 & 0.4 & 4.68 & 8.04 & 300 \\
\hline 12 & Gbonyin & Ikole & 70 & 34.5 & 0.266 & 0.4 & 9.18 & 13.8 & 255 \\
\hline 13 & Gbonyin & $\begin{array}{l}\text { Irepodun } \\
\text { (2) }\end{array}$ & 70 & 17.5 & 0.266 & 0.4 & 4.66 & 7.00 & 255 \\
\hline 14 & Osogbo & Efon & 100 & 30 & 0.233 & 0.4 & 6.99 & 12.00 & 300 \\
\hline 15 & Efon & Ekiti west & 100 & 13.5 & 0.233 & 0.4 & 3.15 & 5.40 & 300 \\
\hline 16 & Ekiti-West & Irepodun & 100 & 6.5 & 0.233 & 1.51 & 1.51 & 2.60 & 300 \\
\hline 17 & Akure & Ikere & 100 & 22.5 & 0.233 & 0.4 & 5.24 & 9.00 & 300 \\
\hline 18 & Ikere & Ise/orun & 100 & 12.1 & 0.233 & 0.4 & 2.82 & 4.84 & 300 \\
\hline 19 & Ise/Orun & Emure & 100 & 12.1 & 0.233 & 0.4 & 2.82 & 4.84 & 300 \\
\hline 20 & Ikere & Ado & 100 & 13.5 & 0.233 & 0.4 & 3.15 & 5.40 & 300 \\
\hline
\end{tabular}




\subsection{CASE STUdies}

In this research work, four case studies were defined.

- Case study-1 (base-case) represents the existing Ekiti-State 33kV grid (2017).

- Case study-2 represent the grid network in 2020, 2025 and 2030.

- Case study-3 assessed the impact of cloud shading on the solar PV and

- Case study-4 evaluate the network losses on the $33 \mathrm{kV}$ distribution systems.

The simulations are carried out in Neplan software environment, a power system analysis tool developed by BCP Switzerland. The proposed location of PV generations is illustrated in Fig 4.2. This research used two PV generations, G1 and G2, 5MW capacity each, and located at Ikole-Ekiti (9) and Oye-Ekiti (21) respectively. PV generators are located at weakest parts of the circuit towards the end of the feeder in order to assess the worst-case scenario. The time series load was connected at node 9.

\subsubsection{Solar photovoltaic system}

The Solar PV is the most readily available technology for development in Nigeria. The mean annual average radiation varies from about $3.5 \mathrm{kWhm}^{-2} \mathrm{days}^{-1}$ in the coastal latitudes to about $7 \mathrm{kWhm}^{-2}$ days $^{-1}$ along with the semi-arid areas in the far north [73], [81]. In Nigeria, solar radiation is fairly well distributed, the minimum average is approximately $3.55 \mathrm{kWhm}^{-2} \mathrm{day}^{-1}$. Solar generation can generate approximately $3.8 \mathrm{x}$ $10^{23} \mathrm{~kW}$, an equivalent of 1,082 million tonnes of oil (Mtoe) worth of energy in a day; this is about 4,000 times the crude oil production and 13,000 times production per day as at 2009. In this study, solar PV was chosen because of its availability and a global reduction in the cost of a solar panel. The solar PV system data used in this study is provided by the Nigeria Meteorological Department, Lagos. The same data have been processed and applied in the following articles [156]. The PV generation profile used for the simulation is as shown in Fig 4.3.

These previous work [156], [157] established that the level of global radiation reaching Nigeria can adequately support any form of a solar energy system. These works also affirmed that higher value of global solar radiation is obtained in the dry season than raining season and this applies to all regions in Nigeria. 


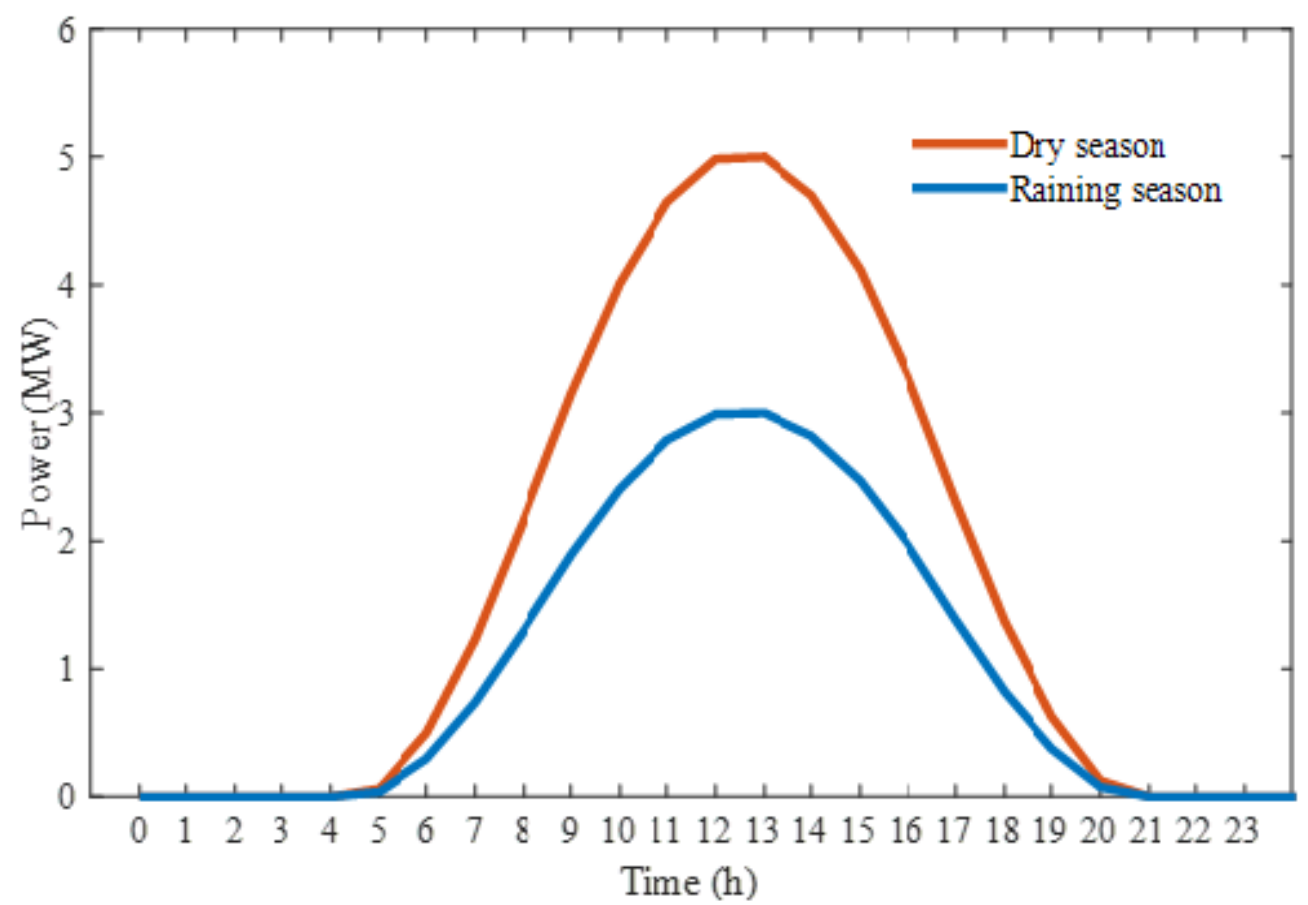

Fig 4.3 PV generation profile over 24 hours

\subsubsection{Electricity demand}

The electricity demand profile used in the modelling work is shown in Fig 4.4. As stated in section 4.6.1, typically, demand for electricity is higher in the raining season than in the dry season. The peak demands in the dry season are usually lower when compared to the low demands of the raining season and the low demands of the dry season are low when compared to the low demands of raining seasons. Demand for electricity tends also to fluctuate over the course of the day, determined by human activity. Fig 4.4 is an electricity demand for Ekiti State (Rainy season: September 05, 2017, and dry season: October 25, 2017) represented in 24 hourly load steps. This load demand is expected to increase yearly up to 2030 as shown in Fig 4.4 [158]. The main characteristics of the case studies are shown in Table 4.3. The two sets of simulations conducted on the distribution network are intended to demonstrate the benefits and future operation of the medium voltage grid with local energy systems. 

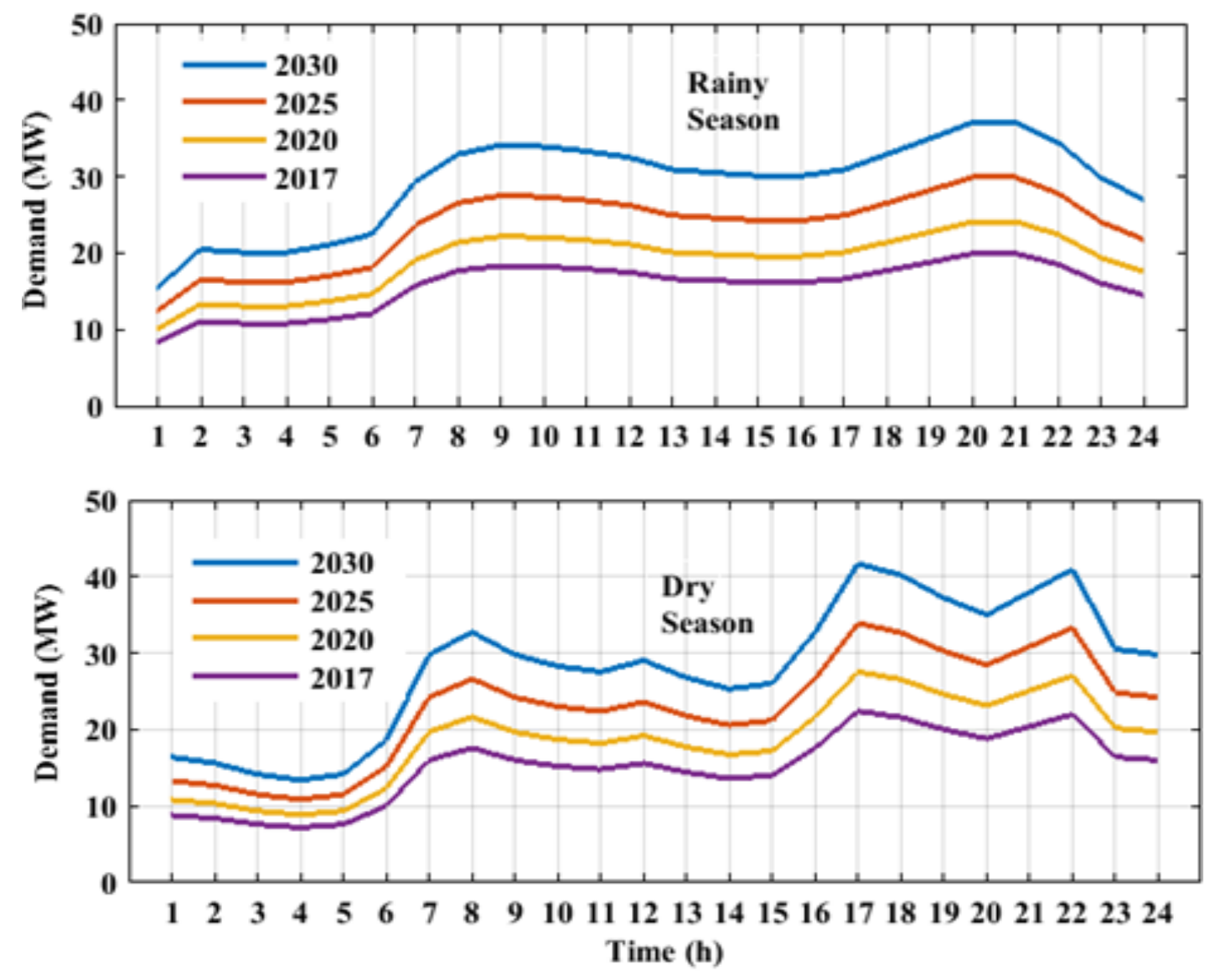

Fig 4.4 Electricity demand over 24 hours

\subsubsection{Assumption and limitations}

In this work it assumed that the PV generators are delivering its real power output at a given time. That means all the energy losses in a PV generator including wiring losses, connection losses and other losses are assumed to be zero. It is assumed that the conversion efficiency of PV generator is $1(n=1)$

Table 4.3 The main characteristics of the case studies

\begin{tabular}{|c|c|c|}
\hline Case Studies & Year & Installed PV(MW) \\
\hline Case 1 (grid / PV) & 2017 & 10 \\
\hline Case 2 (grid / PV) & 2020,2025, and 2030 & 20,30, and 40 \\
\hline
\end{tabular}




\subsubsection{Case study 1}

The base case is represented by the existing Ekiti-State $33 \mathrm{kV}$ electricity network. Electricity demand for this case is shown in Fig 4.4 which is derived from the actual data of the typical rainy and dry season days $\left(5^{\text {th }}\right.$ September and $25^{\text {th }}$ October 2016 , respectively). Load flow analyses were carried out with and without PV generation to determine the impact on the distribution network.

\subsubsection{Case study 2}

Case study-2 represents the network in the year 2020, 2025 and 2030. The electricity demand was obtained by applying an annual increase rate of $0.3 \%$, and the demand projection is shown in Fig 4.4 [158]. The network was simulated over 24 hours with and without the PV generators connected.

\subsection{RESULTS AND ANALYSIS}

Simulation results for all the case studies are presented in this section. This covers the network voltages, losses, and cloud shading.

\subsubsection{Case study 1}

Year 2017: The results of the simulation at node 9 showed that during the peak hours (7:00 to 9:00 and 20:00 to 22:00), the network voltage is low as shown in Fig 4.5. However, the lowest voltage permitted by DNO has not been exceeded. In Nigeria, the expected lower and upper voltage limits at $33 \mathrm{kV}$ are $31.02 \mathrm{kV}(0.94 \mathrm{pu})$ and $34.98 \mathrm{kV}$ $(1.06 \mathrm{pu})(+/-6 \%)$ respectively [155]. Naturally, there are no overvoltage problems in this case. In the second simulation, $10 \mathrm{MW}$ of solar PV was connected to the network. There are voltage increases during the day when the PV generation is active (between 7:00 and 19:00). For instance, it was recorded a voltage rise by $50.8 \mathrm{~V}$ and $50.9 \mathrm{~V}$ at 9:00 for the rainy season and dry season loads respectively. However, the voltage rise did not happen during the night hour when the sun has set. 


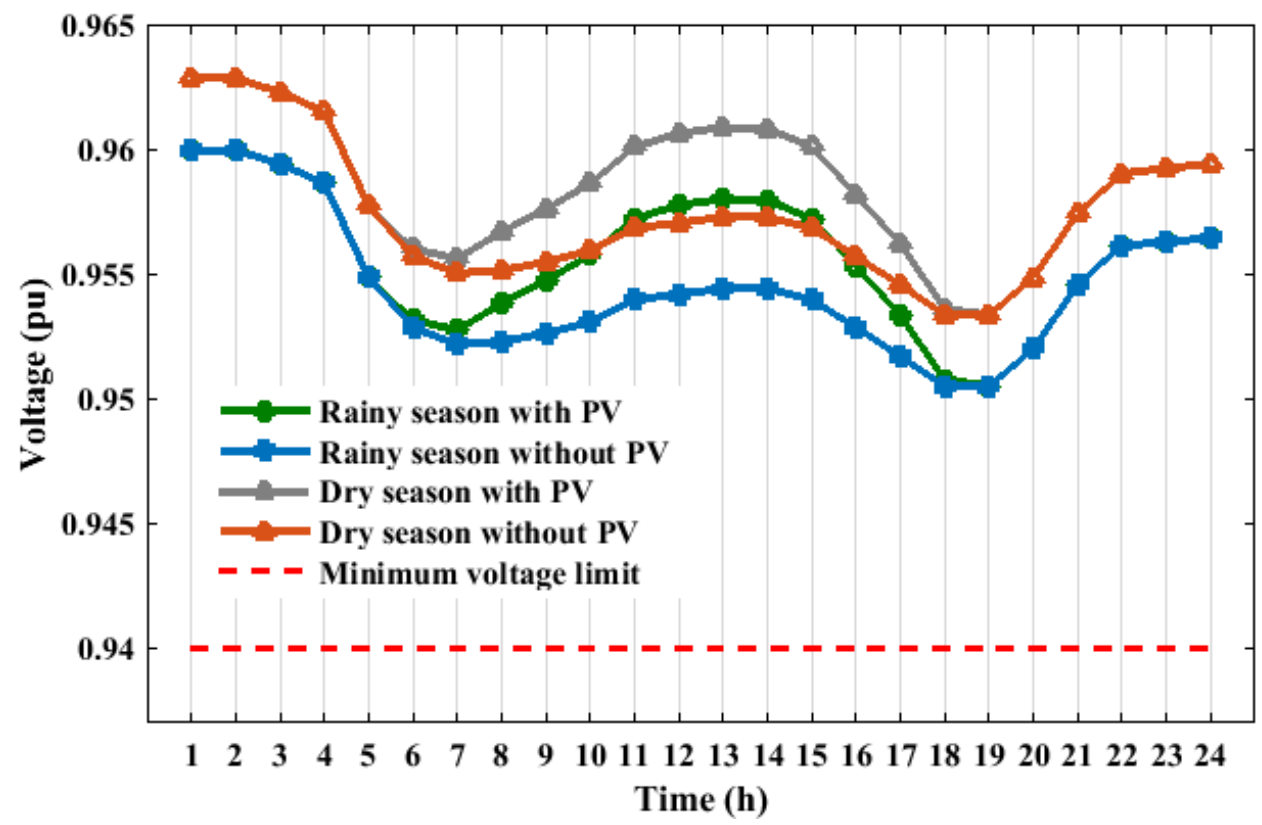

Fig 4.5 Voltage profile with and without PV generation at node 9 (year 2017)

\subsubsection{Case study- 2}

Year 2020: The results of one day simulation in hourly step is shown in Fig 4.6. Without PV generation, the voltage in the $33 \mathrm{kV}$ network does not have any under voltage or overvoltage value, but very close to DNO permissible under-voltage limit.

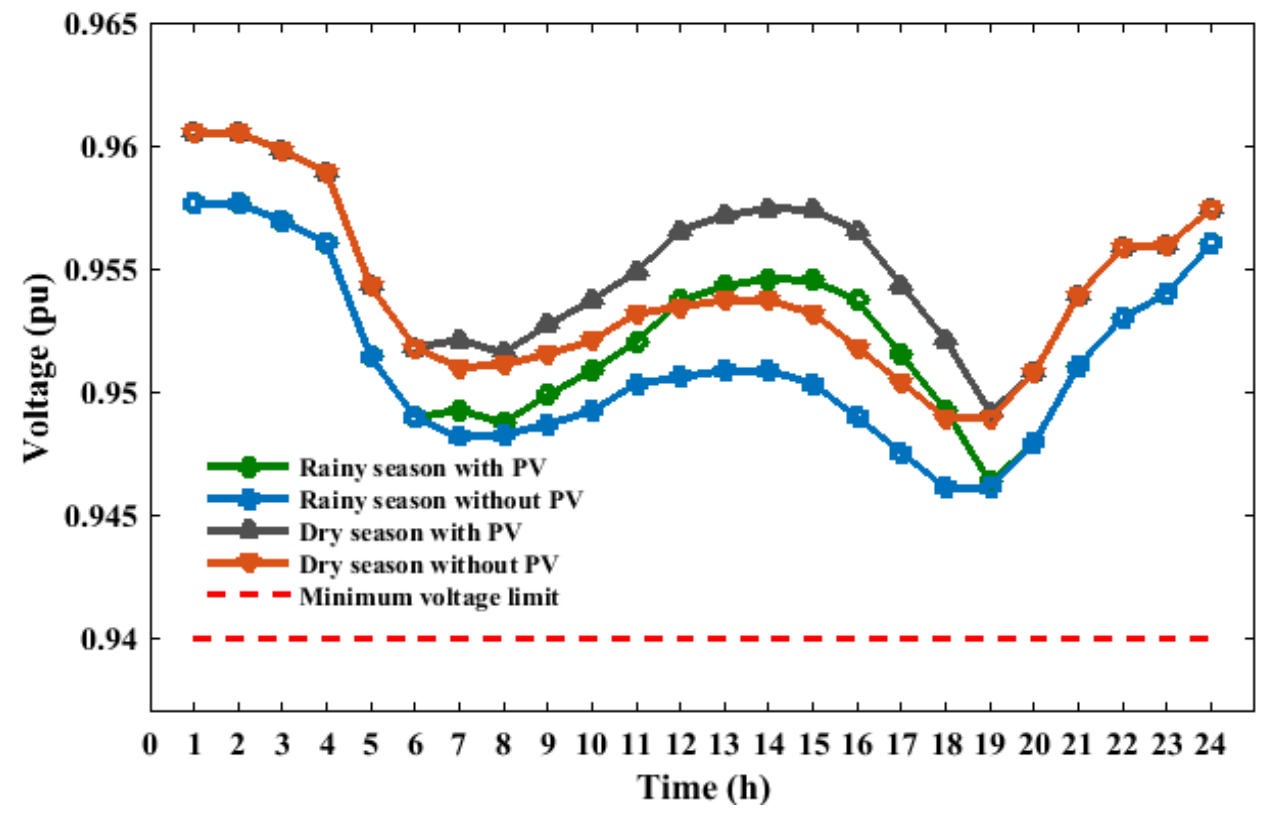

Fig 4.6 voltage profile with and without PV at node 9 (year 2020) 
When 20MW PV generator was connected to the network, the voltage increases by about $117 \mathrm{~V}$ at $13: 00$. Also, there is significant increase in voltage during both dry season and raining season peak demand without any overvoltage despite having PV connected to the network.

Year 2025: The electricity demand was increased further as shown in Fig 4.7. With 30MW PV connected in the network the voltage rose by $128.9 \mathrm{~V}$ at 13.00 during the dry season day and by $126.5 \mathrm{~V}$ in the raining season day.

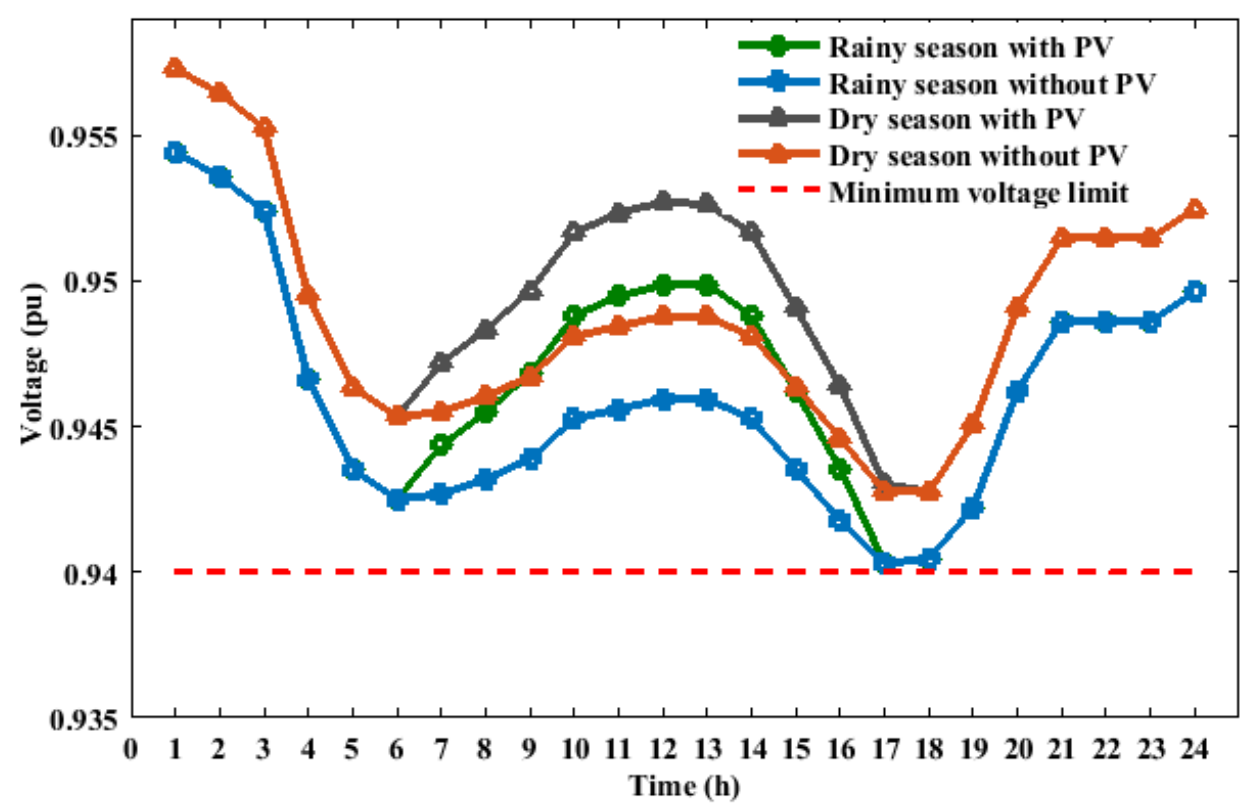

Fig 4.7 Voltage profile with and without PV at node 9 (year 2025)

Also, it was not recorded any overvoltage or under voltage in the network, but the voltage during the raining season evening peak demand is almost out of permissible limit at 20:00. This is an indication that further increase in demand will drop the voltage outside the acceptable limit.

Year 2030: The simulation results showed that without PV generation, the network voltage during the afternoon peak load was on the verge of crossing the minimum voltage limit line in the raining season day. 


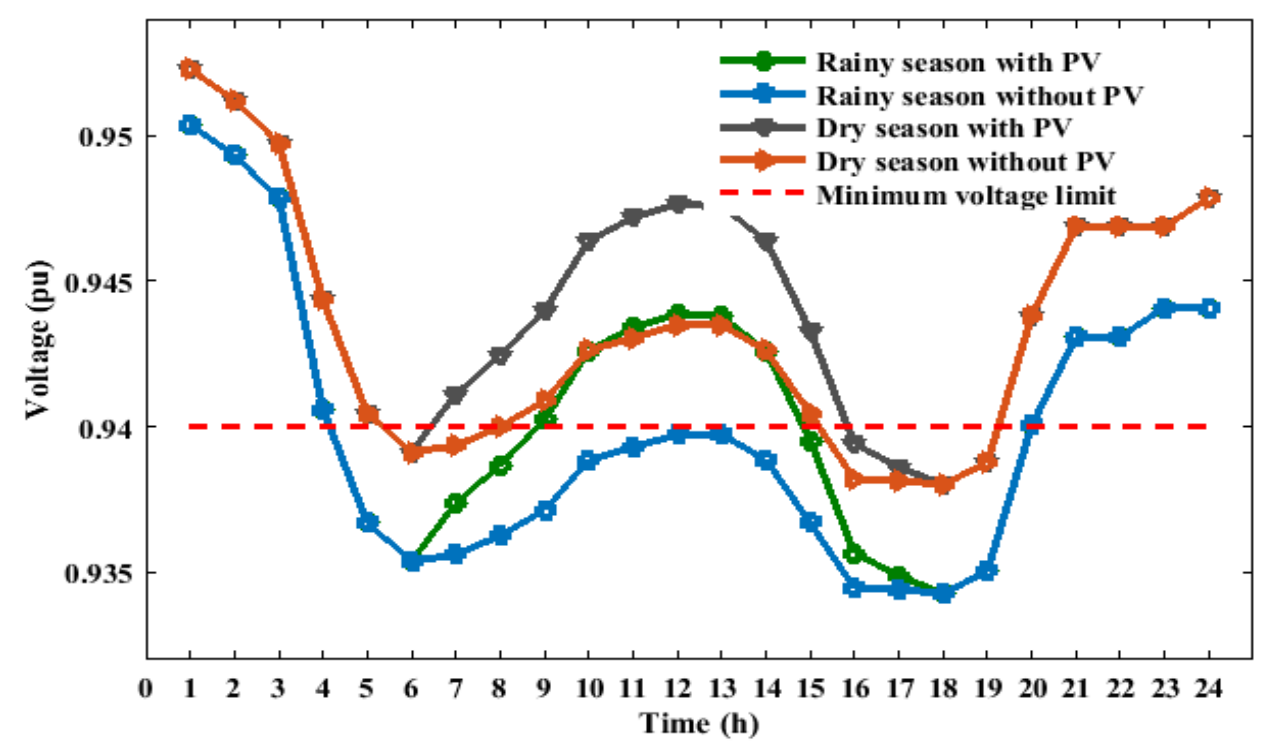

Fig 4.8 Voltage profile with and without PV at node 9 (year 2030)

There was a significant reduction in the voltage at the connection node throughout the 24 hours period due to the size of the connected load. At 19:00 the voltage has fallen to $30.82 \mathrm{kV}(0.934 \mathrm{pu})$ in the raining season and $30.95 \mathrm{kV}(0.938 \mathrm{pu})$ in the dry season. The voltage value is outside the DNO permissible lower voltage limit during the rainy season due to the high load demand.

When a 40MW of PV generation was connected to the network, the voltage rose by $135 \mathrm{~V}$ at $13: 00$ on the dry season day. Also, the voltage rose by $134.4 \mathrm{~V}$ at $13: 00$ in the raining day. The highest voltage recorded at $15: 00$ is $31.2 \mathrm{kV}(0.944 \mathrm{pu})$ and is within the permissible DNO lower voltage.

As shown in Fig 4.8, the voltage during raining season suffered severe undervoltage problems in the early hours of the day (5:00 to 8:00) and evening (16:00 to 19:00) despite PV generation. This under-voltage is due to the intermittency of PV generation output during these hours.

\subsubsection{Case study-3}

Cloud shading can have a significant impact on the performance of solar photovoltaic systems. If a small portion of the solar photovoltaic panel is shaded, the performance of the whole solar photovoltaic panel will significantly reduce [159]. This is because solar photovoltaic panel consists of many solar photovoltaic cells that are wired together into a series circuit. When a single cell is affected, it affects the power output 
of the photovoltaic panel. Therefore, a little shading can significantly reduce the performance of the entire solar photovoltaic system.

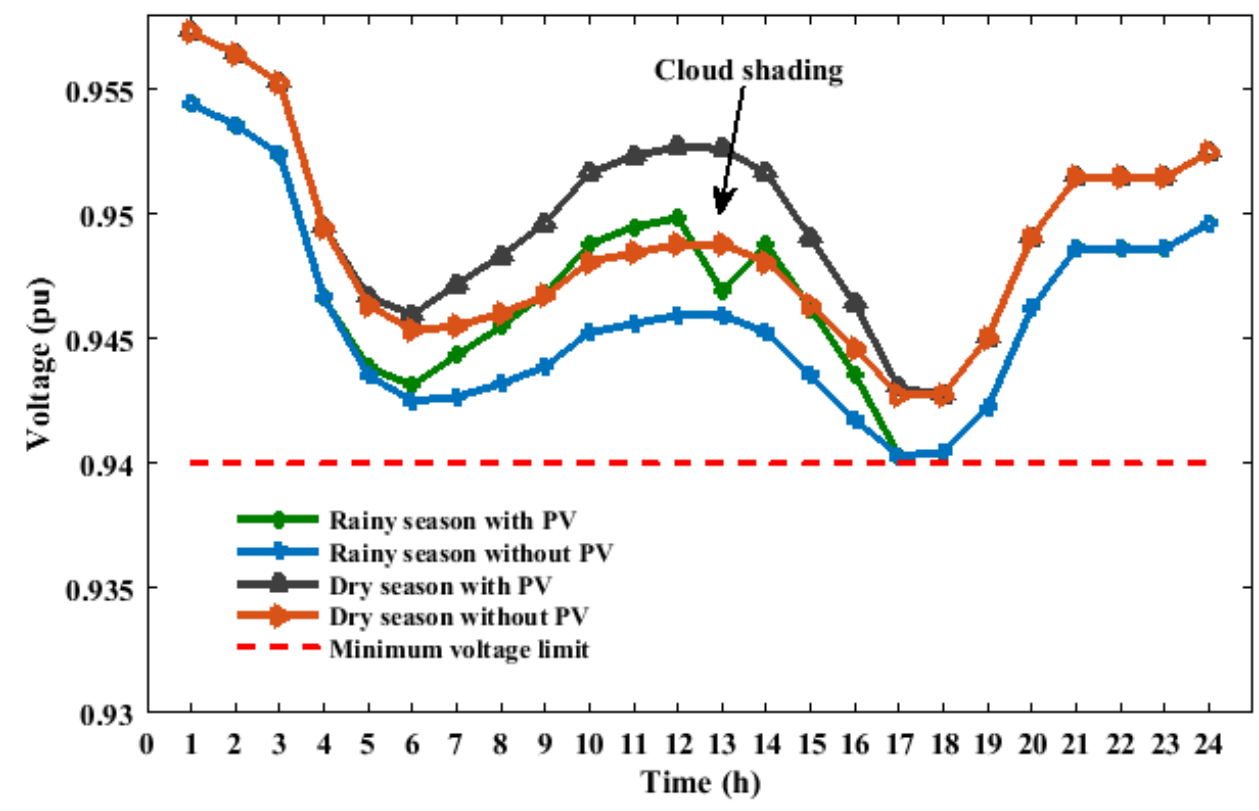

Fig 4.9 Voltage profile at node 9 with cloud shading

In this section, the impact of cloud shading is analysed. Cloud shading is a common phenomenon during the raining season and the effect on PV generation cannot be overemphasised. At 13:00 of the simulated day, cloud shading is assumed to take place. The cloud shading is modelled by decreasing the irradiation power of 13:00 to $75 \%$ of the maximum value as used in [160]. As shown in Fig 4.9, irradiations drop from $100 \%$ to $25 \%$. This condition is extremely rare and can only be caused by very dark rain clouds or shading with trees or objects. During normal cloud shading, the rest of the irradiation is higher than $25 \%$. The resulting voltage drop of $0.75 \mathrm{~V}$ as can be seen in Fig 4.10 from 13:00 to 14:00. Despite the cloud shading the voltage obtained with PV integration is still within the acceptable voltage limit.

\subsubsection{Case study 4}

The network losses in the test network are presented in Fig 4.10. In all case studies, the added PV generation causes the total network losses to decrease significantly. The loss reduction increased as more PV generation are added to the network. 


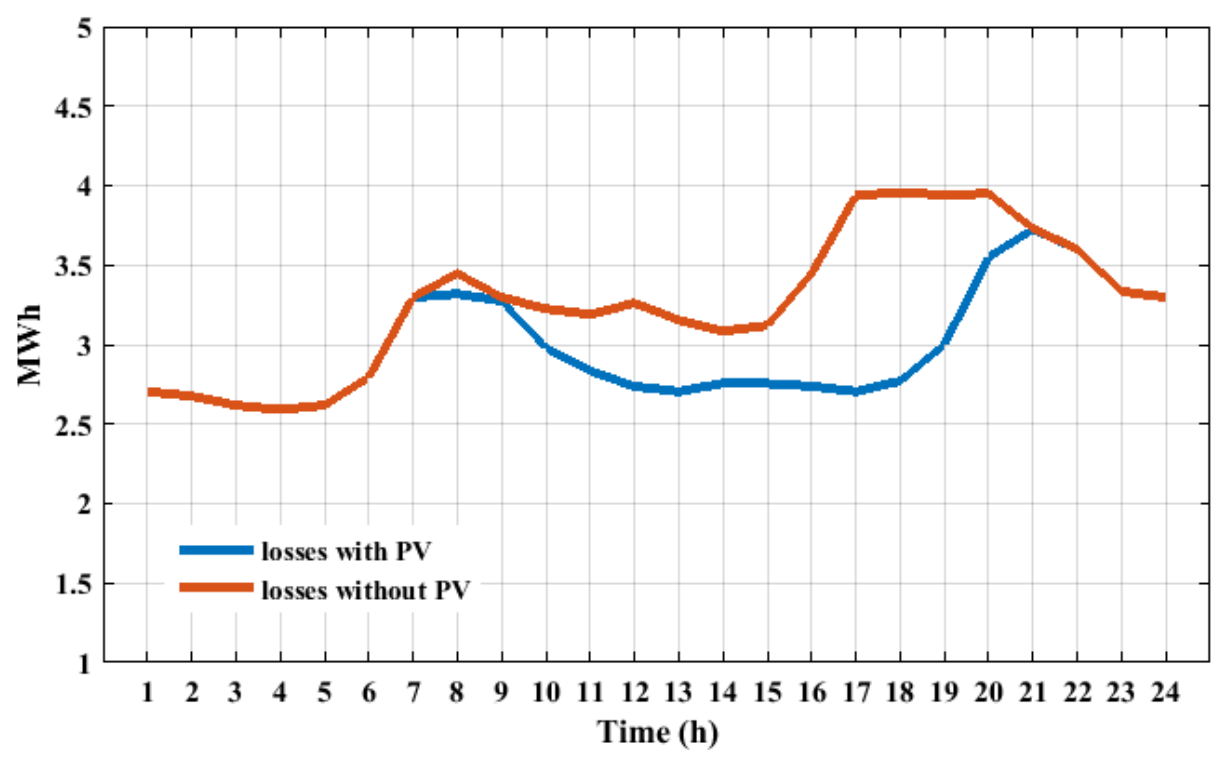

Fig 4.10 Network losses over 24 hours at node 9

The results showed that in 2017, 10MW PV generation will lead to losses reduction of approximately $3.73 \mathrm{MWh}$ over 24 hours. Whereas, in 2030, the network losses reduced by $10.03 \mathrm{MWh}$. For each of the cases studied, the losses are greater in the raining season than in the dry season due to the increased residential demand in the raining season. The summary of the results is shown in Table 4.4.

Table 4.4 Summary of the results

\begin{tabular}{|c|c|c|c|c|}
\hline & $\mathbf{2 0 1 7}$ & $\mathbf{2 0 2 0}$ & $\mathbf{2 0 2 5}$ & $\mathbf{2 0 3 0}$ \\
\hline $\begin{array}{c}\text { Voltage } \\
\text { Improvement } \\
\text { (Raining season) }\end{array}$ & $50.9 \mathrm{~V}$ & $117 \mathrm{~V}$ & $128 \mathrm{~V}$ & $135 \mathrm{~V}$ \\
\hline $\begin{array}{c}\text { Loss Reduction } \\
(\%)\end{array}$ & 7.97 & 13.4 & 18.39 & 19.26 \\
\hline $\begin{array}{c}\text { Annual Savings on } \\
\text { Loss Reduction } \\
\text { (US\$) }\end{array}$ & 203,308 & 330,318 & 463,308 & 545,096 \\
\hline
\end{tabular}

\subsubsection{Electrical storage system (ESS)}

As shown in Fig 4.11, overall electricity demand is very high in the evening and also in the morning for the customer's load. PV is unable to provide enough electricity 
during the peak demand hours (7:00 to 12:00, and 19:00 to 23:00), whereas, there is excess electricity during off-peak hours, between $12 \mathrm{pm}$ and $6 \mathrm{pm}$.

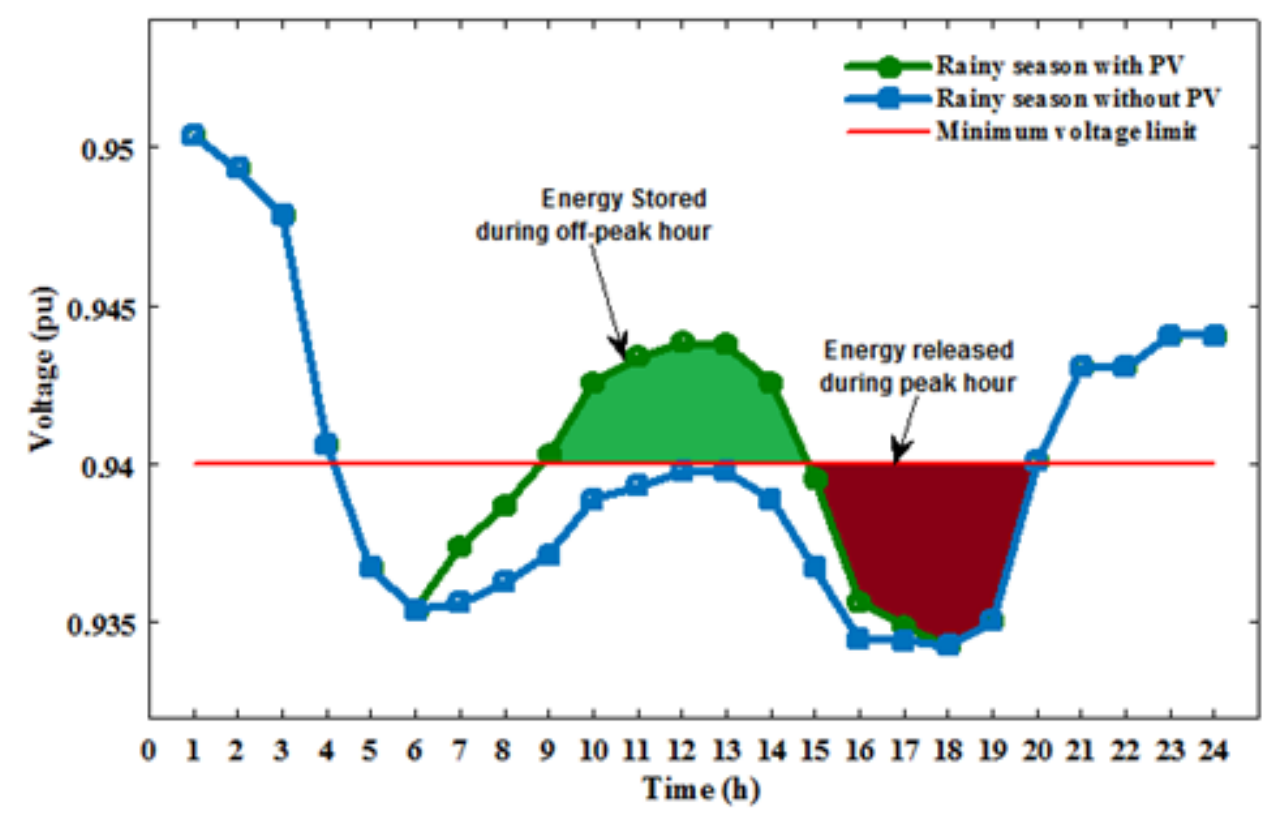

Fig 4.11 Voltage profile with and without PV generation at node 9 (year 2030)

Therefore, it can be said that PV is unable to generate electricity by following the load demand which is a major challenge in energy management. In this case study, the resident needs to purchase costly electricity during peak hours in the morning and the evening.

The electrical storage system can perform the critical role of proper energy management during the peak and off-peak hours. The excess electricity is stored in the battery storage system but later released to the distribution network during the peak demand hours. The storage system is used to overcome the intermittency of PV generation and improve power quality. However, the adoption of storage with the PV system will incur additional cost to the system, but the benefits of adding storage are significant.

PV system must be properly sized to meet the load requirements. Otherwise, energy from the PV is wasted and cannot be stored. This situation occurs when the battery state of charge exceeds its maximum allowable value, and the solar power output exceeds load demand. The amount of wasted energy can be avoided or reduced by proper choice of battery and PV generation sizes. 


\subsection{SUMMARY DISCUSSION AND KEY FINDINGS}

This chapter presents an analysis of some of the potential benefits, opportunities and likely challenges of LES in Ekiti State distribution systems. The inability of the federal government of Nigeria to provide sufficient funds to install additional generating capacity to the existing conventional generators and the need to meet growing electricity demand, government $\mathrm{CO} 2$ and greenhouse gas emission reduction targets has motivated the shift toward renewable generation sources. The knowledge obtained by studying LES in the UK network in chapter three of this thesis with respect to network voltage was transferred to the Nigeria power system. The aim is to assess the benefits of the proposed LES on Nigerian power networks. Ekiti State $33 \mathrm{kV}$ distribution system was particularly chosen because of the importance to the socioeconomic development of Nigeria. Recently, both private and public universities were established in the state to train manpower in all facets of the economy. Thereby increasing the demand for electricity in the state. Solar PV is used in this study due to its availability, climate-friendly attributes and is one of the most promising renewable energy sources in Nigeria.

In this chapter, the model of Ekiti state distribution system was developed in Neplan software, with the data obtained from both the utility companies and local and international journal. The simulation of different case studies was carried out. The results show that integration of 40MW of LES in the modelled distribution systems is able to improve the condition of the network in terms of voltage profile and network losses. As 40MW PV generator connected in the distribution system, the network voltage increased by $50.9 \mathrm{~V}$ in the year 2017 and by $135 \mathrm{~V}$ in the year 2030. Likewise, the losses reduced by $7.97 \%$ in the year 2017 and $19.26 \%$ in the year 2030 .

However, at higher penetration of LES, the voltage rise is the major challenge. This voltage rise would affect standard operating limits and could damage network equipment. In this study, the connection of 40MW PV generation produces a voltage that is within the permissible voltage limit. This is driven by the high load demand. The impact of PV is highly location dependent, and in this case study, the PV generation was connected at the distribution level and to the weak section of the network to avoid unnecessary voltage increase. 
Power output from PV generation is largely dependent on the solar irradiance level which is a fluctuating resource and hence cannot be easily controlled, and this could limit the penetration of LES in the system. The problem of PV intermittency can be addressed with storage technology as suggested in this study or through demand response. The study analyses the use of energy storage as backup energy during peak demand and during the rainy season when solar irradiation is low to provide reliable electricity supply to the utility's customers.

The simulation is carried out with real data provided partly by PHCN and partly by personal interviews of power professionals, and other sources both local and internationals. The simulation results provide information on the bus voltages, lines power flow and losses. Also, the results reveal the weak and vulnerable sections of the distribution network that determine the location of the PV generation. Since this is the first comprehensive study on this medium voltage network, the results obtained from the load flow study will provide valuable information to other researchers in their work and assist the Power Holding Company of Nigeria in network planning and maintenance.

Now a study of increasing penetrations of LES in a constrained power grid in a developing country like Nigeria will be presented in Chapter 5 because the impact is now fully understood. Furthermore, the opportunity for energy storage will be investigated to counterbalance against variability in frequency and voltage issues. 


\section{CHAPTER 5}

\section{A STUDY OF INCREASED PENETRATION OF LOCALISED ENERGY SYSTEM IMPACTS IN NIGERIA AND ENERGY STORAGE OPPORTUNITIES}

\subsection{BACKGROUND}

The electric power demand by consumers varies continually, and it is necessary that the power generated be varied to achieve generation - load demand balance [161]. Synchronous generators store kinetic energy in their rotors. The kinetic energy stored varies with their speed of rotation. The amount of energy stored in each machine is proportional to its rotating inertia. But solar PV is a non-synchronous generator and does not store kinetic energy. Therefore, replacing conventional sources with PV generation will reduce system inertia which increases the magnitude of frequency excursions [162]. For an inverter-based solar generation, the solid-state controls have no rotating components. Hence, frequency regulation after a large disturbance becomes a major challenge in a power system with high PV penetration. High penetration of renewable energy sources can affect the dynamic behaviour of the power system in a way that might be different from the conventional generators [163], [164]. Whether a traditional system or a system with renewable sources, maintaining the frequency within specified limits is a requirement of any grid, to assure stable and safe operation [165]. The renewable energy sources decrease dependence on fossil fuel, increase the reliability of the power system and improve voltage profile. In Nigeria, thermal generation is the primary energy source. The installed thermal generation is $74 \%$ of the total generation capacity and the remaining $26 \%$ is hydro generation. Thus, both the thermal and hydro generations can participate in frequency regulation. 


\section{Energy Storage Opportunities}

The federal government in conjunction with the ministry of power have set a target of $30 \%$ renewables generation installation mostly, solar PV by 2030 [166]. In order to meet this renewable generation target, the power industry is considering using solar PV resources. However, high PV penetration in the power system may increase uncertainties during abnormal operation and introduce several technical implications. According to [88], increased PV integration may lead to severe frequency deviations which can affect relay operation thereby disconnect generations and loads leading to system collapse.

Nigeria has a generating capacity of $12,000 \mathrm{MW}$ but the available capacity is far lower as the grid constantly suffers partial or complete collapse; as of June 2017, there has been a total of 213 collapses in the last nine years with twelve total collapses and two partial collapses in 2017 alone [167]. Notable among the collapses is the case of Egbin generating station. According to the Transmission Company of Nigeria (TCN), a total system collapse of the national electricity grid was recorded on September 28, 2017, at 8:03 pm resulting in temporary loss of electricity for the nation's power grid. The sequence of events generated by the SCADA system indicated that the system collapse was triggered by the tripping of Egbin Units ST4, ST6 and ST5 (The Egbin Thermal Power Plant is a gas-fired plant with six 220MW independent boiler turbine units (ST1, ST2, ST3, ST4, ST5 and ST6) [168]. The analysis of the issue indicated that the grid generation was curtailed to about 4,262.7MW before the disturbance. The capacity underutilisation and operational capability required to maintain grid stability, which had worsened, made the grid system vulnerable. The vulnerability and disturbance of the system resulted in a severe system dip that culminated in the system collapse.

Work had been reported in the literature to improve frequency regulation [169], [170]. One method to improve the performance of frequency regulation is the introduction of storage facilities during the peak load period [125], [169]. ESS also improves the reliability of supply during peak load periods. The importance of using ESS to perform frequency regulation due to its capacity to absorb/deliver significant amounts of power within a very short time is discussed in [171]. In [123], the advantages of using asynchronous machines in ESS to offset the network frequency variations caused by wind power fluctuations in a microgrid is highlighted. The 
importance of fast frequency response that ESS could provide in coordination with other technologies for frequency regulation is explained in [170].

In [172] a field oriented control model of an induction machine based ESS facility to provide frequency regulation and evaluates its impact when the microgrid is either connected to the network or is on the islanded operation is presented. There is no significant study carried out on the frequency regulation with regards to PV integration in the Nigeria power system. Therefore, this research study investigates the integration of LES in the Nigeria power system from a frequency regulation perspective. The research results will enable the Power Holding Company of Nigeria, power generation investors, and policymakers to make more informed grid planning decisions on PV integration. This research study is expected to answer the question: What percentage of solar PV can the power network accommodate without affecting the frequency regulation?

This chapter is organised as follows: A review of frequency response characteristics in Nigeria power network is presented. The methodology of the research with the transfer functions of the solar PV and the flywheel storage system is presented. The test system, a two-area interconnected hydro-thermal power system with the case studies and discussion of results were provided.

\subsubsection{Frequency response characteristics in the Nigerian power network}

The Power Holding Companies of Nigeria (PHCN) defines frequency ranges that customers could expect their supply to stay within [155]. The nominal frequency shall be $50 \mathrm{~Hz} \pm 0.5 \%$. Under system stress, the frequency on the power system could experience variations within the limits of $50 \mathrm{~Hz} \pm 2.5 \%$ (i.e. $48.75-51.25 \mathrm{~Hz}$ ). Under system stress or following system faults, voltages can be expected to deviate outside the limits by further $\pm 5 \%$ [4], [155], [173]. The nominal voltages are $330 \mathrm{kV}, 132 \mathrm{kV}$, $33 \mathrm{kV}, 11 \mathrm{kV}$, and $0.415 \mathrm{kV}$. Nigerian Power System requires a minimum spinning reserve that is sufficient to cover the largest credible trip (220MW) to secure its network. Fig 5.1 shows the Nigeria national grid comprises $132 \mathrm{kV}$ and $330 \mathrm{kV}$ circuits and substations. The hydro generations stations (blue coloured) are located far north at Jebba, Shiroro and Kainji while the thermal generation stations (red coloured) are located in the south of the country, generally near to the source of gas. The Nigerian 


\section{Energy Storage Opportunities}

power system is characterized by insufficient generation, incompatible governor controls and insufficient transmission lines [95]. In such a situation, the system is exposed to the risk of stress and the last resort is to introduce load shedding. Load shedding in Nigeria is done manually which is characterised by human error [94]. Load shedding, loss of generation, loss of load and transmission line trip causes frequency deviation. Therefore, adequate attention is needed if local generation must be integrated into the Nigeria power network.

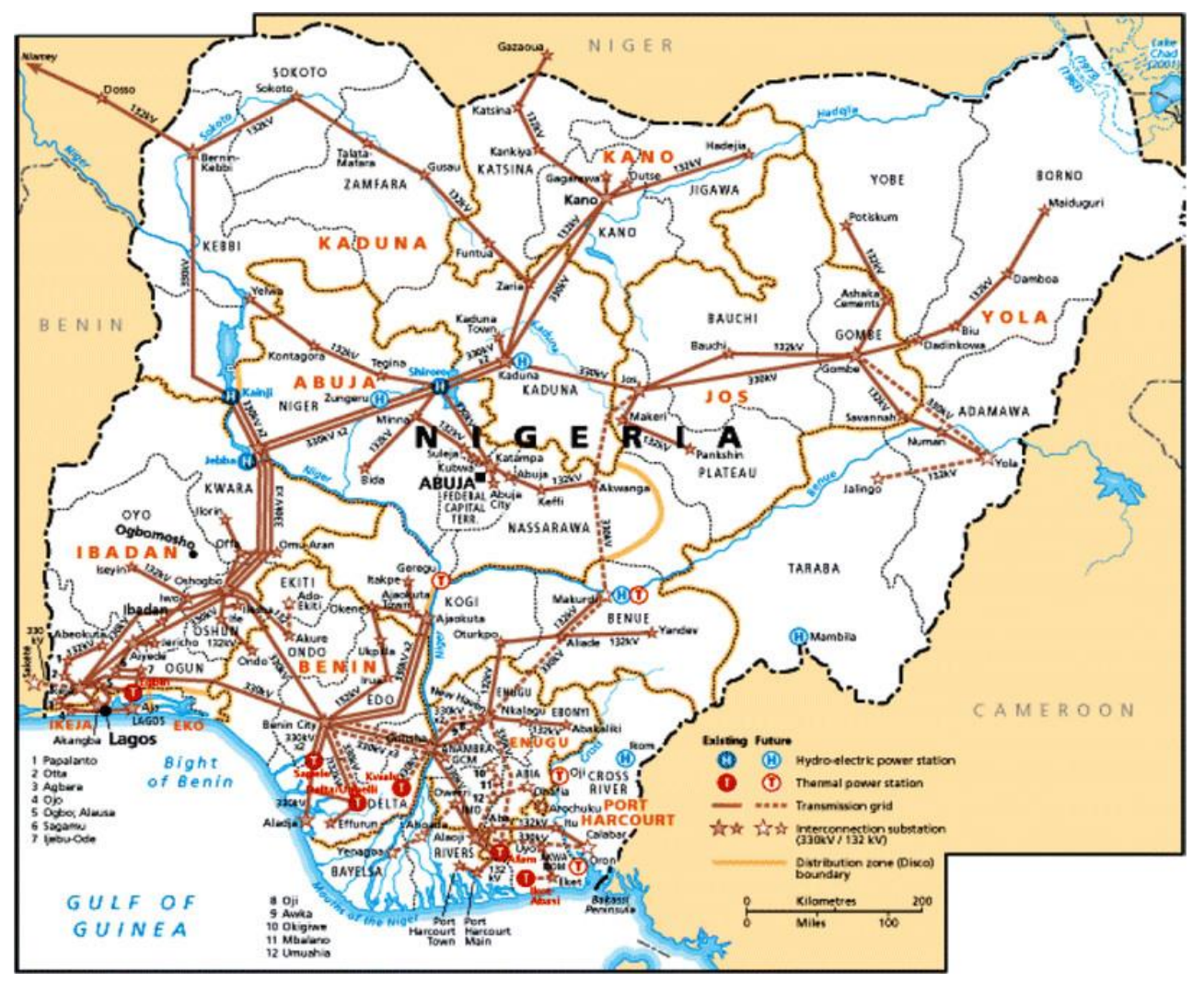

Fig 5.1 The Nigeria national grid [174]

Nigerian power sector as at December 2017 consisted of 3590MW (74\%) thermal generation and $1233 \mathrm{MW}(26 \%)$ hydro generation [166].

\subsection{Methodology}

The Nigerian two-area hydrothermal system model is developed in MATLAB Simulink environment. The two areas are assumed to be operating in parallel at the nominal frequency of $50 \mathrm{~Hz}$. Three case studies were simulated. The first simulation considered the existing power system without PV generation following the disturbance applied at $\mathrm{t}=10 \mathrm{~s}$ (generation loss of $220 \mathrm{MW}$ ). The second simulation investigated the 
behaviour of the network model with PV systems connected in increasing penetration. The third simulations study the effect of FESS on frequency regulation with PV systems.

\subsubsection{Transfer functions of $P V$ and energy storage systems}

PV Systems: PV arrays convert sunlight to DC power, and a power conditioning unit converts the DC power to AC power. The voltage and current relationship are nonlinear in nature. The maximum power output of the PV array varies according to solar radiation or load current. The output power of the solar PV is given in [175] as,

$\mathrm{P}_{\mathrm{PVPG}}=\eta \mathrm{S}_{\varphi}\left[1-0.005\left(\mathrm{~T}_{\mathrm{a}}+25\right)\right]$

Where are: $\eta$-the conversion efficiency of the PV array,

$\mathrm{S}$ is the measure area of PV array $\left(\mathrm{m}^{2}\right)$,

$\Phi$ is the Solar radiation $\left(\mathrm{kW} / \mathrm{m}^{2}\right)$ and

$T_{a}$ is the ambient temperature (Celsius degree).

The transfer function of PV can be given by a simple linear first order lag function as [176],

$\mathrm{G}_{\mathrm{PV}}=\frac{\mathrm{K}_{\mathrm{PV}}}{1+\mathrm{sT}_{\mathrm{PV}}}=\frac{\Delta \mathrm{P}_{\mathrm{PVPG}}}{\Delta_{\varnothing}}$

With $\mathrm{K}_{\mathrm{PV}}$ - the gain constant and

$\mathrm{T}_{\mathrm{PV}}$ - the time constant.

According to [176], the power generation from the solar PV generation source is generally treated as negative load, the variation in overall system load is then a combination of actual load variation $\Delta P_{L}$ and solar PV generation fluctuations. The solar PV system non-linearity have not been taken into account, and the systems are simulated in a simplified form as a linear first-order transfer function [175], [176].

Flywheel energy storage (FESS): flywheel storage stores energy in the form of kinetic energy and it has the ability to stores surplus energy during off-peak periods and quickly releases energy during peak loads [177]. Other advantages of FESS are higher power density, insensitivity to environmental conditions, and no hazardous chemical. With storage capabilities of up to $500 \mathrm{MJ}$ and power range from $\mathrm{kW}$ to $\mathrm{GW}$, they performed a variety of important energy storage applications in power systems [107]. Due to its high energy efficiency, and high power and energy density, Flywheels 


\section{Energy Storage Opportunities}

compete with other storage technologies in electrical energy storage application, as well as in transportation, military services, and space satellite [178]. The transfer function of the FESS can be expressed as a first-order lag as in [179]

$\mathrm{G}_{\mathrm{FESS}(\mathrm{s})}=\frac{\mathrm{K}_{\mathrm{FESS}}}{1+\mathrm{sT}_{\mathrm{FESS}}}=\frac{\Delta \mathrm{P}_{\mathrm{FESS}}}{\Delta \mathrm{f}}$

Where $\mathrm{K}_{\mathrm{FESS}}$ is the gain,

$\Delta \mathrm{P}_{\mathrm{FESS}}$ is the power output of FESS and

$\mathrm{T}_{\mathrm{FESS}}$ is the time constant of the FESS.

It is assumed that the FESS has enough capacity to store surplus energy generated by the generating units. When the demand in the control area increases, FESS can release enough energy to the connected load within a very short time.

\subsubsection{Test system}

The test system is a Nigerian Power System represented as a two-area, hydro and thermal system connected by tie-line as shown below. The network base parameters are given in Table 5.1 and Table 5.2.

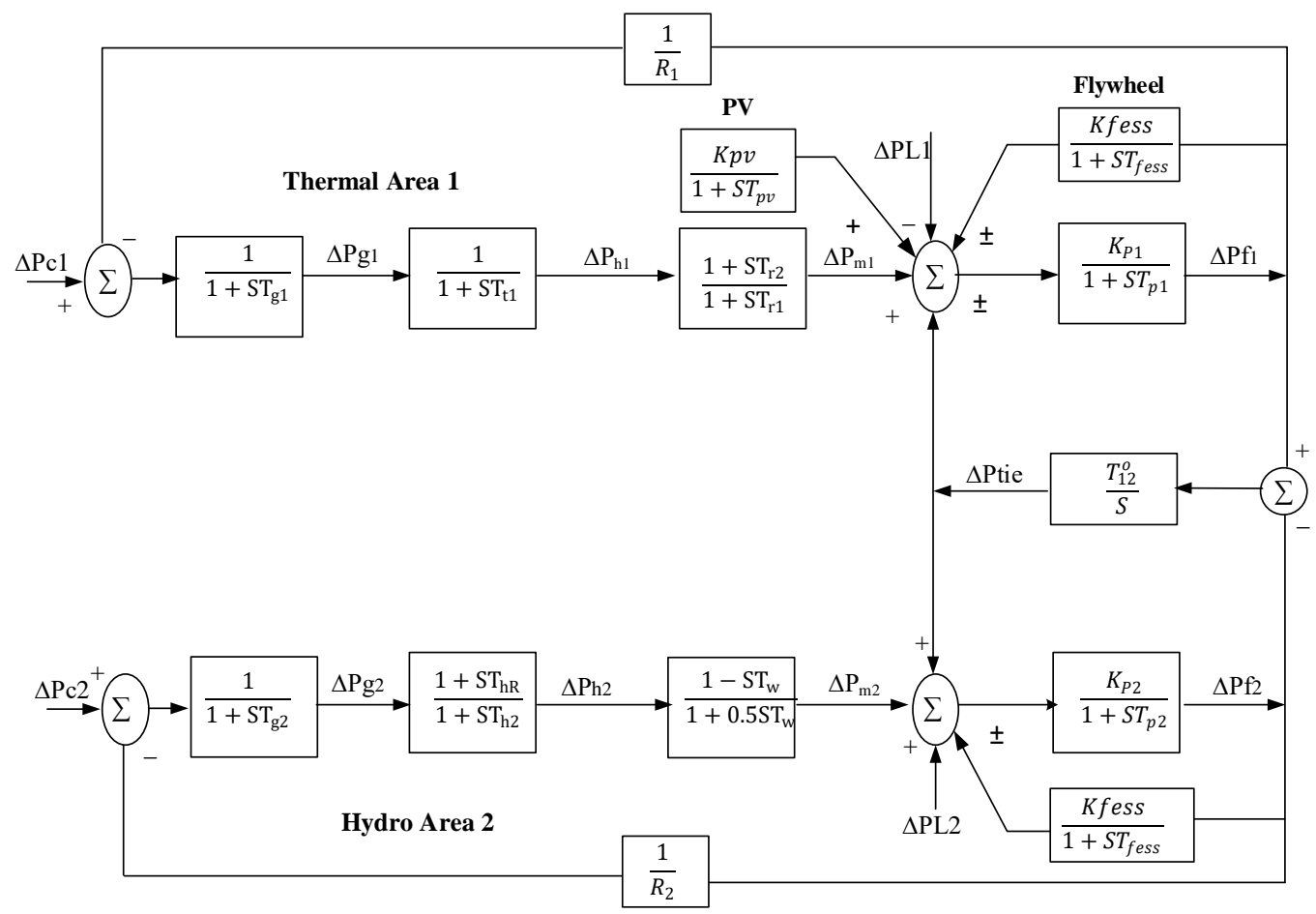

Fig 5.2 Nigerian two-area power system with localised energy system [91] 
Table 5.1 Base parameter of the system [91]

\begin{tabular}{|l|l|}
\hline Areas & Parameters - Base 3000MVA \\
\hline Thermal & $\begin{array}{l}T_{g i}=0.59 \mathrm{~s} ; \quad T_{t 1}=0.4 \mathrm{~s} ; \quad T_{r 1}=8 \mathrm{~s} ; T_{r 2}=3.2 \mathrm{~s} ; R_{1}=2.6 \mathrm{~Hz} / \mathrm{puMW} ; \\
K_{P 1}=130 \mathrm{~Hz} / \mathrm{pu} \mathrm{MW} ; H_{1}=6.5 \mathrm{~s} \& T_{t i e}=0.245 \quad B_{1}=0.425\end{array}$ \\
\hline Hydro & $\begin{array}{l}T_{g 2}=0.51 \mathrm{~s} ; T_{h R}=10 \mathrm{~s} ; T_{h 2}=50 \mathrm{~s} ; T_{w}=1.7 \mathrm{~s} ; R_{1}=2.24 \mathrm{~Hz} / \mathrm{pu} \mathrm{MW} ; \\
K_{P 2}=112 \mathrm{~Hz} / \mathrm{pu} \mathrm{MW} ; \& B_{2}=8 \mathrm{~s} ; B_{2}=0.425\end{array}$ \\
\hline
\end{tabular}

Definition of symbols used in the Table 5.1 are given below.

$i=$ Subscript referring to area $\mathrm{i}$;

$\Delta P_{c i}=$ Change in speed changer setting of area $\mathrm{i}$;

$H_{i}=$ Inertia constant of area $\mathrm{i}$;

$R_{i}=$ Aggregate speed regulation of area $\mathrm{i}$

$D_{i}=$ load frequency characteristics of area i;

$T_{g i}=$ Governor time constant of area i;

$T_{w}=$ Water time constant of hydro area;

$T_{12}=$ Synchronizing power coefficient $(\mathrm{pu})\left(\mathrm{T}_{12}{ }^{\mathrm{o}}=2 \prod \mathrm{V}_{1} \mathrm{~V}_{2} \cos \left(\delta_{1}{ }^{\mathrm{o}}-\delta_{2}{ }^{\mathrm{o}}\right) / \mathrm{X}_{12}\right)$

$T_{t 1}=$ Thermal are turbine time constant

$T_{r 1}=$ Thermal area Reheat time constants

$T_{h R}$ and $T_{h 2}=$ hydro are time constants

$\delta_{i}^{o}=$ operating voltage of area $\mathrm{i}$

$V_{i}=$ nominal voltage of area $\mathrm{i}$

$X_{12}=$ Tie - line equivalent reactance $(\mathrm{pu})$ between area $1 \& 2$ 
Table 5.2 Breakdown of peak and off-peak generation

\begin{tabular}{|l|c|c|}
\hline Station & Peak Generation (MW) & Off-peak Generation (MW) \\
\hline Thermal & 3590 & 2894.4 \\
\hline Hydro & 1233 & 680 \\
\hline Total & 4823 & 3574.4 \\
\hline
\end{tabular}

\subsection{CASE STUdies}

This section presents three cases for investigating frequency regulation in the Nigerian power systems with localised energy systems. Case study 1 represents the existing power system in 2017 without PV penetration. Case study 2 represents the grid network in the years; 2020, 2025, and 2030 with PV penetration. Case study 3 is the network in the year 2030 with FESS.

Table 5.3 Case studies description

\begin{tabular}{|l|l|l|l|l|l|}
\hline Simulation case & Case 1 & \multicolumn{3}{|c|}{ Case 2 } & Case 3 \\
\hline $\begin{array}{l}\text { Year of } \\
\text { simulation }\end{array}$ & 2017 & 2020 & 2025 & 2030 & 2030 \\
\hline $\begin{array}{l}\text { Solar PV installed } \\
(\%)\end{array}$ & - & 10 & 20 & 30 & 30 \\
\hline Storage & - & - & - & - & FESS \\
\hline
\end{tabular}

These case studies and their simulations description are shown in Table 5.3. These simulations were carried out in a MATLAB Simulink environment. A generation loss of $220 \mathrm{MW}\left(\Delta P_{G(\text { loss })}\right)$ is used for the simulation. This corresponds to the case of Egbin ST4 described in section 5.1 above. The disturbance was assumed to happen in the thermal area after 10 seconds.

\subsubsection{Assumptions and limitations}

For the sake of simulations, random variations of solar isolation have been taken into consideration. In the PV generator, all losses including connection losses, wiring losses, and other losses are assumed to be zero. It is assumed that the PV generator has a maximum power point tracker i.e. $n=1$ where $n$ is the conversion efficiency of PV 


\section{Energy Storage Opportunities}

generator. It is also assumed that FESS have enough capacity to store surplus energy generated by the generating units.

\subsubsection{Case study 1}

The first simulation considered the existing power system without PV generation. Following the disturbance applied at $\mathrm{t}=10 \mathrm{~s}$ (generation loss of $220 \mathrm{MW}$ ), the primary control loop of all generating units is expected to respond within seconds by reestablishing the balance between generation and demand to ensure that the system frequency remains at safe operation.

\subsubsection{Results for case study 1}

The results of these simulations are shown in Fig 5.3. With the generation loss of $220 \mathrm{MW}$, the frequency dropped, and the power outputs $\Delta P_{m 1}$, and $\Delta P_{m 2}$, increased providing their primary frequency response at $49.94 \mathrm{~Hz}$. This response was enough to supply the load and the frequency stop dropping. According to equation (8), the change in mechanical power in each area is given by $\Delta P_{m 1}=-\frac{\Delta F_{1}}{R_{1}}$, and $\Delta P_{m 2}=-\frac{\Delta F_{2}}{R_{2}}$. Thus, the thermal area increases the generation by $197.4 \mathrm{MW}$ and hydro area by $53 \mathrm{MW}$ at the new operating frequency of $49.988 \mathrm{~Hz}$. That is, 53MW flows from the hydro area to the thermal area.

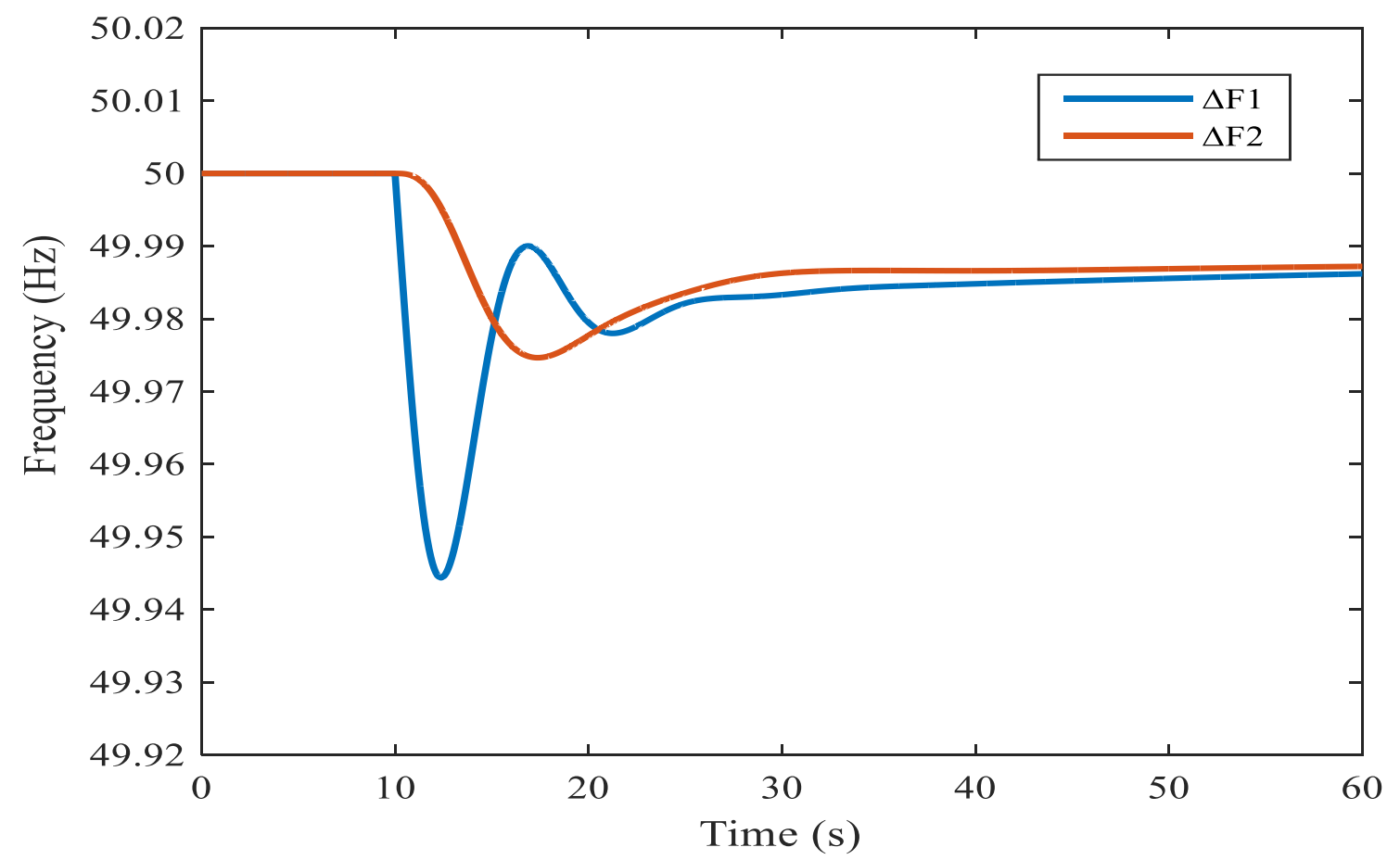

Fig 5.3 Frequency deviation step response of thermal and hydro areas 


\subsubsection{Case study2}

The second case study investigated the behaviour of the network model when the PV generator was connected. Since Solar PV does not provide inertia for frequency regulation, then the overall system inertia will be affected. This reduction in the inertia in the thermal area is computed by using the equation

$$
H_{e q}=\sum_{i}^{N} H_{i} * \frac{S_{i}}{S_{\text {area }}}
$$

as provided in [180], where $\mathrm{H}_{\mathrm{i}}$ is the equivalent inertia constant for each power plant according to fuel type, $S_{i}$ is the power rating for each power plant, $S_{\text {area }}$ is the total power rating for the current area, and $\mathrm{N}$ is the number of power plants. Table 5.4 shows the change in the equivalent inertia with PV penetration. PV generation was connected in the network to meet the increasing load supply. The load supply was assumed to increase by $2.35 \%$ annually.

Table 5.4 Change in equivalent inertia with PV penetration

\begin{tabular}{|l|l|l|l|l|}
\hline $\begin{array}{l}\text { Year of } \\
\text { Simulation }\end{array}$ & $\mathbf{2 0 1 7}$ & $\mathbf{2 0 2 0}$ & $\mathbf{2 0 2 5}$ & $\mathbf{2 0 3 0}$ \\
\hline $\begin{array}{l}\text { Equivalent } \\
\text { Inertia (Heq) }\end{array}$ & 6.5 & 5.62 & 4.74 & 3.86 \\
\hline PV installed (\%) & - & 10 & 20 & 30 \\
\hline
\end{tabular}

\subsubsection{Results for case study 2}

With the generation loss of $220 \mathrm{MW}$ at $\mathrm{t}=10 \mathrm{~s}$, the frequency deviation response in the thermal area dropped from the nominal value of $50 \mathrm{~Hz}$ as shown in Fig 5.8. This drop in frequency is due to the increase in the supply load demand and the corresponding increase in PV generation. 


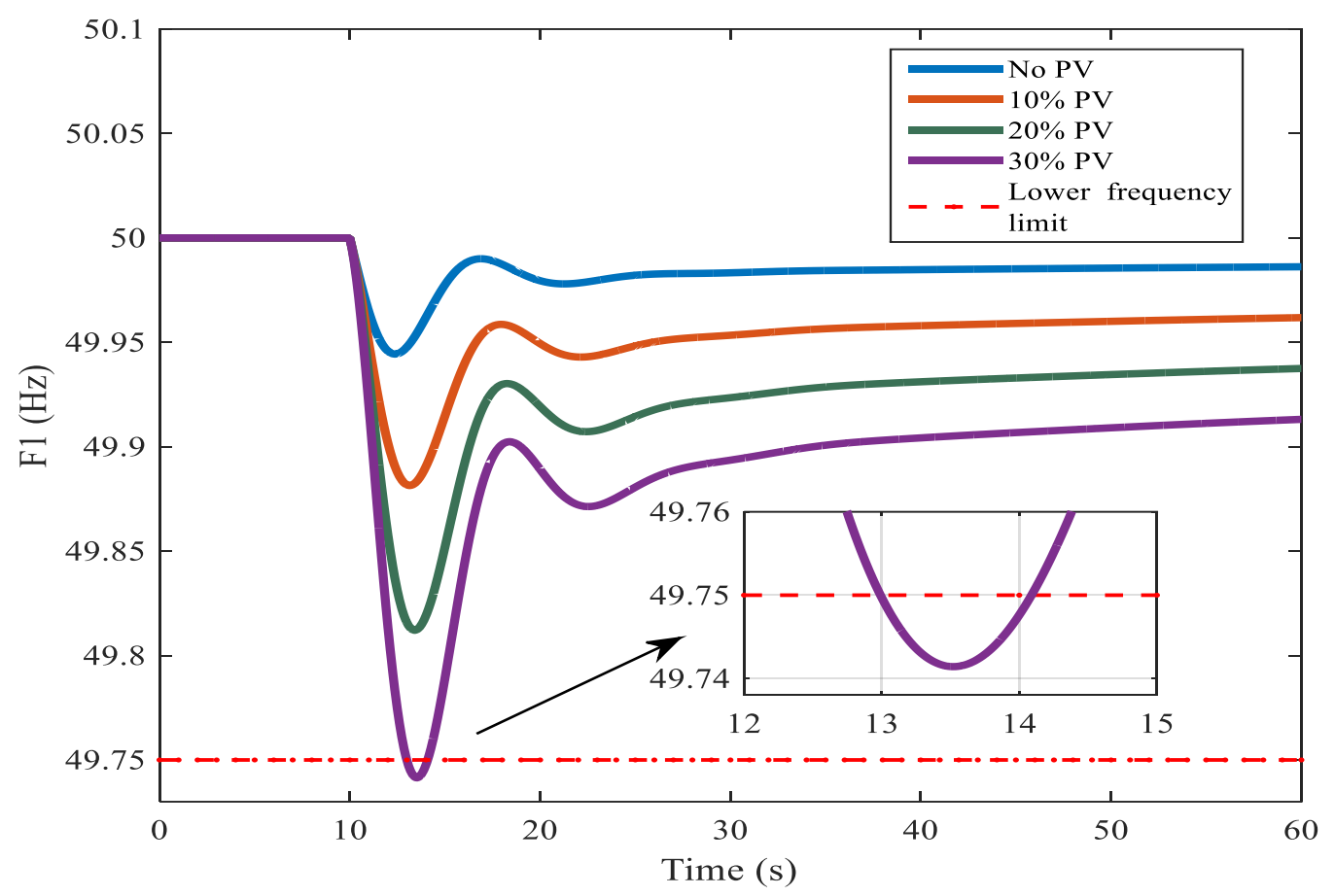

Fig 5.4 Frequency deviation step response in thermal area

The frequency drop was highest at $30 \%$ PV penetration because at this point the value of the equivalent inertia has reduced to 3.86 . That is at $30 \% \mathrm{PV}$ penetration, the new operating frequency was below the safe operating limit of $49.75 \mathrm{~Hz}$ (red dashed line in Fig 5.4.). Also, in the hydro area, the frequency response F2, dropped from nominal value but this time, the value falls within safe operating limit of the power system. The summary of the operating frequency in the thermal area with different level of PV penetration is presented in Table 5.5

Therefore, in order to avoid the adverse effect of severe frequency deviation, a suitable control strategy must be applied to assist in load-generation balance to maintain frequency at safe operation. 


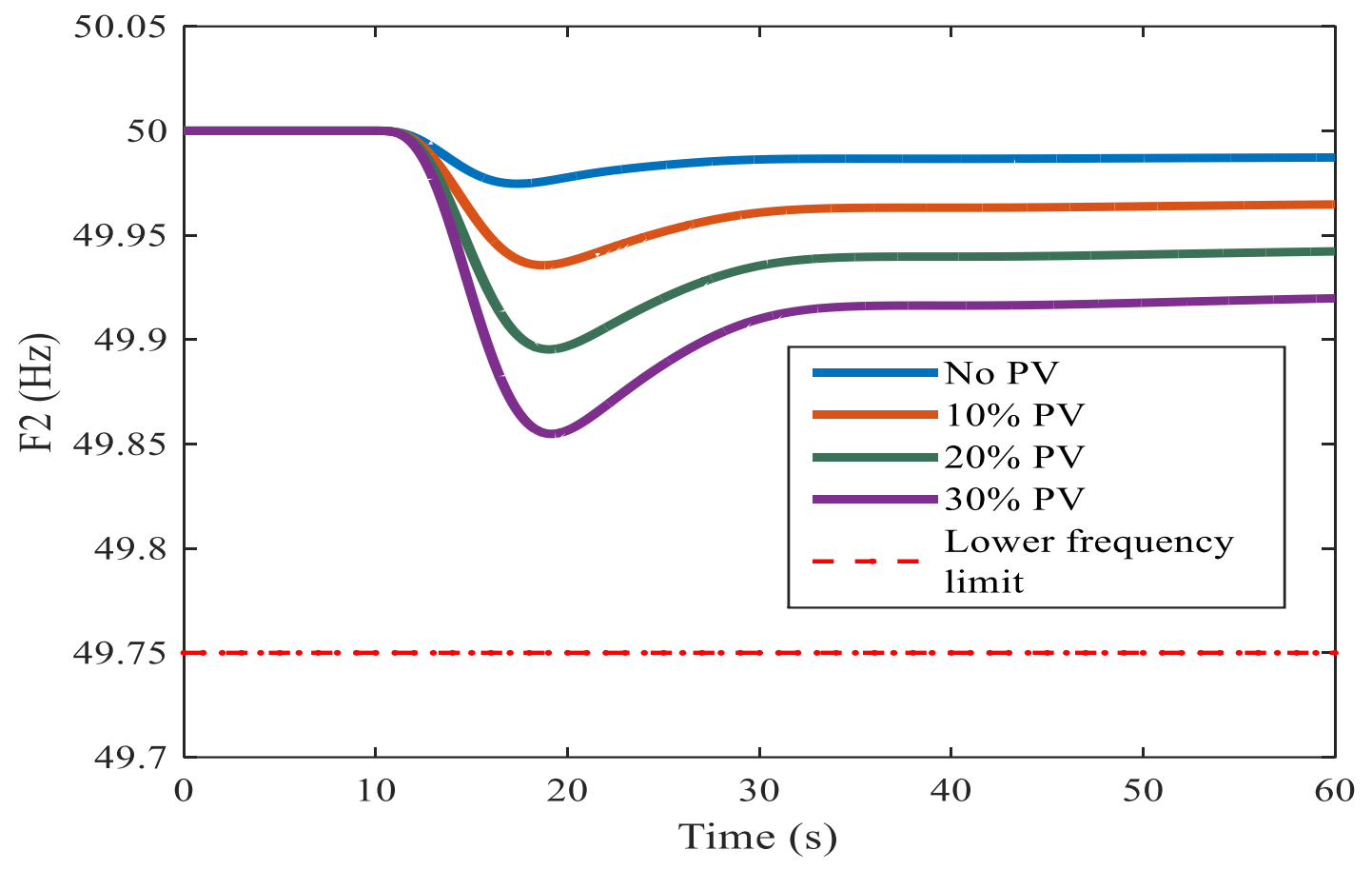

Fig 5.5 Frequency deviation step response in Hydro area with PV penetration

Table 5.5 Summary of the frequency deviation in the thermal area

\begin{tabular}{|c|c|c|}
\hline Year & PV (\%) & Operating Frequency (Hz) \\
\hline 2017 (base-case) & - & 49.94 \\
\hline 2020 & $10 \%$ & 49.88 \\
\hline 2025 & $20 \%$ & 49.81 \\
\hline 2030 & $30 \%$ & 49.74 \\
\hline
\end{tabular}

\subsubsection{Case study3}

In this case study the effect of FESS on frequency regulation is analysed using the test model of Fig 5.2. Normally, these storage systems will operate in discharging mode during peak load period and will be in charging mode during off peak hours. This research also explore the need of storage systems to maximise the use of PV system. The simulation parameters for FESS are given in Table 5.6. 
Table 5.6 Simulation parameters for PV and FESS

\begin{tabular}{|l|c|c|c|c|c|}
\hline Parameter & $\mathbf{K}_{\mathbf{P V}}$ & $\mathbf{T}_{\mathbf{P V}}$ & $\mathbf{K}_{\text {fess }}$ & $\mathbf{T}_{\text {fess }}$ & $\begin{array}{c}\text { FESS } \\
(\mathbf{M W})\end{array}$ \\
\hline Value & 1 & 1.8 & -0.01 & 0.1 & 1200 \\
\hline
\end{tabular}

\subsubsection{Results for case study3}

\section{Flywheel energy storage system}

The basic purpose of FESS is to control and regulate the system frequency in the presence of PV generation. The first simulation results show that FESS reduces the drop in the system frequency with reduced undershoot as presented in Table 5.7 and Fig 5.6. Without FESS in the network, the operating frequency of the system is $49.741 \mathrm{~Hz}$, but with FESS in the network the operating frequency increase to $49.753 \mathrm{~Hz}$. The rise in frequency is due to the use of FESS in the system to complement the PV generation and to provide a faster response in the power system. Speed limiter was used to prevent either the shortage or the surplus of energy store in the FESS. 


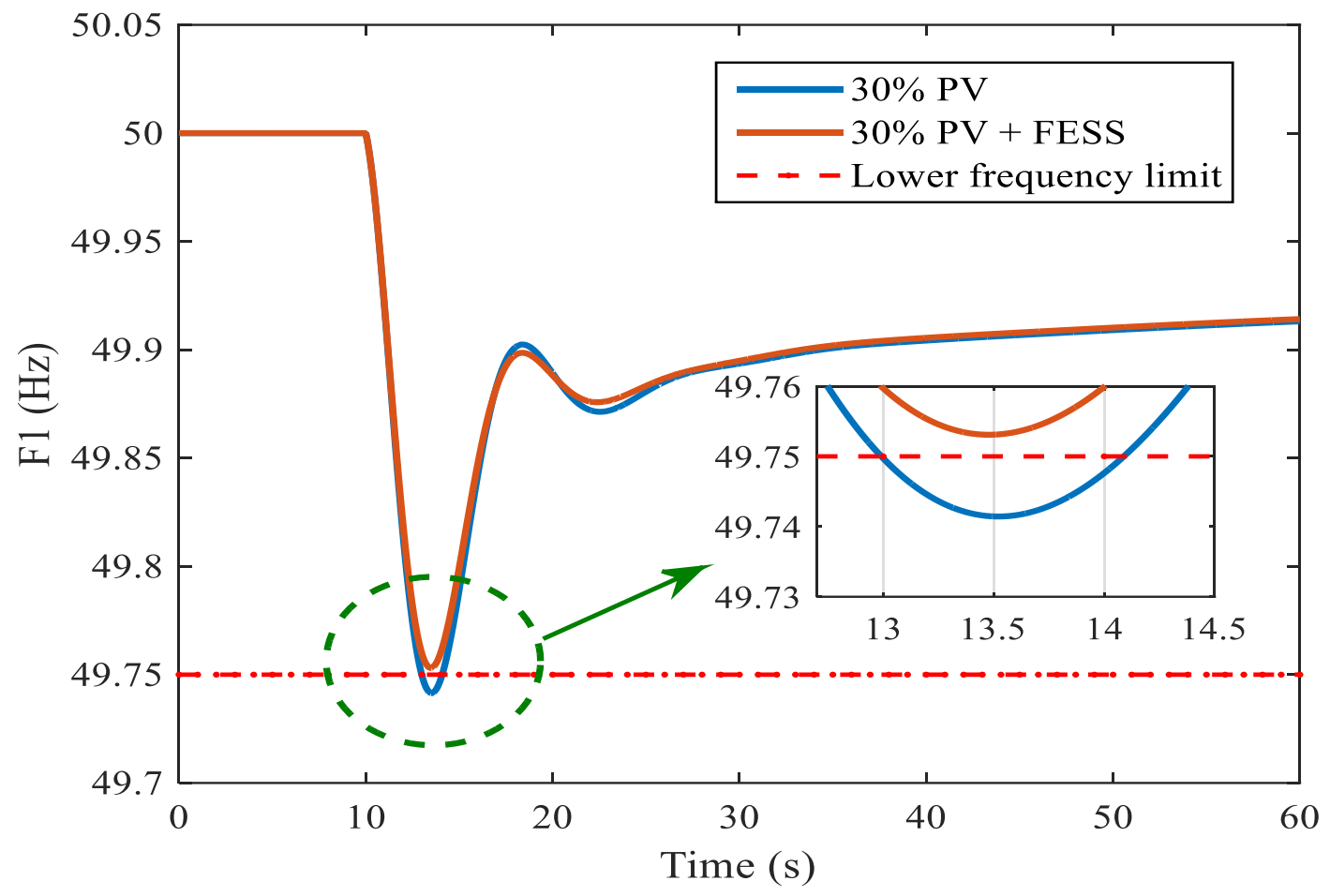

Fig 5.6 Response of power system with and without FESS in the thermal area

Table 5.7 New operating frequency with and without FESS

\begin{tabular}{|c|c|c|}
\hline & Without FESS & With FESS \\
\cline { 2 - 3 } & Operating frequency $(\mathbf{H z})$ & Operating frequency $(\mathbf{H z})$ \\
\hline$\Delta \mathbf{F}_{\mathbf{1}}(\mathbf{H z})$ & 49.741 & 49.753 \\
& & \\
\hline
\end{tabular}

\subsection{SUMMARY DISCUSSION AND KEY FINDINGS}

This chapter presents a comprehensive study of the influence of localised energy system on the Nigerian two-area interconnected hydro/thermal system with respect to frequency regulation. In Chapter four of this thesis, LES is integrated into Ekiti state $33 \mathrm{kV}$ distribution system which is an integral part of the Nigeria power system. However, chapter five considered integrating LES into the entire Nigeria power network. Three case studies were carried out to determine the ability of the existing 


\section{Energy Storage Opportunities}

power system to cope with $30 \%$ PV penetration. The results show that the stored kinetic energy in the existing conventional generators could not absorb variations in electricity output from $30 \%$ PV penetration. This PV output variation could only be supported by network upgrade or by using energy storage technology. However, network upgrade is not feasible due to lack of fund. Therefore, this research used flywheel and battery energy storage.

The flywheel storage system is used in this research to counterbalance the intermittency of the PV generation and to damp out the frequency deviations and support frequency regulation by injecting the amount of required energy to the power system immediately following a disturbance. That means, with a flywheel storage system the possibility of connecting $30 \%$ renewable in the Nigeria power system is guaranteed.

Flywheel energy storage was chosen due to its high power density, low environmental impact, short recharge time, ability to provide active power compensation. Flywheels are capable of storing up to 500MJ and peak power range from kilowatts to gigawatts and high response time.

Although the economic benefits of FESS for frequency regulation in Nigeria power system have not been computed, the PHCN should consider the construction of a demonstration site for this purpose. 


\section{ChAPTER 6}

\section{DISCUSSION AND CONCLUSION}

\subsection{DisCUSSION}

In Africa, access to the transmission grid is limited, and it is costly to upgrade the existing power infrastructure. Localised energy systems concept could be an interesting option to meet these local challenges. In this thesis, a brief literature review of technologies of smart grids, microgrids and localised energy systems in electricity distribution systems are presented.

The ability to connect local generations, renewable resources, storage, and distributed generation is becoming more regulated and cost-effective with the help of smart grids. Without a smart grid, high penetrations of variable renewable resources may become more difficult and expensive to manage due to the greater need to coordinate these resources with dispatchable generation and demand. In the UK there is a paradigm shift from traditional centralised generation toward a low carbon emission and environmentally friendly distributed renewable technologies. However, this move towards distributed renewable technologies is popular in UK, USA, Europe, and other developed nations but the developing nations in sub-Sahara Africa are yet to adopt these changes.

The Nigerian energy system and its power needs were reviewed and were found to be faced with several challenges. These challenges are the inability to effectively dispatch generated power to meet the load demand, generating plants are outdated, lack of maintenance of power infrastructure, low investment in power generation, high losses, power theft and poor tariffs. In addition, some of the transmission lines are fragile and radial nature, which is prone to frequent system collapse, a poor network configuration in some regional work centres and large numbers of overloaded transformers in the grid system. This resulted in an unreliable and unstable electric power supply situation in the country with customers exposed to frequent power cuts and outages. 
In order to address these challenges. This research study the impact of LES on the UK power network with respect to benefits, opportunities, and limitations in order to transfer the knowledge obtained to Nigeria power network. This study involves modelling and simulation of the UK generic distribution network with and without LES with respect to voltage, losses, and transformers loadings. The result shows that integration of LES caused the network voltage to rise by $2.75 \%$, distribution losses reduced by $15 \%$ and the transformer loading is reduced by $22 \%$. The reduction in the network losses and transformer loadings is because the local generators are connected very close to the loads which prevent large amount of power flowing from substation to the loads. However, the extent of losses reduction depends on the squares of the current flows in the lines and the parameters of the lines. Since LES was able to reduce distribution transformers overload due to growing demand for electricity, there is no need for transformer upgrade which is cost saving for the power system owners and operators.

In the second study, the Ekiti-State $33 \mathrm{kV}$ network (a section of the Nigerian main grid) was simulated over 24 hours with and without LES (PV generators). The result shows increase in network voltage by $135 \mathrm{~V}$ and reduction in the network losses by $19.26 \%$. The increase in voltage and reduction in the network losses happened during both the dry and the rainy season of the year. However, at 30\% PV penetration, power supplied cannot meet the power demanded during the peak hours due to the PV intermittency. This problem of PV intermittency is addressed with storage technology as suggested in this study. The use of storage as backup energy during peak demand hour and during raining season when solar irradiation is low is suggested. In addition, the effect of cloud shading was studied to prevent any adverse impact on the PV integration. But in this study, despite $25 \%$ reduction in solar irradiation, the effect of cloud shading on the PV generation does not have any significant impact on the network voltage profile.

In chapter five of this thesis, a study of high LES penetration impact using MATLAB Simulink was carried out on the Nigerian two-area hydrothermal power system to determine the effect on the frequency regulation. Three case studies were carried out to determine the ability of the existing power system to cope with $30 \% \mathrm{PV}$ penetration as proposed by the ministry of power and the federal government of Nigeria with respect to frequency regulation. The results show that the stored kinetic 
energy in the existing conventional generators could not absorb variations in electricity output from $30 \%$ PV penetration causing the frequency to deviate beyond safe operation of the system. The PV output variation could only be supported by network by using energy storage technology. Otherwise, network upgrade will be required which is not feasible due to lack of fund. In this research, FESS is used for frequency regulation purpose due to its high-power density, low environmental impact, short recharge time, ability to provide active power compensation, can undergo a considerably large number of charge/discharge cycles, rapid response, high efficiency and fast ramping capability. These features render the FESS to be particularly suitable to closely follow the continuously changing AGC signals.

Flywheel storage system is employed to counterbalance the intermittency of the PV generation and to damp out the frequency deviations and support frequency regulation by injecting the amount of required energy to the power system immediately following a disturbance. That means, with the support of FESS the possibility of $30 \%$ PV penetration is possible in Nigeria power network.

\subsection{CONCLUSION}

Considering the current situation of electricity availability and use in Nigeria and other African countries and the prospects for transformations, this thesis introduces LES as a tool to address these problems. The localised energy system is currently in demand in the UK, Germany and other developed economies. The developing countries with less access to sustainable electricity must equally embrace the opportunities offered by LES to address their power problem. This study presents the opportunities and benefits of LES in the UK and recommends the application to Nigeria and other developing countries. In Nigeria, the power sector has not witnessed any tangible investment over the years due to the economic recession. This inability to invest in power generation has resulted in low voltage, high transmission and distribution losses and constant partial and total collapse of the system. These challenges coupled with the needs to meet the carbon emission reduction target has prompted this study

It is observed from the results that the integration of LES in the UK power system improves the voltage profile and makes the power system more secure and reliable. The network losses reduce drastically which will lead to savings in network cost. The 
transformer overloading is limited through LES technology by connecting local generation/storage next to the load. However, at high penetration of LES, there could be a reversal in power flow leading to voltage rise. This voltage rise could affect standard operating limits and could damage network equipment.

Power output from PV generation is largely dependent on the solar irradiance level which is a fluctuating resource and hence cannot be easily controlled and this could limit the penetration of LES in the system. The problem of PV intermittency can be addressed with storage technology as suggested in this study or through demand response. The energy storage system is used as backup energy during peak demand and during the rainy season when solar irradiation is low to provide reliable electricity supply to the utility's customers.

The simulation is carried out with real data provided partly by PHCN and partly by personal interviews of power professionals, and other sources both local and internationals. The simulation results provide information on the bus voltages, lines power flow and network losses. In addition, the results reveal the weak and vulnerable sections of the distribution network which determine the optimal location of the PV generation in the network. Since this is the first comprehensive study on this medium voltage network, the results obtained from the load flow study will provide valuable information to other researchers in their work and assist the Power Holding Company of Nigeria in network planning and maintenance.

The flywheel storage system is employed in this research to counterbalance the intermittency of the PV generation and to damp out the frequency deviations. Other power systems in the developing countries in sub-Sahara Africa can emulate this technology also in their power system. Flywheels can store up to 500MJ and peak power range from kilowatts to gigawatts and high response time. One important challenge of FESS is their high initial cost. It is expected that by future advancements in technologies the speed of the FESS will be increased, and its cost will be reduced. In addition, the FESS has low energy density and high-power density which limits its application. This problem can be solved by the application of several of this storage system like a farm of FESS to provide high energy density. Although the economic benefits of FESS for frequency regulation in Nigeria power system have not been computed, the PHCN should consider the construction of a demonstration site for this purpose. The results of this research on LES application in the UK network is relevant 
in Nigeria and other developing countries in sub-Sahara Africa where power consumers are located mostly far away from the centralised generations.

Grid connection guidelines are still a major problem with LES. The grid connection rules and technical requirement differ from country to country. Efficient and flexible integration of LES in Nigeria and sub-Sahara Africa will require a common standard on technical requirements for LES rather than having the manufacturers and the operators having to conform to numerous local practice and guidelines. Governments in sub-Sahara Africa must establish a clear regulatory framework and rules of engagement for LES in terms of retail, generation and network operation and ownership. Also, a clear rule of engagement between existing distributors and the new LES must be established.

\subsection{CONTRIButions}

The main contributions of this thesis are summarised:

- A model of low voltage distribution network with localised energy systems was developed. The model was used for impact studies on the distribution network.

- A methodology for determining the allowable capacity of DG and EV in a localised energy system for efficient network operation was developed.

- A model of a Nigeria $33 \mathrm{kV}$ distribution system was developed with localised energy systems. The model was used to analyse the effect of PV penetration on the network voltage and losses.

- The operation of a Nigeria $33 \mathrm{kV}$ distribution network with significant amount of PV generation, considering the effect of seasonal variation (dry and raining seasons) on PV generation. It provides possible methods and solutions to mitigate the impact of high PV penetration on the network voltages.

- A two-area hydrothermal systems model was used for frequency regulation studies. The study investigated the contribution of electrical energy storage systems in frequency regulation.

- A methodology to address power system challenges in developing countries and sub-Sahara Africa is provided. 


\subsection{FUTURE WORKS}

The work presented in this thesis can be extended in the following ways:

1. The study on localised energy systems impact can be extended to cover the cost impact of local energy resources.

2. Localised energy systems research can be extended to cover the grid code update for LES and storages.

3. Localised energy systems research can be extended to cover feed-in payments assessment as they cannot subsidy indefinitely.

4. A larger dynamic grid study that looks at the response in real time and variation in PV generation to examine technical implication.

5. The study on localised energy systems can be extended to cover policy and road map for energy. 


\section{REFERENCES}

[1] International Energy Agency (IEA), "Energy and climate change," World Energy Outlook Special Report, OECD/IEA PARIS, 2015.

[2] IRENA (2015), "Renewable power generation costs in 2014," International Renewable Energy Agency, pp. 1-8, 2015.

[3] REN21 (2017), "Renewables 2017 Global Status Report (Paris: REN21 secretariat),, 2017.

[4] J. katende and F. I. Isaac Samuel, "Voltage Collapse and the Nigeria National Grid," EIE's 2nd International Conference Compututer Energy Networks, Robot and Telecomunication. Elecon2012, pp. 128-131.

[5] O. Oluwatoni, "Integrating Renewable Energy into Nigeria's Energy Mix: Implications for Nigeria's Energy Security," Norwegian University of Life Science, 2017.

[6] G. Artizzu; A. Paola; E. Patriarca, "Decentralized renewable energy solutions to foster economic development," Renewable Energy Solution for Africa, 2017.

[7] Greenpeace, "Decentralising power : an energy revolution for the 21 st century," 2005.

[8] P. Wolfe, "The implications of an increasingly decentralised energy system," Energy Policy, vol. 36, pp. 4509-4513, 2008.

[9] P. K. Ainah and K. A. Folly, "Development of micro-grid in sub-Saharan Africa: an overview," International Review of Electrical Engineering, vol. 10, no. 5, pp. 633-645, 2015.

[10] J. P. Murenzi and T. S. Ustun, "The case for microgrids in electrifying SubSaharan Africa," 6th International Renewable energy Congress (IREC)., pp. 16, 2015.

[11] PowerGen, "How Micro-grids Can Solve Energy Access in Africa while Building the Energy System of the Future," 2018.

[12] E.ON, "Local Energy Systems | The future is local - E.ON," 2017. [Online]. Available: https://www.eon.se/en_US/samhaelle---utveckling/local-energysystems/the-future-is-local.html. [Accessed: 15-Nov-2017].

[13] S. Hall and K. Roelich, "Local Electricity Supply: Opportunities, archetypes and outcomes," 2015. 
[14] PwC, "Powering Nigeria for the future," The Power Sector in Nigeria, 2016.

[15] Nesistat, "Nigeria Power Baseline Report," Office of the Vice President.Federal Republic of Nigeria, 2016.

[16] M. Oni, “Global Energy Industry Review,” Meyer Brown, 2014.

[17] A. S. Sambo, "Matching Electricity Supply with Demand in Nigeria," pp. 32$36,2008$.

[18] SE4ALL, "Sustainable energy for all: action agenda \& investment prospectus implementation," in Presented At the 3rd Annual Workshop on Advancing SE4All Country Action in Africa Abidjan - Cote D'Ivoire 9th -12th February 2016, 2016.

[19] S. O. Oyedepo, "Towards achieving energy for sustainable development in Nigeria," Renewable and Sustainable Energy Review, vol. 34, pp. 255-272, 2014.

[20] IRENA, Global Energy Transformation: A Roadmap to 2050. 2018.

[21] E. Buchmann, S. Kessler, P. Jochem, and K. Bohm, "The costs of privacy in local energy markets," Proc. - 2013 IEEE International Conference on Business Informatics, IEEE CBI 2013, pp. 198-207, 2013.

[22] N. Jenkins, C. Long, and J. Wu, "An Overview of the Smart Grid in Great Britain," Journal of Engineeering, vol. 1, no. 4, pp. 413-421, 2016.

[23] Y. Hong, S. Goel, H. Lu, and S. Wang, "Discovering Energy Communities for Microgrids on the Power Grid."

[24] Q. Fu, A. Nasiri, A. Solanki, A. Bani-Ahmed, L. Weber, and V. Bhavaraju, "Microgrids: Architectures, Controls, Protection, and Demonstration," Electrical Power Components Systems, vol. 43, no. 12, pp. 1453-1465, 2015.

[25] ClimateXChange, "Local Energy Systems in the UK Event Report," 2016.

[26] Siemen, "Smart Local Energy Systems," Siemens UK, 2018.

[27] ofgem, "Local Energy in a Transforming Energy System," in Future insights Series, 2016, no. 3, pp. 1-16.

[28] UNECE, "Electricity System Development: A Focus on Smart Grids," 2015.

[29] IEA, "Overview of Activities and Players in Smart Grids Electricity System Development: A focus on Smart Grids,” 2015.

[30] T. Morgan, "Smart Grids and Electric Vehicles: Made for Each Other? Discussion Paper No. 2012-02,” 2012.

[31] M. Bazilian et al., "Smart and Just Grids: Opportunities for sub-Saharan 
Africa."

[32] IEA(International Energy Agency) (2011), "World Energy Outlook 2011, OECS/IEA, Paris,” 2011.

[33] T. Morgan, "Smart Grids and Electric Vehicles: Made for Each Other?"

[34] N. Uribe-Pérez, L. Hernández, D. de la Vega, and I. Angulo, "State of the Art and Trends Review of Smart Metering in Electricity Grids," Applied Science, vol. 6, no. 3, pp. 1-24, 2016.

[35] F. Y. Xu and L. L. Lai, "Scope design, charateristics and functionalities of Smart Grid," IEEE Power Energy Society General Meeting, pp. 1-5, 2011.

[36] U.S. Department of Energy, "Smart grid system report," 2009.

[37] M. Mourshed et al., "Smart Grid Futures: Perspectives on the Integration of Energy and ICT Services,” Energy Procedia, vol. 75, pp. 1132-1137, 2015.

[38] U.S. Department of Energy, "Smart Grid System Report," 2009.

[39] J.-P. Vasseur and A. Dunkels, "Smart Grid," Interconnecting Smart Objects with IP, pp. 305-324, 2010.

[40] C. Schw and L. Tao, "Microgrids: The Microgrids Concept," pp. 1-24, 2003.

[41] REN21, GSR_2016_Full_Report, Global status report. 2016.

[42] G. S. Report, "Renewables 2017 global status report 2017,” 2017.

[43] Carbon Trust, "Making sense of renewable energy technologies," p. 64, 2012.

[44] "Local Energy Systems," Siemens UK. [Online]. Available: https://www.siemens.com/content/dam/webassetpool/mam/tag-siemens$\mathrm{com} / \mathrm{smdb} /$ regions/united-kingdom/energy-management/local-energysystems-uk-brochure.pdf. [Accessed: 25-Jun-2018].

[45] House of Commons, "Local Energy," Sixth Report of Session 2013-14, Energy Climate Change, volume 1, 2013.

[46] House of Commons, "Local Energy," Sixth Report of Session 2013-14, Energy Climate Change, volume II, 2013.

[47] House of Commons Energy and Climate Change Committee, "Local Energy Sixth Report of Session 2013-14 The Energy and Climate Change Committee," 2013.

[48] M. Tingey, J. Webb, and D. Hawkey, "Local Authority Engagement in UK Energy Systems: Highlights From Early Findings," A Report by Energy Technology Institute, UKERC, london ETI ,loughbrgh., 2017.

[49] B. Woodman and P. Baker, "Regulatory frameworks for decentralised energy," 
Energy Policy, vol. 36, pp. 4527-4531, 2008.

[50] V. Simonds and B. Hall, "Overcoming grid connection issues for community energy projects for Co-operatives UK and The Co-operative Group. Cornwallenergy. 3 October 2013," no. October, 2013.

[51] 2016 EIA, International Energy Outlook 2016-World energy demand and economc outlook, vol. 0484, May. 2016.

[52] R. Pandey, "Reinforcing Energy Grid in Developing Countries and role of Energy Storage," Journal of Undergraduate Research. University of Illinois, Chicago, vol. 10, no. 1, 2017.

[53] EIA, "Energy implications of higher economic growth in Africa," 2018.

[54] EIA, “International Energy Outlook 2016,” 2016.

[55] M. Leybourne et al., "Status and Prospects of the Offshore Wind Sector in India," 2014.

[56] E. Fernstrom, "The Nigerian Power Sector A case study of Power sector reform and the role of PPP Background : Nigeria," 2011.

[57] M. M. G. A.Sambo, I. A. Zarma, "Electricity Generation and the Present Challenges in the Nigeria Power Sector.," October, 2013.

[58] F. Oladipo and T. Olowu, "The Nigerian Power System Till Date: A Review .," International Journal of Advance Foundation and Research in Science \& Engineering, vol. 1, no. 5, pp. 20-33, 2014.

[59] NERC, "Transmission," Nigerian Electricity Regulatory Commission, 2018. [Online]. Available: http://www.nercng.org/index.php/home/nesi/404transmission. [Accessed: 14-Jul-2018].

[60] A. Sambo, I. Haliru, Zarma, M. Musa, and Gaji, "Electricity Generation and the Present Challenges in the Nigerian Power Sector," no. February 2016, 2010.

[61] A. S. Sambo, B. Garba, I. H. Zarma, and M. M. Gaji, "Electricity Generation and the Present Challenges in the Nigerian Power Sector," 2012.

[62] nesistats, "Nigerian Power Baseline Report," Office of the Vice President of Nigeria, 2015.

[63] NESP, "Nigerian Electricity Supply Industry," Nigeria Electricity Regulatory Commission. [Online]. Available: http://www.nercng.org/index.php/home/nesi. [Accessed: 01-Jul-2018].

[64] A. Iwayemi, "Nigeria's Dual Energy Problems: Policy Issues and Challenges," International Association for Energy Economics, pp. 17-21, 2008. 
[65] I. Samuel; J. Katende and F. Ibikunle, "Voltage Collapse and the Nigerian National Grid," EIE's 2nd International Conference on Computer Energy Networks Robotics and Telecommunication, pp. 128-131, 2012.

[66] DAI and SDN, "Niger Delta Electricity Value Chain," Scoping Study Executive Summary, 2015.

[67] World Bank, "Program-For-Results Information Document (PID) Concept Stage," 2017.

[68] M. O. Oseni and M. G. Pollitt, "The economic costs of unsupplied electricity: evidence from backup generation among African firms,"Cambridge Working Paper in Economics, 2013.

[69] Africa Development Bank Group, “Annual report 2014,” pp. 1-285, 2014.

[70] NERC, "Regulation on Feed-in tarif for renewable energy sourced electricity in Nigeria," 2005.

[71] O. Oluwatoni, "Integrating Renewable Energy into Nigeria's Energy Mix: Implications for Nigeria's Energy Security,” 20017.

[72] C. O. Osueke and C. . A. K. Ezugwu, "Study of Nigeria Energy Resources and Its Consumption," International journal of Science and Engineering Reviews, vol. 2, no. 1, pp. 2229-5518, 2011.

[73] A. S. Sambo, "Strategic Developments In Renewable Energy In Nigeria," International Association of Energy Econonmics, June, pp. 15-19, 2009.

[74] V. I. E. A. John Tariilanyo Afa, "Proper Energy Mix: A Solution to Stable Power Supply in Nigeria," Academic Journal of Interdisciplinary Studies, MCSER, Rome-Italy, vol. 2, no. 13, pp. 93-102, 2013.

[75] S. O. Oyedepo, "Towards achieving energy for sustainable development in Nigeria," Renewewable Sustaintainable Energy Reviews, vol. 34, pp. 255-272, 2014

[76] ECREEE, "ECOWAS Renewable Energy and Energy Efficiency:Status Report," 2014.

[77] UNIDO, "Baseline Report on Small-Scale HydroPower Systems in the ECOWAS region," ECOWAS Regulation Work on Small-Scale Hydropower, 2012.

[78] NESP, The Nigerian Energy Sector : An Overview with a Special Emphasis on Renewable Energy, Energy Efficiency and Rural Electrification, 2nd Edition, GOPA, 2015. 
[79] C. Newsom, "Renewable Energy Potential in Nigeria," International Institute for Environmental Development, 2012.

[80] M. Shaaban and J. O. Petinrin, "Renewable energy potentials in Nigeria: Meeting rural energy needs," Reneweable and Sustainable Energy Review, vol. 29, pp. 72-84, Jan. 2014.

[81] A. S. Sambo and E. J. Bala, "Penetration of Solar Photovoltaic into Nigeria's Energy Supply Mix,” World Renewable Energy Forum, WREF 2012, Including World Renewable Energy Congress XII and Colorado Renewable Energy Society (CRES) Annual Conference, 2012, vol. 6, pp. 4748-4756.

[82] O. S. Ohunakin, M. S. Adaramola, O. M. Oyewola, and R. O. Fagbenle, "Solar energy applications and development in Nigeria: Drivers and barriers," Reneweable and Sustainable Energy Review, vol. 32, pp. 294-301, Apr. 2014.

[83] S. O. Oyedepo, "Energy and sustainable development in Nigeria: the way forward," Energy Sustainability and Society, 2012.

[84] A.S. Sambo, "Renewable Energy For Rural Development: the Nigeria Perspective," ISESCO Science and Technology Vision, vol. 1, pp. 12-22, May 2005.

[85] D. Kukoyi and E. Adeyemi, Renewable Energy Law Review, Law Business Reserch Limited, 2018.

[86] B. J. Kirby, "Frequency Regulation Basics and Trends," Prepared by OAK ridge National Laboratory for the U.S. Department of Energy, December, 2004.

[87] IRENA, "Renewable Energy Prospects for the European Union," European Commission, 2018.

[88] H. Bevrani, A. Ghosh, and G. Ledwich, "Renewable energy sources and frequency regulation: survey and new perspectives," IET Renewable Power Generation, vol. 4, no. 5, pp. 438, 2010.

[89] L. Bird, K. Clark, and E. Ela, "Variable Renewable Generation Can Provide Balancing Control to the Electric Power System." U.S department of Energy, Office of Energy Efficiency and Renewable Energy, 2013

[90] A V. Jayawardena, L. G. Meegahapola, S. Perera, and D. A. Robinson, "Dynamic characteristics of a hybrid microgrid with inverter and non- inverter interfaced renewable energy sources: A case study," 2012 IEEE International Conference Power System Technology, pp. 1-6, 2012.

[91] U. O. Aliyu, G. K. Venayagamoorthy, and S. Y. Musa, "Adaptive Load 
Frequency Control of Nigerian Hydrothermal System Using Unsupervised and Supervised Learning Neural Networks," IEEE Power Engineering Society General Meeting 2004., pp. 1-6, 2004.

[92] J. Katende and F. N. Okafor, "Automatic generation control performance of the Nigerian power system after deregulation," 2004 IEEE Africon. 7th Africon Conf. Africa (IEEE Cat. No.04CH37590), vol. ol.1, no. May, pp. 717-722, 2014.

[93] I. Samuel, J. Katende, S. A. Daramola, and A. Awelewa, "Review of System Collapse Incidences on the 330-kV Nigerian National Grid," International Journal of Engineering Science Invention, vol. 3, April, pp. 55-59, 2014.

[94] L. Vanfretti, U. Aliyu, J. H. Chow, and J. A. Momoh, "System frequency monitoring in the nigerian power system," 2009 IEEE Power Energy Society. General Meeting, PES ’09, pp. 1-6, 2009.

[95] M. Mohammed and L. M. Isah, "Analysis of Nigerian Electric Power System Frequency using FDR Measurements," International Journal of Operational Research Management,. Social Science and Education, vol. 2, no. 1, pp. 139$145,2016$.

[96] L. Vanfretti, U. Aliyu, J. Pierre and D. Trudnowski, "Estimation of the Nigerian Power System Electromechanical Modes using FDR Measurements," The 9th International Conference on Power System Operations and Planning (ISCPSOP), January, 2010.

[97] H. Saadat, Power System Analysis, Third Edition. PSA Publishing, 2002.

[98] S. Eftekharnejad, V. Vittal, G. T. Heydt, B. Keel, and J. Loehr, "Impact of Increased Penetration of Photovoltaic Generation on Power Systems," Power System IEEE Transaction, vol. 28, no. 2, pp. 893-901, 2013.

[99] H. Chen, T. N. Cong, W. Yang, C. Tan, Y. Li, and Y. Ding, "Progress in electrical energy storage system: A critical review," Progress in Natural Science, vol. 19, no. 3, pp. 291-312, 2009.

[100] Q. Fu, A. Hamidi, A. Nasiri, V. Bhavaraju, S. B. Krstic, and P. Theisen, "The Role of Energy Storage in a Microgrid Concept: Examining the opportunities and promise of microgrids," IEEE Electrification Magazine, vol. 1, no. 2, pp. 21-29, 2013.

[101] P. Crespo, D. Granado, P. Stein, and W. W. Zhan, "The Value of Energy Storage in Residential Buildings : A Smart grid perspective," Energy System, 
vol. 5, no. 2, pp. 232, 2014.

[102] B. H. Kenny, P. E. Kascak, R. Jansen, T. Dever, and W. Santiago, "Control of a high-speed flywheel system for energy storage in space applications," IEEE Transactions on Industrial Applications, vol. 41, no. 4, pp. 1029-1038, 2005.

[103] B. Vafakhah, M. Masiala, J. Salmon, and A. Knight, "Emulation of flywheel energy storage systems with a PMDC machine," Proceedings of the 2008 International Conference on Electrical Machines. ICEM'08, pp. 1-6, 2008.

[104] CNESA, "Energy Storage Industry White Paper (Summary).” China Energy Storage Alliance, 2017.

[105] S. M. Mousavi G, F. Faraji, A. Majazi, and K. Al-Haddad, "A comprehensive review of Flywheel Energy Storage System technology," Renewable and Sustainable Energy Reviews, vol. 67, pp. 477-490, 2017.

[106] A. A. K. Arani, H. Karami, G. B. Gharehpetian, and M. S. A. Hejazi, "Review of Flywheel Energy Storage Systems structures and applications in power systems and microgrids," Renewable and Sustainable Energy Reviews, vol. 69, no. September 2015, pp. 9-18, 2017.

[107] B. Bolund, H. Bernhoff, and M. Leijon, "Flywheel energy and power storage systems," Renewable and Sustainable Energy Reviews, vol. 11, pp. 235-258, 2007.

[108] P. Breeze, "Power generation technologies," Power System Energy Storage Technologies, Second Edition, 2014.

[109] F. Zhang, M. Tokombayev, Y. Song, and G. Gross, "Effective flywheel energy storage (FES) offer strategies for frequency regulation service provision," Proc. - 2014 Power System Computation Conference, PSCC 2014, pp. 1-7, 2014.

[110] R. Arghandeh, M. Pipattanasomporn, and S. Rahman, "Flywheel energy storage systems for ride-through applications in a facility microgrid," IEEE Transactions on Smart Grid, vol. 3, no. 4, pp. 1955-1962, 2012.

[111] M. E. Amiryar and K. R. Pullen, "A Review of Flywheel Energy Storage System Technologies and Their Applications," Applied Science Reviews, vol. 7, no. 3, 2017.

[112] H. Liu and J. Jiang, "Flywheel energy storage-an upswing technology for energy sustainability," Energy Buildings, vol. 39, no. 5, pp. 599-604, 2007.

[113] H. R, B. J, and W. A., "Flywheel batteries come around again," IEEE Spectrum, vol. 4, no. 39, pp. 46-51, 2002. 
[114] R. Sebastián and R. Peña Alzola, "Flywheel energy storage systems: Review and simulation for an isolated wind power system," Renewable and Sustainable Energy Reviews, vol. 16, no. 9, pp. 6803-6813, 2012.

[115] D. R. Brown and W. D. Chvala, "Flywheel energy storage: An alternative to batteries for UPS systems," Energy Engineering, vol. 102, no. 5, pp. 7-26, 2005 .

[116] S. Sabihuddin, A. Kiprakis, and M. Mueller, "A numerical and graphical review of energy storage technologies," Energies, vol. 8, no. 1, pp. 172-216, 2015.

[117] P. Medina, A. W. Bizuayehu, J. P. S. Catalão, E. M. G. Rodrigues, and J. Contreras, "Electrical energy storage systems: Technologies' state-of-the-art, techno-economic benefits and applications analysis," Proceedings of Annual Hawaii International Conference on System Science, pp. 2295-2304, 2014.

[118] I. Hadjipaschalis, A. Poullikkas, and V. Efthimiou, "Overview of current and future energy storage technologies for electric power applications," Renewable and Sustainable Energy Reviews, vol. 13, no. 6-7, pp. 1513-1522, 2009.

[119] M. Farhadi and O. Mohammed, "Energy Storage Technologies for High-Power Applications," IEEE Transactions on Industrial Applications, vol. 52, no. 3, pp. 1953-1962, 2016.

[120] M. I. Daoud, A. S. Abdel-Khalik, A. Massoud, S. Ahmed, and N. H. Abbasy, "On the development of flywheel storage systems for power system applications: A survey," Proceedings of 20th International Conference on Electrical Machines. ICEM 2012, pp. 2119-2125, 2012.

[121] R. Peña-Alzola, R. Sebastián, J. Quesada, and A. Colmenar, "Review of flywheel based energy storage systems," International Conference on Power Engineering, Energy and Electric Drives, May, 2011.

[122] Y. Yu, Y. Wang, and F. Sun, "The latest development of the motor/generator for the flywheel energy storage system," Proceedings of the 2011 International Conference on Mechatronic Science, Electric Engineering and Computer, MEC 2011, pp. 1228-1232, 2011.

[123] M. A. Awadallah and B. Venkatesh, "Energy Storage in Flywheels: An Overview," Canaian Journal of Electrical and Computer Engineering, Vol. 38, No. 2, Spring 2015, vol. 38, no. 2, pp. 183-193, 2015.

[124] S. . Aditya and D. Das, "Battery energy storage for load frequency control of an interconnected power system," Electric Power System Research, no.58, 
pp.179-185 2001.

[125] D. Kottick, M. Blau, and D. Edelstein, "Battery Energy Storage for Frequency Regulation in an Island Power System," IEEE Transactions on Energy Conversions, vol. 8, no. 3, pp. 455-459, 1993.

[126] C. F. Lu, C. C. Liu, and C. J. Wu, "Effect of battery energy storage system on load frequency control considering governor deadband and generation rate constraint," IEEE Transactions on. Energy Conversions, vol.10,no.3, pp.555$561,1995$.

[127] S. Ingram, S. Probert, and K. Jackson, "The impact of small scale embedded generation on the operation of distribution networks," DTI Reports, pp. 1-145, 2003.

[128] A. Mahmud, M. A. Mahmud, M. J. Hossain, and H. R. Pota, "Analysis of voltage rise effect on distribution networks with distributed generation," Proceedings of the 18th IFAC World Congress 2011, Milan, Italy, vol. 18, no. 1, pp. 1-7, 2011.

[129] N. Jenkins, J. B. Ekanayake, and G. Strbac, Distributed Generation, Renewable Generation Series, IET, London, UK, 2010.

[130] M. A. Mahmud, M. J. Hossain, and H. R. Pota, “Analysis of Voltage Rise Effect on Distribution Network with Distributed Generation," Proceedings of the 18th IFAC World Congress 2011, Milan, Italy, vol. 44, no. 1, pp. 14796-14801, 2011.

[131] M. A. Kashem, A. D. T. Le, M. Negnevitsky, and G. Ledwich, "Distributed generation for minimization of power losses in distribution systems," 2006 IEEE Power Engineering Society General Meeting, p. 8 pp., 2006.

[132] Sohn Associates Limited, "Electricity Distribution Systems Losses: NonTechnical Overview," Report prepared by ofgem, 2006.

[133] R. Hunt and M. L. Giordano, "Thermal Overload Protection of Power Transformers - Operating Theory and Practical Experience," Proceedings of 59th Annual Protective Relaying Conference Georgia Tech Atlanta, Georgia, 2005, pp. 1-33.

[134] L. M. Cipcigan and P. C. Taylor, "Investigation of the reverse power flow requirements of small-scale embedded generation," Renew. Power Gener. IET, vol. 1, no. 3, pp. 10-16, 2007.

[135] R. Tonkoski, D. Turcotte, and T. H. M. El-Fouly, "Impact of high PV 
penetration on voltage profiles in residential neighborhoods," IEEE Transactions on Sustainable Energy, vol. 3, no. 3, pp. 518-527, 2012.

[136] A. Woyte, V. Van Thong, R. Belmans, and J. Nijs, "Voltage fluctuations on distribution level introduced by photovoltaic systems," IEEE Transactions on Energy Conversions, vol. 21, no. 1, pp. 202-209, 2006.

[137] BBC News, "New diesel and petrol vehicles to be banned from 2040 in UK BBC News," 2017. [Online]. Available: https://www.bbc.co.uk/news/uk40723581. [Accessed: 26-Jul-2018].

[138] P. Papadopoulos, S. Skarvelis-Kazakos, I. Grau, L. M. Cipcigan, and N. Jenkins, "Electric vehicles' impact on British distribution networks," IET Electric System in Transportation, vol. 2, no. 3, p. 91, 2012.

[139] IEA, "Global EV Outlook 2017: Two million and Counting," 2017. .

[140] S. Ingram, S. Probert, and K. Jackson, “The Impact of Small Scale Embedded Generation on the Operating Parameters of Distribution Networks," DTI New Renewable Energy Programme, pp. 1-145, 2003.

[141] UKERC, “UKERC Energy Data Centre." [Online]. Available: http://ukerc.rl.ac.uk/DC/cgi-

bin/edc_search.pl?GoButton=Detail $\&$ WantComp=42\&WantResult $=\&$ WantTe $\mathrm{xt}=\mathrm{EDC} 0000041$. [Accessed: 12-Feb-2018].

[142] Scheider Electric, "Practical values of power factor - Electrical Installation Guide," Electrical Installation WiKi, 2018. [Online]. Available: http://www.electrical-

installation.org/enwiki/Practical_values_of_power_factor. [Accessed: 05-May2018].

[143] Department of Trade and Industry, "Guidance on The Electricity Safety, Quality and Continuity Regulations 2002," Rep. Number URN 02/1544, no. October, pp. 1-47, 2002.

[144] Eseosa O. and Ogujor E., "Determination of Bus Voltages, Power Losses and Flows in the Nigeria 330kV Integrated Power System," international Journal of Advances in Engineering and Technology, vol. 4, no. 1, pp. 94-106, 2012.

[145] O. A. Komolafe, M. O. Omoigui, and A. Momoh, "Reliability investigation of the Nigerian Electric Power Authority transmission network in a deregulated environment," 8th IAS Annual Meeting on Conference Record of the Industry Applications Conference 2003., vol. 2, pp. 1328-1331, 2003. 
[146] P. M. Adebayo Charles, "How is $100 \%$ renewable energy possible for Nigeria?," Global Energy Network Institute, pp. 1-42, 2014.

[147] PWC, "Powering Nigeria for the Future," The Nigeria Power Sector, 2016.

[148] G. A. Adepoju and O. A. Komolafe, "Power Flow Analysis of the Nigerian Transmission System Incorporating Facts Controllers," vol. 1, no. 5, pp. 186200, 2011.

[149] U. C. Ogbuefi and T. C. Madueme, "A Power Flow Analysis of the Nigerian 330 KV Electric Power System," International Journal of Applied Science and Technology, vol. 10, no. 1, pp. 46-57, 2015.

[150] R. A. Jokojeje, I. A. Adejumobi, and O. I. Adebisi, "Reactive Power Compensation in Nigeria Electricity Grid Using Static Synchronous Compensator (STATCOM)," IOSR Journal of Electrical and Electronics Engineering. Ver. IV, vol. 10, no. 2, pp. 2278-1676, 2015.

[151] K. A. Adebayo, I. G. Aborisade, D. O. and Oyesina, "Steady State Voltage Stability Enhancement Using Static Synchronous Series Compensator ( SSSC ); A Case Study of Nigerian 330KV Grid System," Research Journal in Engineering and Applied Science, vol. 2, no. 1, pp. 54-61, 2013.

[152] A. O. Melodi and S. A. Adeoye, "Normal Mode Limitations of Existing $33 \mathrm{kV}$ Power Grid for Full Electrification of Urban and Rural Areas of Ekiti State , Journal of Emerging Trends in Engineering and Applied Sciences, vol. 4, no. 3, pp. 485-492, 2013.

[153] Vanguard Nigerian Newspaper, "2017 projections for power supply: Nigerians resign to fate as system collapses 22 times in 12 months - Vanguard News," Vanguard, $2017 . \quad$ [Online]. Available: https://www.vanguardngr.com/2017/01/2017-projections-power-supplynigerians-resign-fate-system-collapses-22-times-12-months/. [Accessed: 19Apr-2018].

[154] O. S. Adeoye, "Estimation of Potential Load Demand of Local Government Areas of Ekiti State, American Journal of Engineering Research (AJER) Nigeria," vol. 3, no. 6, pp. 101-106, 2014.

[155] NERC, "The Distribution Code For The Nigeria Electricity Distribution System," Federal Ministry of Power, Nigeria, vol. 1, 2016.

[156] M. S. Okundamiya and O. Omorogiuwa, "Environment Viability of a Photovoltaic Diesel Battery Hybrid Power System in Nigeria," Iranica Journal 
of Energy \& Environment, vol. 6, no. 1, pp. 5-12, 2015.

[157] C. O. Osueke, P. Uzendu, and I. D. Ogbonna, "Study and Evaluation of Solar Energy Variation in Nigeria," International Journal of Emerging Technology and Advance Engineering, vol.3, Issue 6, June 2013.

[158] A. S. Sambo, "Matching Electricity Supply with Demand in Nigeria," Fourth Quarter, Nigerian Energy Commission, pp. 32-36, 2008.

[159] E. E. Ekpenyong and F. Anyasi, "Effect of Shading on Photovoltaic Cell," IOSR Journal of Electrical and Electronic Engineering, vol. 8, no. 2, pp. 2278-1676, 2013.

[160] D. Sperling, "Systems Integration of PV Aiming at a 100\% Renewable Electricity Supply for Costa Rica," TU München, 2015.

[161] G. Crabtree, J. Misewich and R. Ambrosio, "Integrating Renewable Electricity on the Grid," 2010.

[162] National Grid, "System Operability Framework 2016," UK Electricity Transmission, pp. 68-72, 2016.

[163] H. Bevrani, Robust Power System Frequency Control, Second Edition. Switzerland: Springer, 2014.

[164] J. B. Ekayanake, N. Jenkins, and G. Strbac, "Frequency response from wind turbines," Wind Engineering, vol. 32, pp. 573-586, 2008

[165] Entso-E, "Supporting Document for the Network Code on Load - Frequency Control and Reserves 28.06.2013,”2013.

[166] Ministry of Power, "Nigerian Sustainable Energy For All (SE4ALL) Action Agenda," 2014.

[167] OpeOluwani Akintayo, "Power: How Nigeria recorded 190 systems collapse in almost 9 years - SweetCrudeReports," Sweet Crude, 2018. [Online]. Available: http://sweetcrudereports.com/2018/03/12/power-how-nigeria-recorded-190systems-collapse-in-almost-9-years/. [Accessed: 07-Jul-2018].

[168] TCN, "Daily operational Report of Monday 02/07/2018,” 2018.

[169] S. K. Aditya and D. Das, "Application of Battery Energy Storage System to Load Frequency Control of An Isolated Power," International Journal of Energy Reviews, vol. 258, no. July 1998, pp. 247-258, 1999.

[170] K. V. Vidyanandan and N. Senroy, "Frequency regulation in a wind-diesel powered microgrid using flywheels and fuel cells," IET Generation, Transmission and Distribution, vol. 10, no. 3, pp. 780-788, 2016. 
[171] J. Jallad, S. Mekhilef, and H. Mokhlis, "Frequency regulation strategies in grid integrated offshore wind turbines via VSC-HVDC Technology: A review," Energies, vol. 10, no. 9, pp. 1-29, 2017.

[172] A. Saghafinia, "Literature Review on Indirect Field Oriented control of Induction Motor Drive", June 2016. 2018.

[173] NCC Osogbo, "Transmission Company of Nigeria," 2017.

[174] GENI, "Map of Nigerian Electricity Grid - Nigeria - National Energy Grids Library - GENI - Global Energy Network Institute.” [Online]. Available: http://www.geni.org/globalenergy/library/national_energy_grid/nigeria/nigeria nnationalelectricitygrid.shtml. [Accessed: 09-Apr-2018].

[175] S. Bhongade, B. Tyagi, and H. O. Gupta, "Automatic Generation Control Scheme including Photo-Voltaic Generating System for Interconnected Power System," $17^{\text {th }}$ National Power System Conference (NPSC-2012), Varanasi, Uttar Pradesh, India pp. 1-6, 2012.

[176] D. J. Lee and L. Wang, "Small-signal stability analysis of an autonomous hybrid renewable energy power generation/energy storage system part I: Time-domain simulations," IEEE Transactions on Energy Conversion, vol. 23, no. 1, pp. 311-320, 2008.

[177] IPCC, "Renewable Energy Sources and Climate Change Mitigation.Summary for Policymakers and Technical Summary,” 2011.

[178] R. Hebner, J. Beno, and A. Walls, "Flywheel batteries come around again," IEEE Spectrum, vol. 39, no. 4, pp. 46-51, 2002.

[179] P. K. Ray, - Soumya, R. Mohanty, and N. Kishor, "Small-Signal Analysis of Autonomous Hybrid Distributed Generation Systems in presence of Ultracapacitor and Tie-Line Operation," Journal of Electrical Engineering, vol. 61, no. 4, pp. 205-214, 2010.

[180] M. T. Muhssin, L. M. Cipcigan, Z. A. Obaid, and W. F. AL-Ansari, “A novel adaptive deadbeat- based control for load frequency control of low inertia system in interconnected zones north and south of Scotland," International Journal of Electrical Power and Energy Systems, vol. 89, pp. 52-61, 2017.

[181] P. Kundur, Power System Stability And Control. Englewood Cliff, New Jersey: McGraw-Hill, Inc., 1994. 


\section{APPENDIX}

\section{POWER FLOW EQUATION}

In a typical bus of a power system network as shown in Fig 7.1. Transmission lines are represented by their equivalent $\pi$ models.

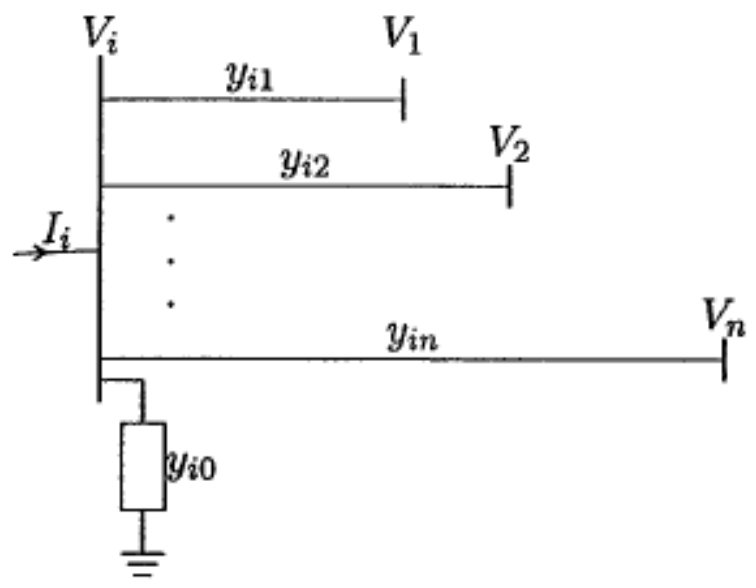

Fig 7.1 A typical bus of the power system [97]

The current $I_{i}$ entering into bus $i$ in Fig 7.1 is given as

$$
\begin{aligned}
I_{i} & =y_{i 0} V_{i}+y_{i 1}\left(V_{i}-V_{1}\right)+y_{12}\left(V_{i}-V_{2}\right)+\cdots+y_{i n}\left(V_{i}-V_{n}\right) \\
& =\left(y_{i 0}+y_{i 1}+y_{i 2}+\cdots y_{i n}\right) V_{i}-y_{i 1} V_{1}-y_{i 2} V_{2}-\cdots-y_{i n} V_{n}
\end{aligned}
$$

Or

$I_{i}=V_{i} \sum_{j=0}^{n} y_{i j}-\sum_{j=1}^{n} y_{i j} V_{j} \quad j \neq i$

The real and reactive power at bus $i$ is

$$
\begin{aligned}
& P_{i}+j Q_{i}=V_{i} I_{i}^{*} \\
& I_{i}=\frac{P_{i}-j Q_{i}}{V_{i}^{*}}
\end{aligned}
$$

Substituting for $I_{i}$ in (A.1) yields

$$
\frac{P_{i}-j Q_{i}}{V_{i}^{*}}=V_{i} \sum_{j=0}^{n} y_{i j}-\sum_{j=1}^{n} y_{i j} V_{j} \quad j=\neq
$$


From the above relation, the power flow problem results in a system of algebraic nonlinear equations which must be solved by iterative techniques[97], [181].

\section{Newton Raphson Method}

The Newton-Raphson method is found to be more efficient for solving a large power systems. Since in the power flow problem real power and voltage magnitude are specified for the voltage-controlled buses, the real power flow equation is formulated in polar form.

For the typical bus of the power system shown in Fig 7.1, this equation can be rewritten in terms of the bus admittance matrix as

$$
I_{i}=\sum_{j=1}^{n} Y_{i j} V_{j}
$$

In the above equation, $\mathrm{j}$ includes bus $\mathrm{i}$. expressing this equation in polar form, we have

$\mathrm{I}_{\mathrm{i}}=\sum_{\mathrm{j}=1}^{\mathrm{n}}\left|\mathrm{Y}_{\mathrm{ij}}\right|\left|\mathrm{V}_{\mathrm{j}}\right|<\theta_{\mathrm{ij}}+\delta_{\mathrm{j}}$

The complex power at bus $i$ is

$P_{i}-j Q_{i}=V_{i}^{*} I_{i}$

Substituting from (A.4) for Ii in (A.5),

$P_{i}-j Q_{i}=\left|V_{i}\right|<-\delta_{i} \sum_{j=1}^{n}\left|Y_{i j}\right|\left|V_{j}\right|<\theta_{i j}+\delta_{j}$

Separating the real and imaginary parts,

$$
\begin{aligned}
& P_{i}=\sum_{j=1}^{n}\left|V_{i}\right|\left|V_{j}\right|\left|Y_{i j}\right| \cos \left(\theta_{i j}-\delta_{i}+\delta_{j}\right) \\
& Q_{i}=\sum_{j=1}^{n}\left|V_{i}\right|\left|V_{j}\right|\left|Y_{i j}\right| \sin \left(\theta_{i j}-\delta_{i}+\delta_{j}\right)
\end{aligned}
$$

Expanding (A.7) and (A.8) in Taylor's series about the initial estimate and neglecting all higher order terms results in the following set of linear equations. 


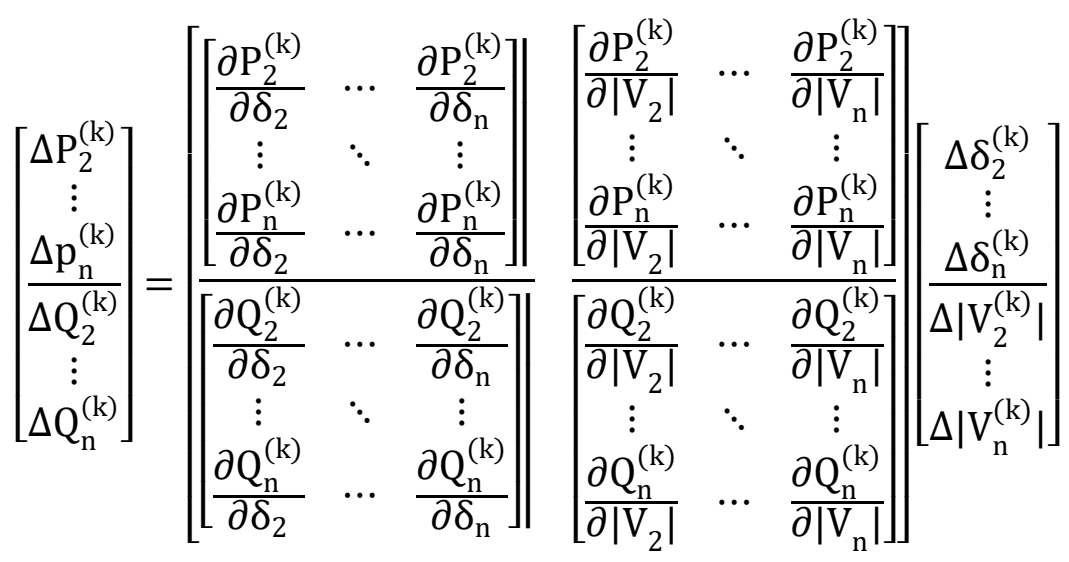

Bus $\mathrm{i}$ is assumed to be slack bus. Element of the Jacobian matrix are the partial derivatives of (A.6) and (A.7), evaluated at $\Delta \delta_{i}^{(\mathrm{k})}$ and $\Delta\left|\mathrm{V}_{\mathrm{i}}^{(\mathrm{k})}\right|$. It can be re-written as $\left[\begin{array}{l}\Delta \mathrm{P} \\ \Delta \mathrm{Q}\end{array}\right]=\left[\begin{array}{ll}\mathrm{J}_{1} & \mathrm{~J}_{2} \\ \mathrm{~J}_{3} & \mathrm{~J}_{4}\end{array}\right]\left[\begin{array}{c}\Delta \delta \\ \Delta|\mathrm{V}|\end{array}\right]$

There are $n-1$ real power constraints and $n-1-m$ reactive power constraints, and the Jacobian matrix is of order $(2 n-2-m) X(2 n-2-m)$.

$J_{1}$ is of the order $(n-1) X(n-1)$,

$J_{2}$ is of the order $(n-1) X(n-1-m)$,

$J_{3}$ is of the order $(n-1-m) X(n-1)$, and

$J_{4}$ is of the $\operatorname{order}(n-1-m) X(n-1-m)$.

The diagonal and off-diagonal elements of $\mathrm{J}_{1}$ are

$$
\begin{aligned}
& \frac{\partial P_{i}}{\partial \delta_{i}}=\sum_{j \neq i}\left|V_{i}\right|\left|V_{j}\right|\left|Y_{i j}\right| \sin \left(\theta_{i j}-\delta_{i}+\delta_{j}\right) \\
& \frac{\partial P_{i}}{\partial \delta_{j}}=\sum_{j \neq i}\left|V_{i}\right|\left|V_{j}\right|\left|Y_{i j}\right| \sin \left(\theta_{i j}-\delta_{i}+\delta_{j}\right) \quad j \neq i
\end{aligned}
$$

The diagonal and the off-diagonal elements of $\mathrm{J}_{2}$ are

$$
\begin{aligned}
& \frac{\partial \mathrm{P}_{\mathrm{i}}}{\partial\left|\mathrm{V}_{\mathrm{i}}\right|}=2\left|\mathrm{~V}_{\mathrm{i}}\right|\left|\mathrm{Y}_{\mathrm{ii}}\right| \cos \theta_{\mathrm{ii}}+\sum_{\mathrm{j} \neq \mathrm{i}}\left|\mathrm{V}_{\mathrm{j}}\right|\left|\mathrm{Y}_{\mathrm{ij}}\right| \cos \left(\theta_{\mathrm{ij}}-\delta_{\mathrm{i}}+\delta_{\mathrm{j}}\right) \\
& \frac{\partial \mathrm{P}_{\mathrm{i}}}{\partial\left|\mathrm{V}_{\mathrm{j}}\right|}=2\left|\mathrm{~V}_{\mathrm{i}}\right|\left|\mathrm{Y}_{\mathrm{ij}}\right| \cos \left(\theta_{\mathrm{ij}}-\delta_{\mathrm{i}}+\delta_{\mathrm{j}}\right) \quad \mathrm{j} \neq \mathrm{i}
\end{aligned}
$$


The diagonal and the off-diagonal elements of $J_{3}$ are

$$
\begin{aligned}
& \frac{\partial Q_{i}}{\partial \delta_{i}}=\sum_{j \neq i}\left|V_{j}\right|\left|Y_{i j}\right| \cos \left(\theta_{i j}-\delta_{i}+\delta_{j}\right) \\
& \frac{\partial Q_{i}}{\partial \delta_{j}}=-\left|V_{i}\right|\left|V_{j}\right|\left|Y_{i j}\right| \cos \left(\theta_{i j}-\delta_{i}+\delta_{j}\right) \quad j \neq i
\end{aligned}
$$

The diagonal and off-diagonal elements of $\mathrm{J}_{4}$ are

$$
\begin{aligned}
& \frac{\partial Q_{i}}{\partial\left|V_{i}\right|}=2\left|V_{i}\right|\left|Y_{i i}\right| \sin \theta_{i i}-\sum_{j \neq i}\left|V_{j}\right|\left|Y_{i j}\right| \sin \left(\theta_{i j}-\delta_{i}+\delta_{j}\right) \\
& \frac{\partial Q_{i}}{\partial\left|V_{j}\right|}=-\left|V_{i}\right|\left|Y_{i j}\right| \sin \left(\theta_{i j}-\delta_{i}+\delta_{j}\right) \quad j \neq i
\end{aligned}
$$

The terms $\Delta \mathrm{P}_{\mathrm{i}}^{(\mathrm{k})}$ and $\Delta \mathrm{Q}_{1}^{(\mathrm{k})}$ are the difference between the scheduled and calculated values, known as the power residuals, given by

$$
\begin{aligned}
& \Delta \mathrm{P}_{\mathrm{i}}^{(\mathrm{k})}=\mathrm{P}_{\mathrm{i}}^{\mathrm{sch}}-\mathrm{P}_{\mathrm{i}}^{(\mathrm{k})} \\
& \Delta \mathrm{Q}_{\mathrm{i}}^{(\mathrm{k})}=\mathrm{Q}_{\mathrm{i}}^{\text {sch }}-\mathrm{Q}_{\mathrm{i}}^{(\mathrm{k})}
\end{aligned}
$$

The new estimates for bus voltages are

$$
\begin{aligned}
& \delta_{i}^{(\mathrm{k}+1)}=\delta_{\mathrm{i}}^{(\mathrm{k})}+\Delta \delta_{\mathrm{i}}^{(\mathrm{k})} \\
& \left|\mathrm{V}_{\mathrm{i}}^{(\mathrm{k}+1)}\right|=\left|\mathrm{V}_{\mathrm{i}}^{(\mathrm{k})}\right|+\Delta\left|\mathrm{V}_{\mathrm{i}}^{(\mathrm{k})}\right|
\end{aligned}
$$

